\title{
Natural slopes and cuts: movement and failure mechanisms
}

\section{S. LEROUEIL*}

Movements and failure of cuts and natural slopes constitute an important geotechnical problem that involves a variety of geomaterials in a variety of geological and climatic contexts, and which has a major socio-economic impact in many countries. The paper reviews the state of knowledge in this domain, examining the basic aspects of soil mechanics that are relevant to the context of slopes, the importance of water on slope behaviour, and then the different stages of slope movements: pre-failure, failure, post-failure and reactivation. Finally it is shown how the geotechnical characterisation of slope movements can be used, in particular for assessing risk associated with such movements. Emphasis is put on for the brittleness of soils and its practical implications for the progressive failure developing at the pre-failure stage and on the characteristics of post-failure movements. The influence of other factors such as creep, fatigue, destructuration, partial saturation and infiltration is also considered.

KEYWORDS: Excavation; failure; ground movements; landslides; pore pressures; slopes
Les mouvements et la rupture des tranchées et des pentes naturelles constituent un problème géotechnique important qui demande une variété de géomatériaux dans une variété de contextes géologiques et climatiques, ce qui a aussi un impact socio-économique majeur dans bien des pays. Cette étude fait le point sur l'état des connaissances dans ce domaine, examinant les aspects fondamentaux des mécanismes des sols dans le contexte des pentes, l'importance de l'eau sur le comportement de la pente et les différents stades de mouvements de pentes : pré-rupture, rupture, post-rupture et réactivation. Enfin, nous montrons comment la caractérisation géotechnique des mouvements de pente peut être utilisée, notamment pour évaluer les risques associés à ce type de mouvement. Nous soulignons l'importance de la friabilité des sols et ses implications pratiques pour la rupture progressive qui se développe au stade de pré-rupture ainsi que ses effets sur les caractéristiques des mouvements de post-rupture. Nous tenons compte également de l'influence de plusieurs autres facteurs comme le glissement, la fatigue, la déstructuration, la saturation partielle et l'infiltration.

\section{INTRODUCTION}

This lecture concerns a geotechnical problem that has an important socio-economic impact in many countries (Brabb \& Harrod, 1989). According to Schuster (1996), the economic losses associated with slope movements reach about US\$ 4.5 billion per year in Japan, US\$ $2 \cdot 6$ billion per year in Italy, on the order of US\$ 2 billion in the United States, and US\$ 1.5 billion in India. Hutchinson (1995) also indicates that the 'annual losses from natural disasters generally, to which landslides contribute significantly, are estimated by the UN Disaster Relief Coordinator to amount to 1 or $2 \%$ of the gross national products in many developing countries'. A dramatic example was provided in 1993 by the 'La Josephina' landslide, which created a $90 \mathrm{~m}$ high dam with a $180 \mathrm{hm}^{3}$ reservoir that failed 33 days later. Seventy-one persons died, and the direct cost was US\$ 141 million: that is, $1 \cdot 24 \%$ of the gross natural product of Ecuador (Léone, 1996).

Human casualties related to landslides are also important. This can be illustrated by the situation in China, which is probably the country that suffers the most from fatalities due to landslides. Table 1 indicates the landslides in China that killed more than 100 people in the period 1917-1987. It includes the earthquake-induced Haiyuan landslides, which killed 100000 (possibly 200000) people; it also includes the Dong Xiang landslide, which in 1983 killed more than 200 people, and which will be mentioned later on. Li (1989) adds that the number of landslide-related fatalities in China exceeds 100 per year.

Because landslides are often included in reports on other natural disasters such as earthquakes, floods, volcanic eruptions, or typhoons, Schuster (1996) considers that landslides are responsible for considerably greater socio-economic losses than is generally recognised. Schuster (1996) also thinks that landslide activity is increasing, owing to continued deforestation, increased urbanisation and development in landslide-prone areas, and increased regional precipitation caused by changing

Manuscript received 2 May 2000; revised manuscript accepted 10 October 2000

Discussion on this paper closes 2 October 2001, for further details see inside back cover.

* Département de Génie civil, Université Laval, Ste-Foy, Québec. climate patterns. So, when the United Nations declared 19902000 the International Decade for Natural Disaster Reduction, it is not surprising that the geotechnical societies (see Cruden, 1997) formed the UNESCO Working Party on World Landslide Inventory to examine the problem more closely

'The earth's surface is part of a dynamic system, evolving both progressively and episodically through the actions of geological, geomorphological and meteorological processes. Landslides form one aspect of this evolution ...' (Hutchinson, 1995). Picarelli (1991) and D'Elia et al. (1998) defined several types of structure that characterise this 'earth's surface' and influence the behaviour of geomaterials at different scales (Fig. 1):

(a) the microstructure, related to soil particles, their arrangement, and possible bonding between particles

(b) the mesostructure, related to the size of laboratory samples (centimetres to decimetres), (which includes fissures, and pockets or laminae of soils of different grain size)

(c) the macrostructure, related to the size of the majority of engineering works (metres to tens of metres), and generally characterised by bedding planes, joints and major heterogeneities

(d) the megastructure, typical of major engineering problems (tens of metres to kilometres), and including faults, folds and other geological features.

All these types of structure result from the geological history of the area. In slopes, they all interact to provide the global behaviour observed.

Geology thus plays a major role in slopes. However, slope movements as such are mechanical responses of soil or rock to changes in geometry, boundary conditions, pore pressures or strength parameters with time. They have thus also to be examined from a mechanical or geotechnical viewpoint. In fact, good understanding of slope movements can be obtained only from a joint effort by geologists, geomorphologists and geotechnical engineers. As water is a major factor in slope behaviour, the contribution of hydrologists and hydrogeologists is also important. Slope movements must thus be seen as a multidisciplinary domain in which the role of the geotechnical engineer is to improve our understanding of soil behaviour in 
Table 1. Landslides in China, from 1917 to 1987 , that killed at least 100 people

\begin{tabular}{|c|c|c|c|c|}
\hline Year & Province & Affected area & Type of slope failure & Deaths \\
\hline 1917 & Yunnan & Daguan & Rockslide & 1800 \\
\hline 1920 & Ningxia & Haiyuan & Loess landslides induced by earthquake & 100000 \\
\hline 1935 & Sichuan & Huili & Rock and debris slide & 250 \\
\hline 1943 & Qinghai & Gonghe & Loess and mudstone slide & 123 \\
\hline 1964 & Gansu & Lanzhou & Landslide and debris flow & 137 \\
\hline 1965 & Yunnan & Luguan & Rock landslide & 444 \\
\hline 1966 & Gansu & Lanzhou & Landslide and debris flow & 134 \\
\hline 1972 & Sichuan & Lugu & Debris flow & 123 \\
\hline 1974 & Sichuan & Nanjiang & Landslide & 195 \\
\hline 1975 & Gansu & Zhuanglong & $\begin{array}{l}\text { Loess slide caused flooding along the shore of the reservoir and } \\
\text { downstream }\end{array}$ & Over 500 \\
\hline 1979 & Sichuan & Yaan & Debris flow & 114 \\
\hline 1980 & Hubei & Yuanan & Rockslide and avalanche & 284 \\
\hline 1983 & Gansu & Dong Xiang & Loess landslide & 277 \\
\hline 1984 & Yunnan & Yinmin & Debris flow & 121 \\
\hline 1984 & Sichuan & Guanlue & Debris flow & Over 300 \\
\hline 1987 & Sichuan & Wushan & Rock avalanche & 102 \\
\hline
\end{tabular}

After Li (1989)

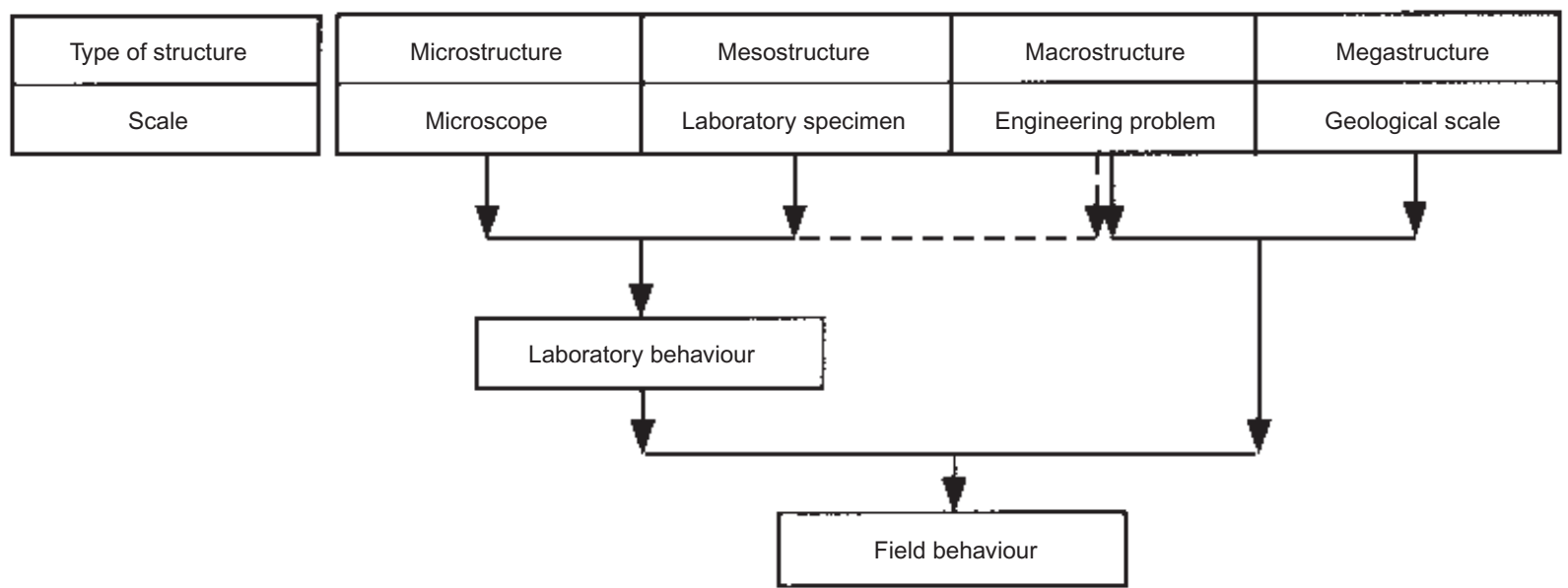

Fig. 1. Relation between structure and material behaviour (after Picarelli, 1991, and D'Elia et al., 1998)

this specific context and to try to minimise the economical and social impacts of slope movements.

\section{Limits of the lecture}

Movements of slopes constitute a complex problem, which involves a variety of geomaterials in a variety of geological and climatic contexts. Because of that, the scope of this lecture has to be limited. In particular:

(a) There will be no emphasis on geological aspects.

(b) Dynamic aspects and in particular the influence of earthquakes will not be considered.

(c) Flows such as debris flows and earthflows will not be treated as such

(d) Cases in which the behaviour is mostly controlled by discontinuities will not be considered.

(e) Even if they often exceed sub-aerial landslides in volumetric terms, submarine landslides will not be examined. (For information on these slides, the reader is referred to Prior, 1984; Lee, 1989; Hampton et al., 1996; Locat \& Lee, 2000).

The present lecture thus refers mainly to materials that are essentially homogeneous and continuous, at least at the scale of the slope considered, and to mechanical processes leading to sliding of slopes.

\section{Different types of slope movements}

Even in the context of relatively homogeneous and continuous materials, the behaviour of slopes is still complex. To

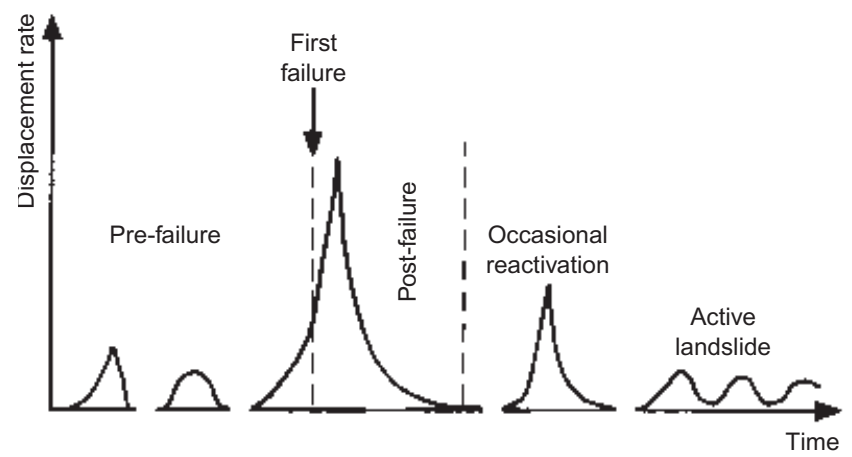

Fig. 2. Different stages of slope movements

simplify the analysis, Vaunat et al. (1994) and Leroueil et al. (1996) suggested dividing slope movements into four stages (Fig. 2):

(a) The pre-failure stage, including all the deformation processes leading to failure. This stage is controlled mostly by deformations due to changes in stresses, creep and progressive failure.

(b) The onset of failure, characterised by the formation of a continuous shear surface through the entire soil mass.

(c) The post-failure stage, which includes movement of the soil mass involved in the landslide, from just after failure until it essentially stops. It is generally characterised by an increase of the displacement rate followed by a progressive decrease in velocity. 
(d) The reactivation stage, when a soil mass slides along one or several pre-existing shear surfaces.

Leroueil et al. (1996) give details of these four stages and the associated behaviours. They point out, in particular, that the mechanical phenomena, controlling laws and parameters involved are very different from one stage to another.

\section{Outline of the lecture}

The four stages of movement indicated above constitute the skeleton of this lecture. After a review of basic aspects of soil behaviour relevant to slopes, and considerations of the influence of water on the behaviour of soil masses, the four stages of movement, pre-failure, failure, post-failure and reactivation will be examined. Finally, a geotechnical characterisation of slope movements aiming at organizing our knowledge of slopes will be presented.

\section{BASIC ASPECTS OF SOIL BEHAVIOUR IN THE CONTEXT OF} SLOPES

To understand the behaviour of slopes in a variety of geomaterials and contexts it is necessary to have a robust mechanical framework that can describe the complex effective stress-strain-time behaviour of soils. The concepts of limit and critical states initially developed at the University of Cambridge (Roscoe et al., 1958; Schofield \& Wroth, 1968) provide the main features of this behaviour, particularly because they can be extended to incorporate the effects of anisotropy, viscosity, partial saturation and microstructure, which characterise many natural soils (Leroueil, 1997; Kavvadas, 1998).

In a stress diagram such as the one shown in Fig. 3, the limit state curve (or yield curve, or 'main yield' curve to differentiate from the boundary between zones 2 and 3 , where plastic strains start developing) delimits an area in which the behaviour is essentially elastic and associated with relatively small strains. In zone 1 , surrounding the initial stress conditions, the material is linear elastic and characterised by the small strain shear modulus, $G_{\max }$. In zone 2 the geomaterial is non-linear elastic. In zone 3 some visco-plastic strains develop, and failure is reached on the peak strength envelope of the overconsolidated ${ }^{\dagger}$ material (Jardine et al., 1991; Jardine, 1992). When sheared, at large strains the soil reaches ultimate conditions on the critical state line (CSL in Fig. 3) corresponding to the strength of the normally consolidated material and characterised by the friction angle, $\phi^{\prime}{ }_{\text {nc }}$.

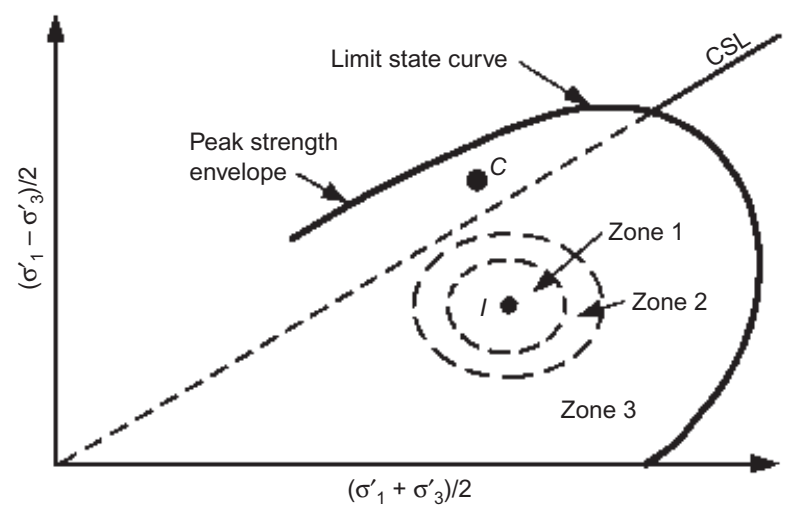

Fig. 3. Basic elements of soil behaviour

$\uparrow$ Overconsolidated here means that applied stresses are smaller than those on the limit state curve along similar stress paths.

IIn some papers, soils with bonding between particles were described as 'structured'. Given the types of structure considered in Fig. 1, it seems more logical to use 'microstructured', which would be in agreement with the use of 'microstructure' by Burland et al. (1996).
Also, it is increasingly being accepted that natural soils are microstructured, with bonds between particles or aggregates. This has several implications for soil behaviour, which have been described, in particular, by Burland (1990), Leroueil \& Vaughan (1990), and Leroueil (1998b). One of the implications is that the peak strength envelope of the overconsolidated material is above that of the same soil when non-structured. Another implication is that the stress state reached at large deformation (point $\mathrm{C}$ in Fig. 3) is inside the limit state curve of the intact material (Aversa et al., 1993; Cotecchia \& Chandler, 1997; Leroueil, 1998b). The main aspects of soil behaviour in the context of cuts and natural slopes will be examined in the following paragraphs.

Viscous behaviour inside the limit state curve

Bishop \& Lovenbury (1969), Larsson (1977), Tavenas et al. (1978) and D'Elia $(1991,1994)$ report long-term creep tests performed on clayey soils in their overconsolidated domain, the domain of interest when considering slopes. Fig. 4 shows

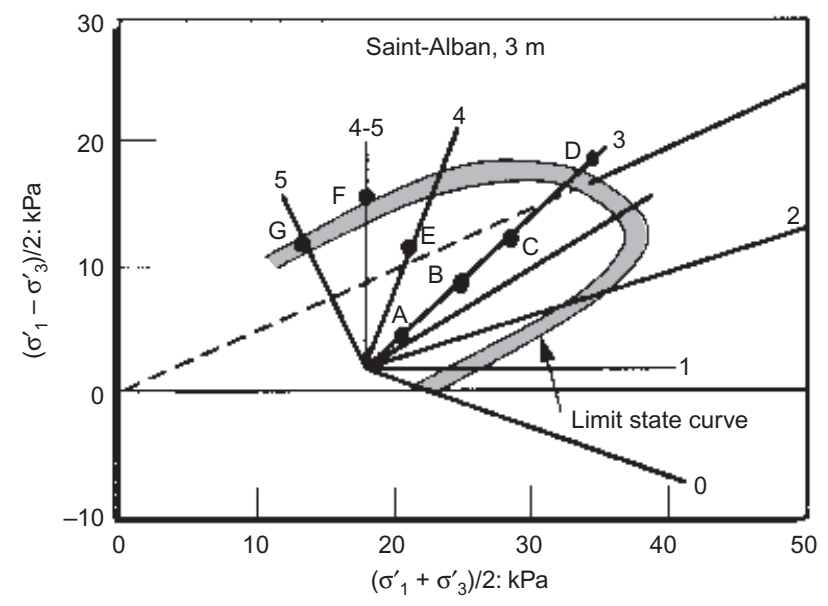

(a)

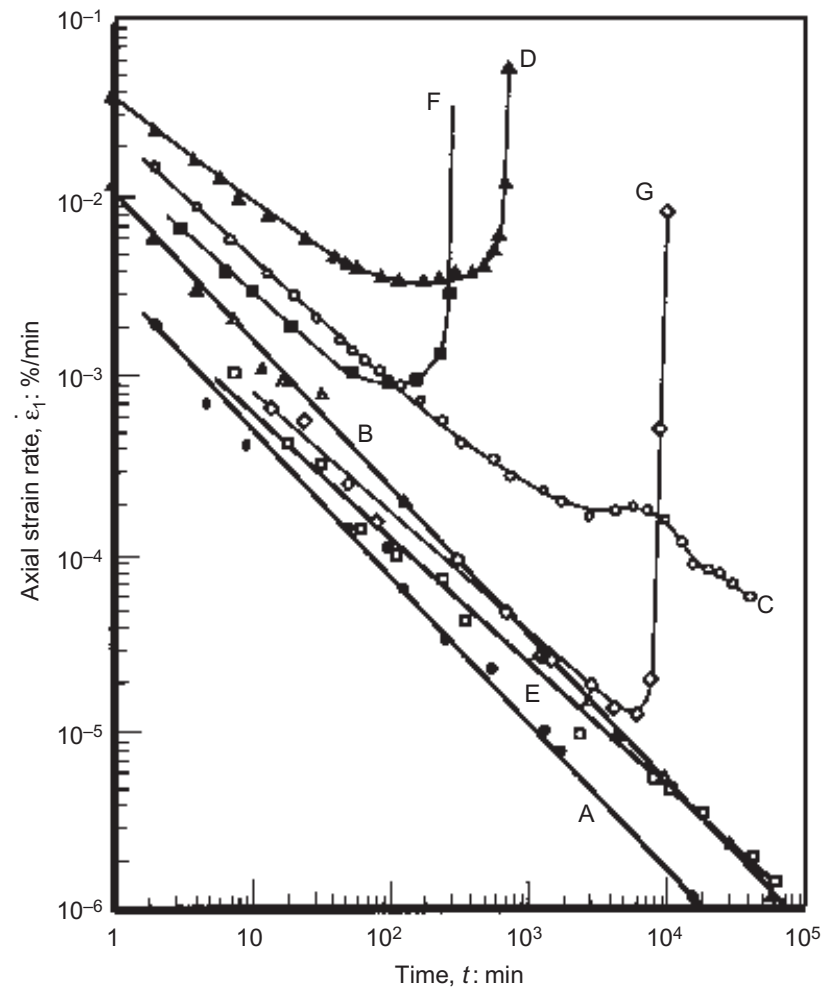

(b)

Fig. 4. Axial strain rate against time relationship for creep tests on Saint-Alban clay (after Tavenas et al., 1978) 
typical creep test results obtained by Tavenas et al. (1978) on Saint-Alban clay for stress conditions A, B, ... inside the limit state curve (Fig. 4(a)). These results show the development of creep strains with time along linear relationships in a diagram of logarithm of axial strain rate plotted against logarithm of time (Fig. 4(b)). For some of the tests, after reaching a minimum value, the strain rate increases up to failure. This is the case for the creep tests performed at points D, F and G. Similar results (Fig. 5) were obtained by D'Elia $(1991,1994)$ on stiffjointed Santa Barbara clay and on structurally complex 'Argille Scagliose', two clayey soils found in the Santa Barbara mine, in Italy, and this will be considered later on. The slopes, $m$, of the $\log \dot{\varepsilon}_{1}-\log t$ curves are almost constant, with a slight tendency to decrease as the stress level increases.

Singh \& Mitchell (1968) described the behaviour observed in creep tests with the following equation:

$$
\dot{\varepsilon}_{1}=A \mathrm{e}^{\alpha q}\left(\frac{t_{1}}{t}\right)^{m}
$$

where $\dot{\varepsilon}_{1}$ is the axial strain rate at any time $t, q$ is the stress level equal to the applied deviatoric stress divided by the deviatoric stress at failure in conventional compression tests, $m$ is the slope of the $\log \dot{\varepsilon}_{1}-\log t$ curve, $t_{1}$ is a reference time generally taken as $1 \mathrm{~min}$, and $\alpha$ and $\mathrm{A}$ are creep parameters.

One major difficulty with equation (1) is that it does not satisfy the axiom of objectivity stated by Eringen (1975): 'The constitutive response functionals must be form-invariant under arbitrary rigid motions of spatial frame and a constant shift of the origin of time.' Indeed, in equation (1), a change in the origin of time modifies the law and its parameters.

Another series of tests have been performed on stiff plastic $\left(I_{\mathrm{p}}=29 \%\right)$ Mascouche clay, from Québec (Marchand, 1982; Leroueil \& Marques, 1996). Compression drained and undrained triaxial tests have been carried out at different strain rates; the stress conditions at failure are shown with squares and triangles in the insert of Fig. 6, with the strain rate indicated nearby in $10^{-8} \mathrm{~s}^{-1}$. Long-term triaxial creep tests were also performed for the stress conditions indicated by black dots on the figure; the numbers correspond to the minimum strain rate reached before failure. It can be seen that all the strain rates indicated in the insert of Fig. 6 are well organised and define a family of strength envelopes corresponding to constant strain rates. The preconsolidation pressures deduced from constant rate of strain (CRS) oedometer tests at different strain rates (diamonds in Fig. 6) indicate that the entire limit state curve is strain rate dependent (Leroueil \& Marques, 1996). Experience shows that the strength of clays typically varies by $10 \%$ per logarithm cycle of strain rate (Kulhawy \& Mayne, 1990; Leroueil \& Marques, 1996).

Whereas Figs 4 and 5, and equation (1) indicate a time dependence of soil behaviour, Fig. 6 indicates a strain rate dependence. The question is: which one is the most representative?

In order to clarify this aspect, a simple model has been established on the basis of reasonable approximations and experience (Leroueil, 1998a). The hypotheses considered were: a hyperbolic stress-strain curve; a $\log -\log$ variation of shear strength with strain rate; and failure controlled by a critical accumulated strain, here $0.9 \%$. The model, with the considered equations and parameters, is shown in Fig. 7.

Creep tests have been simulated for the deviatoric stresses indicated by arrows in Fig. 7, and the results are shown in Fig. 8. It can be seen that the plots of logarithm of strain rate against logarithm of time lines are linear as observed in laboratory tests (Figs 4 and 5) and as indicated by equation (1). For this author, this means that, fundamentally, soil behaviour is strain rate dependent and that the time model proposed by Singh \& Mitchell (1968) reflects both this strain rate dependence and the test itself, in which stress conditions are suddenly applied at time zero. It is worth noting that the strain rate model shows a slight decrease of the slope, $m$, of the curves of $\log \dot{\varepsilon}$ against $\log t$ as shear stress level increases, as observed in laboratory creep tests.

The critical accumulated strain seems to be an important parameter. Because of that, after a slight decrease in deviatoric stress from $190 \mathrm{kPa}$ to $170 \mathrm{kPa}$ after 50 min (Figs 7 and 9), creep strains continue to develop, and the soil reaches failure when the critical accumulated strain (here $0.9 \%$ ) is reached (Fig. 9). Marchand (1982) observed such a creep failure after decreasing the shear stress level. Such an approach could be used to study excavations in which there is an origin of strains, but not natural slopes in which the origin of strains is unknown.

Behaviour similar to that described for clayey soils was also observed on weak rocks (Nishi et al., 1983; Adachi et al., 1998).

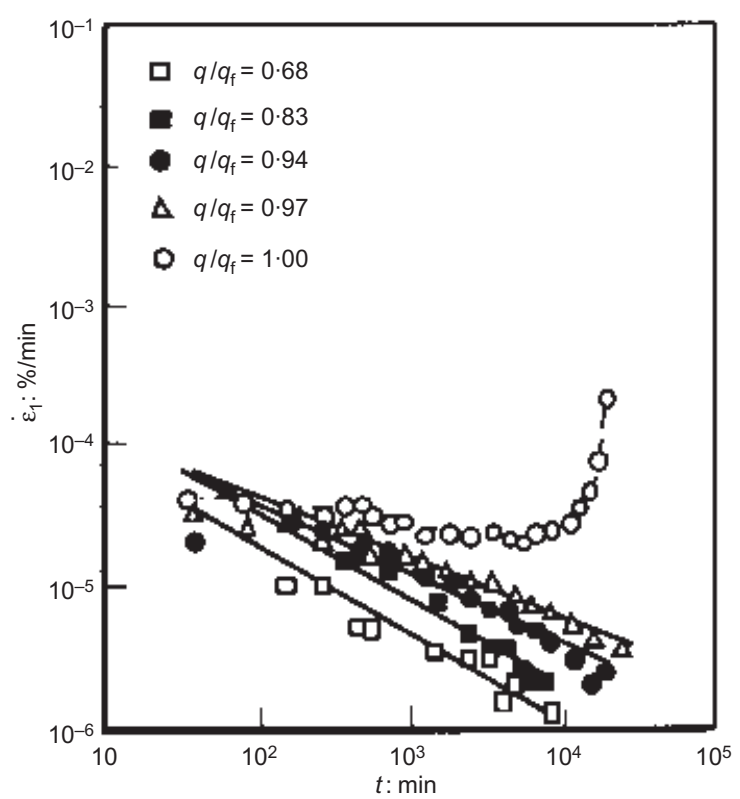

(a)

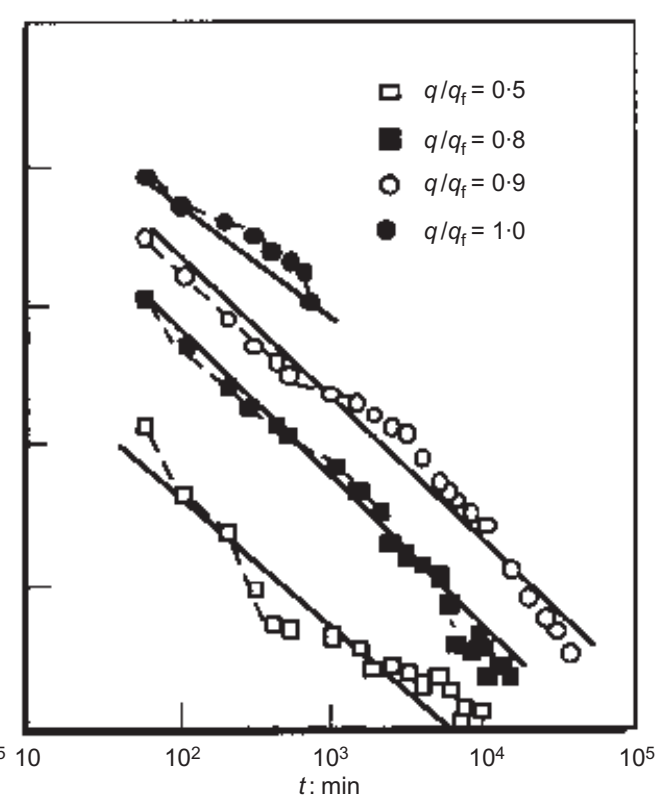

(b)

Fig. 5. Axial strain rate against time relationships obtained at various stress levels $\left(q / q_{\mathrm{f}}\right)$ during creep tests $\left(\sigma^{\prime}{ }_{3}\right.$ decreasing and $\sigma_{1}^{\prime}$ constant) on: (a) Santa Barbara clay (from D'Elia, 1994); (b) 'Argille Scagliose' (from D'Elia, 1991) 


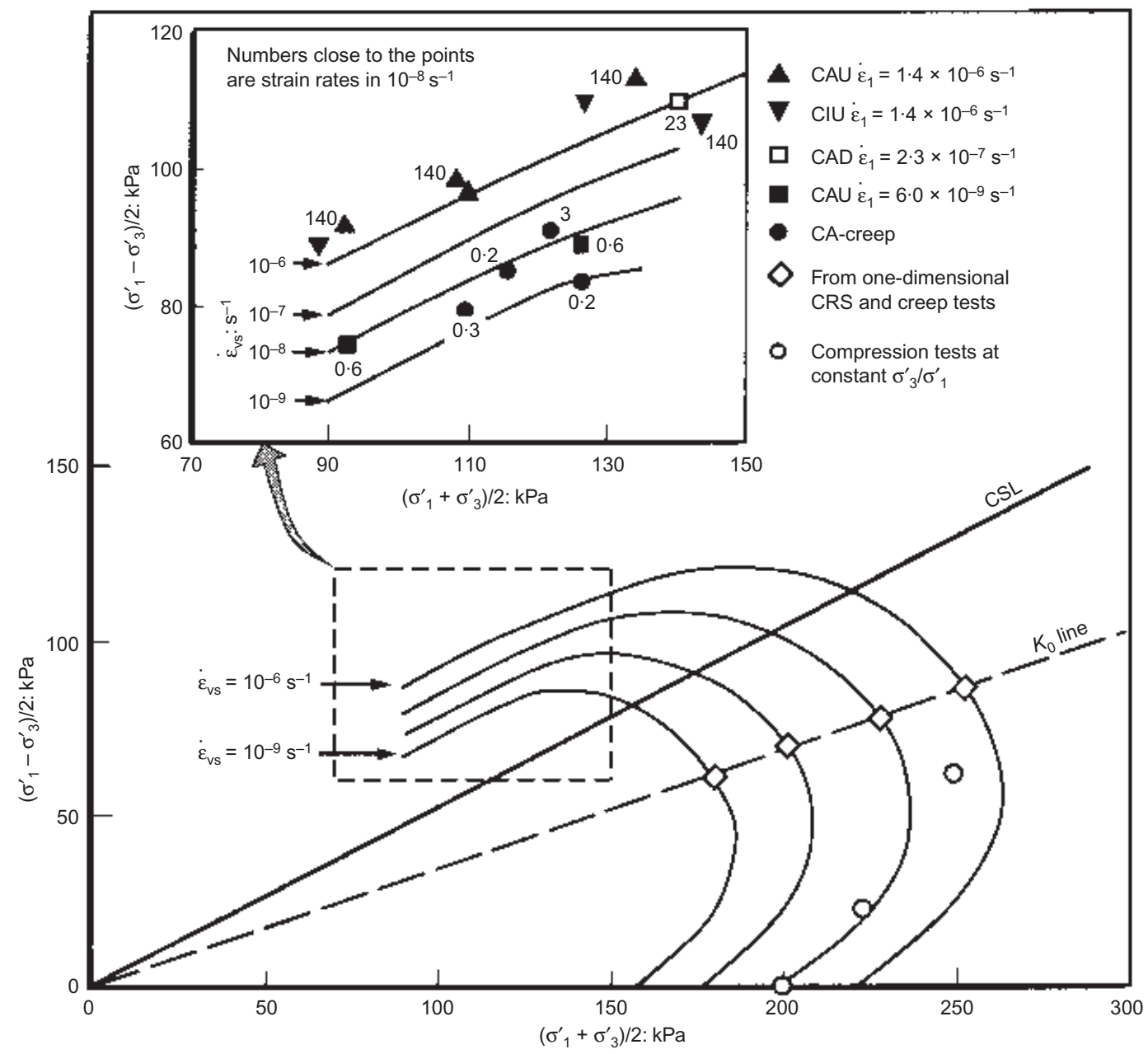

Fig. 6. Influence of strain rate on the limit state curve of Mascouche clay (after Marchand, 1982; from Leroueil \& Marques, 1996)

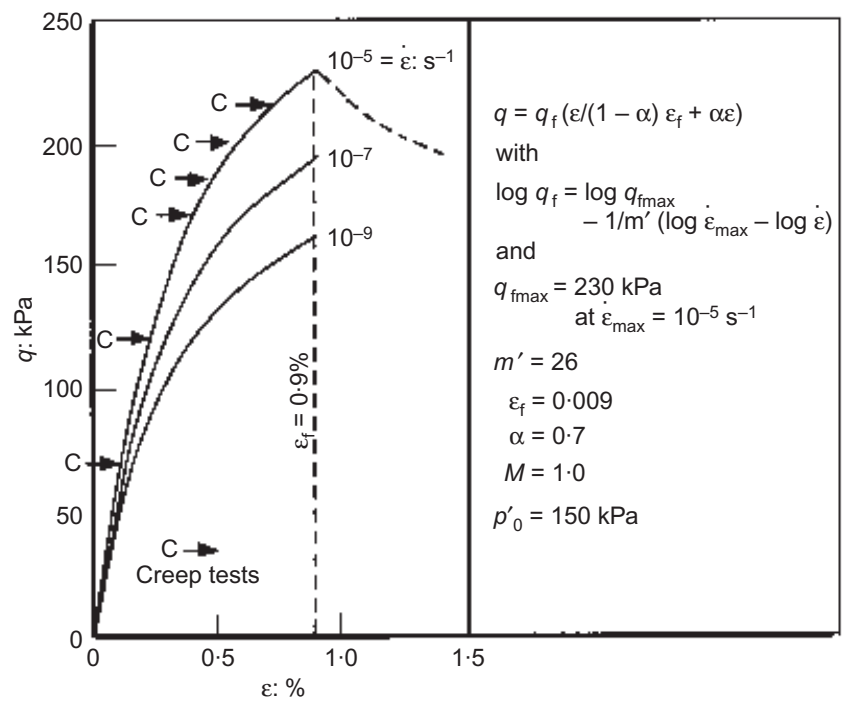

Fig. 7. Strain rate dependence of stress-strain behaviour, and input parameters used for the simulation of triaxial creep tests (from Leroueil, 1998a)

Peak strength envelope

The upper part of the limit state curve, which is also the peak strength envelope of the soil in its overconsolidated range, plays an important role in the development of slope failures. It is influenced by several factors that the geotechnical engineer

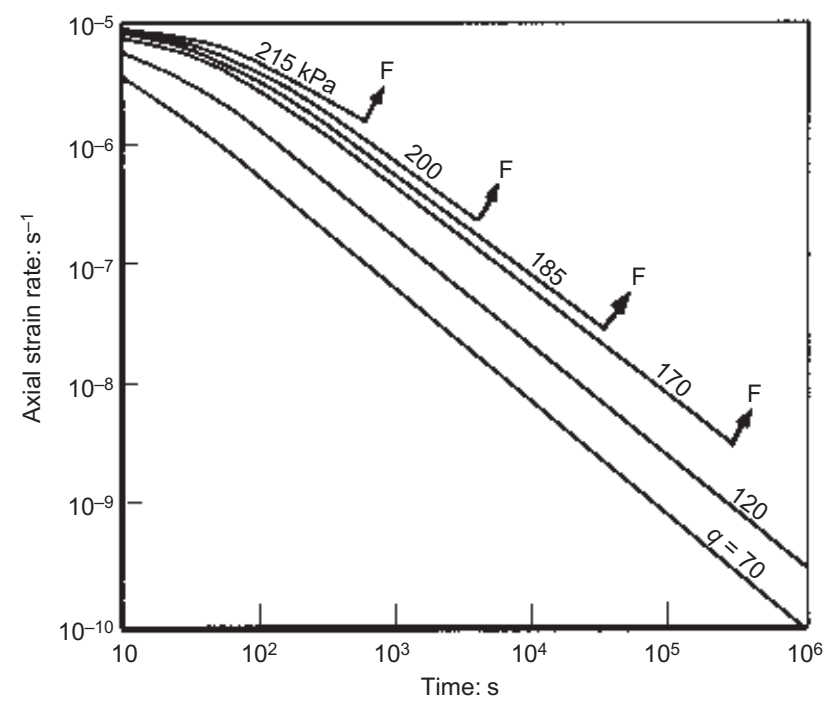

Fig. 8. Simulated creep tests for the conditions given in Fig. 7 (from Leroueil, 1998a). $F$ = failure

must have in mind. In addition to strain rate (already mentioned), we can add anisotropy and stress axis rotation (Hight, 1998), void ratio (Hvorslev, 1937), the size of the tested specimens in fissured clays (Marsland \& Butler, 1967; Marsland, 


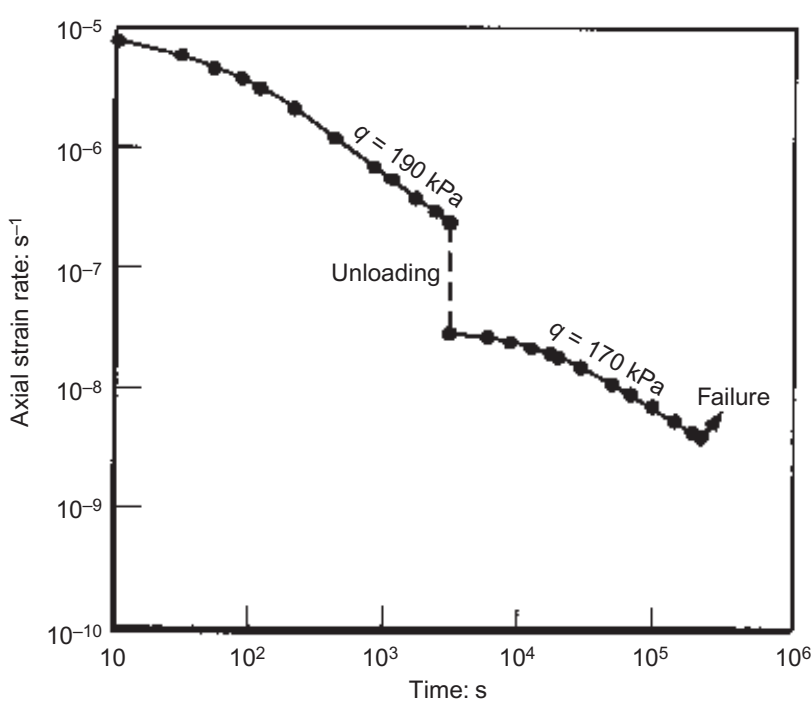

Fig. 9. Simulated creep test in which the deviatoric stress has been applied at a value of $190 \mathrm{kPa}$ for $3000 \mathrm{~s}$ and then decreased to $170 \mathrm{kPa}$ (from Leroueil, 1998a)

1974), fatigue, destructuration, weathering and change in suction in unsaturated materials. These four later aspects will be examined below.

Fatigue. Yoshinaka \& Osada (1995) examined four soft sedimentary rocks under static and cyclic loading. The monotonic tests were performed in undrained conditions at an axial rate of $0.01 \mathrm{~mm} / \mathrm{min}$. In the fatigue (or cyclic) tests the axial load was repeatedly applied at a frequency of $0.2 \mathrm{~Hz}$ until the specimen reached failure. The normalised maximum deviatoric stress, defined as the ratio of the maximum deviatoric stress applied in cyclic tests to the deviatoric stress at failure in the monotonic tests, varied from $80 \%$ to $120 \%$. Fig. 10 shows the normalised maximum deviatoric stress applied in the fatigue tests as a function of the number of cycles necessary to reach failure for the Yokohama siltstone. It can be seen that the number of cycles to failure increases as the applied stress level decreases, and that failure at the first loading cycle is reached at a normalised maximum deviatoric stress of about $1 \cdot 2$. This latter ratio is explained by the fact that the stress and strain rates in cyclic loading tests are much larger than those in the monotonic tests. It thus appears that the strength under cyclic loading is influenced by strain rate, as evidenced under the first loading

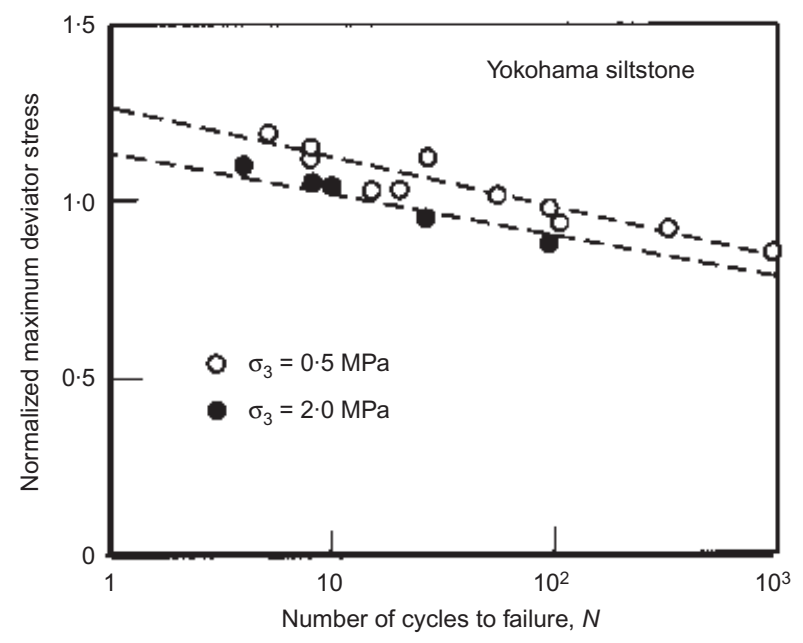

Fig. 10. Number of cycles to failure as a function of the maximum deviatoric stress applied in undrained cyclic triaxial tests (from Yoshinaka \& Osada, 1995) cycle, and by the fatigue phenomenon during the subsequent loading cycles. Also, on the basis of measured pore pressures, Yoshinaka \& Osada (1995; 1998, personal communication) concluded that the reduction in strength results from a lowering of the strength envelope with the accumulation of cycles and fatigue.

Lefebvre \& Leboeuf (1987) performed undrained triaxial tests on eastern Canada clays under monotonic conditions at different strain rates and under cyclic conditions, and came to conclusions similar to those of Yoshinaka \& Osada (1995; 1998, personal communication). In particular:

(a) The cyclic strength results from the combined effect of strain rate and fatigue. This is confirmed by observations made by Attewell \& Farmer (1973) and by Ishizuka et al. (1993) showing an increase in the number of cycles to reach failure with the excitation frequency, and thus an increase of the cyclic shear strength with strain rate.

(b) In the overconsolidated range, fatigue induces a progressive lowering of the peak strength envelope.

The strain rate effect, which results in a strength increase during the first loading cycles, probably explains why landslides due to earthquakes seem to be relatively infrequent in homogeneous and microstructured geomaterials.

Lacerda (1989) considered that cyclic variations of pore pressures in slopes could lead to some fatigue of the material involved and a lowering of its strength envelope. He then suggested performing drained cyclic tests in which the pore pressure would be changed in such a way that the effective stress conditions would vary, at constant deviatoric stress, from stress conditions corresponding to low pore pressure to stress conditions corresponding to high pore pressure (points LW and HW respectively in Fig. 45). Santos et al. (1997) performed such tests at constant deviatoric stress on a residual soil from Rio de Janeiro. They cycled effective stress conditions from I to A (insert of Fig. 11(a)) by a change in pore pressure, $u_{\max }$, normalised in relation to $u_{\mathrm{o}}$, the pore pressure to reach the CSL, and $u_{\mathrm{f}}$, the pore pressure necessary for the soil to fail by a monotonic increase in pore pressure. The normalised pore pressure parameter used is $U_{\mathrm{c}}=\left(u_{\max }-u_{\mathrm{o}}\right) /\left(u_{\mathrm{f}}-u_{\mathrm{o}}\right)$. Fig. 11(b) shows that the number of cycles to reach failure in these cyclic tests increases as $U_{\mathrm{c}}$ decreases, which also implies a lowering of the peak strength envelope with cyclic loading.

Fatigue is a well-known process in continuous material technology, where it is associated with the development and propagation of cracks. It is also accepted in rock mechanics (Attewell \& Farmer, 1973; Tien et al., 1990; Yoshinaka \& Osada, 1995). As most soils and weak rocks are microstructured with more or less rigid bonds between particles, aggregates, or lumps, a progressive damage of these bonds by cycling loading is expected. Like fatigue, creep can also be associated with a progressive damage of the bonds of microstructured geomaterials; creep, however, seems to be more general since it is observed in both microstructured and unstructured geomaterials, and in particular in normally consolidated clays. In this text we shall refer to creep-fatigue phenomena for describing delayed failures that could be associated with cyclic variations of the applied shear stress level.

Destructuration. In microstructured soils or weak rocks, the limit state curve reflects the void ratio of the material, its stress history, and the strength of the bonds between particles or aggregates. So, when an effective stress path reaches the limit state curve, a large proportion of the bonds are broken, and the material is destructured. The main consequences of destructuration are (Leroueil et al., 1979; Leroueil \& Vaughan, 1990; Amorosi \& Rampello, 1998):

(a) a decrease in stiffness of the soil inside the limit state curve

(b) a lowering of the peak strength envelope

(c) a decrease in the yield stress in compression as well as a decrease of the compression index of the soil in the normally consolidated range. 


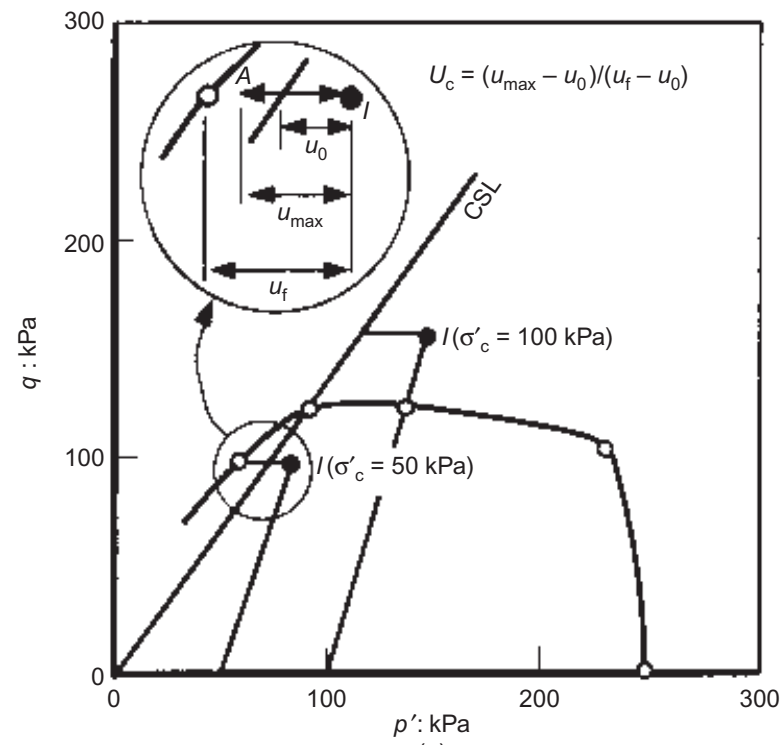

(a)

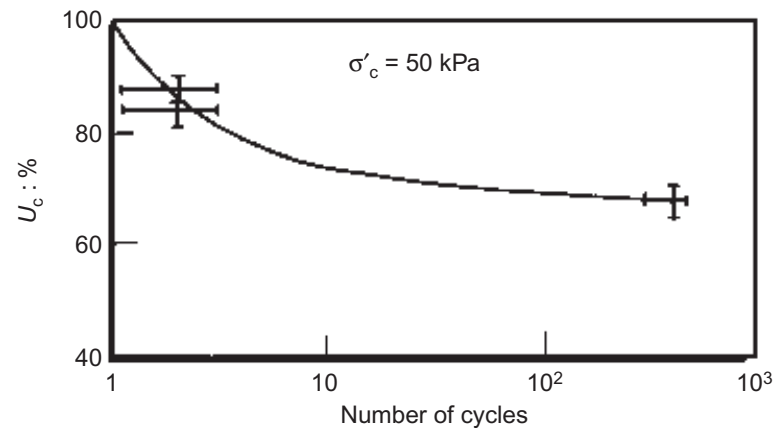

(b)

Fig. 11. Constant deviatoric stress cyclic tests on a residual soil from Rio de Janeiro: (a) stress path; (b) variation of the number of cycles at failure with $U_{c}$ (after Santos et al., 1997)

As indicated by Leroueil \& Vaughan (1990), destructuration can be reached by compression (between $\mathrm{A}$ and $\mathrm{B}$ in Fig. 12(a)), by shearing (between A and D or B and C in Fig. 12(a); this may happen in particular during sampling) and possibly by swelling (between C and D in Fig. 12(a)). If a microstructured soil containing expansive clay minerals is progressively unloaded, it has a tendency to swell, and then two different things can happen:

(a) The bonds are stronger than the swelling forces and the soil remains microstructured, even under zero effective stress. In such a case, the soil has a tensile strength.

(b) At some stage, the swelling forces become larger than the bonds, which break; there is then destructuration and yielding in swelling. Such a behaviour has been observed in London Clay (Bishop et al., 1965; Leroueil \& Vaughan, 1990) and in Todi clay (Calabresi \& Scarpelli, 1985).

Let us assume a microstructured clay element with a limit state curve such as that shown in Fig. 12(a), and stress conditions represented by point I, chosen close to the isotropic line for reasons of simplicity. If such a soil element is subjected to evaporation, its effective stress will increase isotropically, reach yielding at point $\mathrm{Y}_{\mathrm{c}}$, and progressively dry as suction and effective stress will increase. Such a soil element would be destructured by compression at $Y_{c}$. If another soil element is progressively unloaded, the effective stress will decrease, reach the limit state curve in $Y_{s}$, and possibly go towards effective stresses close to zero. Such a soil element would be destructured by swelling at $\mathrm{Y}_{\mathrm{s}}$. Yielding by compression and by swelling are schematically shown in Fig. 12(b), in a diagram of $\Delta$ e plotted against $\left(\sigma^{\prime}{ }_{1}+\sigma^{\prime}{ }_{3}\right) / 2$

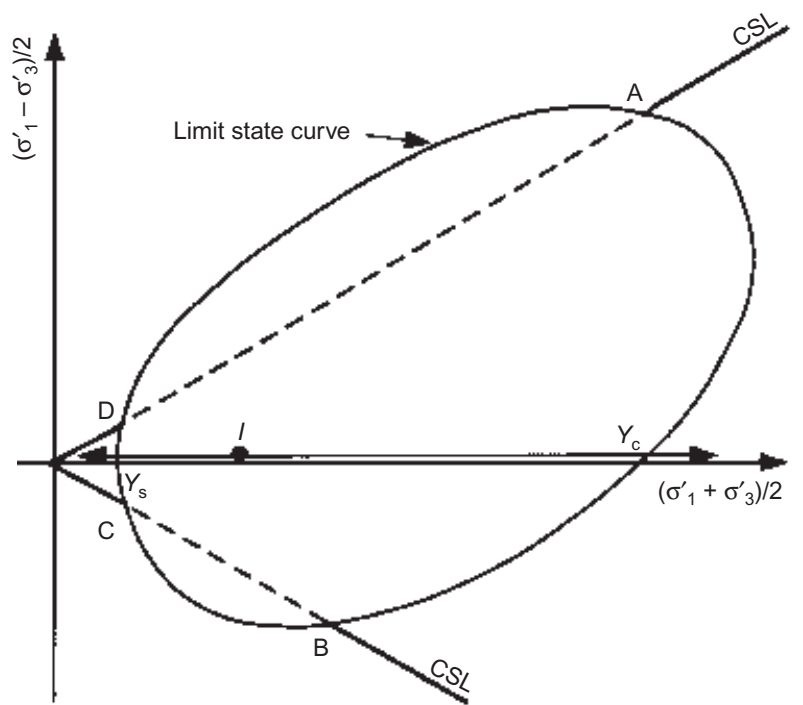

(a)

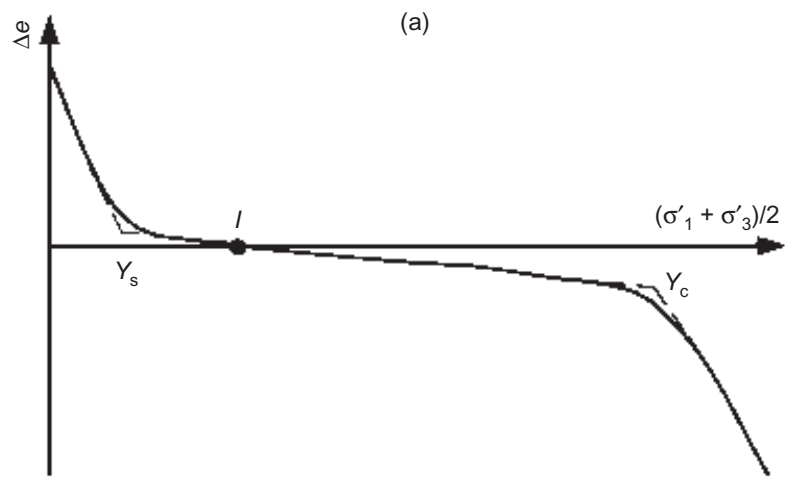

(b)

Fig. 12. Schematised yielding by compression and by swelling (after Leroueil \& Vaughan, 1990)

The influence of unloading and/or drying-wetting cycles on the peak strength envelope of Todi clay, a heavily overconsolidated clay from central Italy, has been studied in detail by researchers from the University of Rome. An important question concerning this type of clay was: why is it that natural slopes inclined on the horizontal by about $10^{\circ}$ are unstable whereas steep slopes of $20 \mathrm{~m}$ or more in large excavations maintain their stability for a long time (Calabresi \& Rampello, 1987; Rampello, 1991)? In relation to this question, Calabresi \& Scarpelli (1985), Calabresi \& Rampello (1987), and Rampello $(1989,1991)$ performed several series of triaxial compression tests:

(a) on the undisturbed material

(b) on soil subjected to free swelling and then reconsolidated before shearing (the volume increase due to free swelling was about $12 \%$ )

(c) on soil first air desiccated and then left to swell before shearing

(d) on the reconstituted Todi clay.

The test results have been described and analysed by the previously mentioned authors, and also by Burland (1990). Fig. 13(a) shows the strength results. The strength envelope of the undisturbed soil is well above those obtained after free swelling or drying-wetting of the soil, evidencing the fact that the intact Todi clay is microstructured and can thus be destructured. The strength envelope of the reconstituted soil is even lower than those of the soil destructured by swelling or drying-wetting.

To take into account the influence of void ratio on strength envelopes, Rampello (1989) normalised them with respect to $p^{\prime}(e)$, which is the mean stress on the compression curve of the 


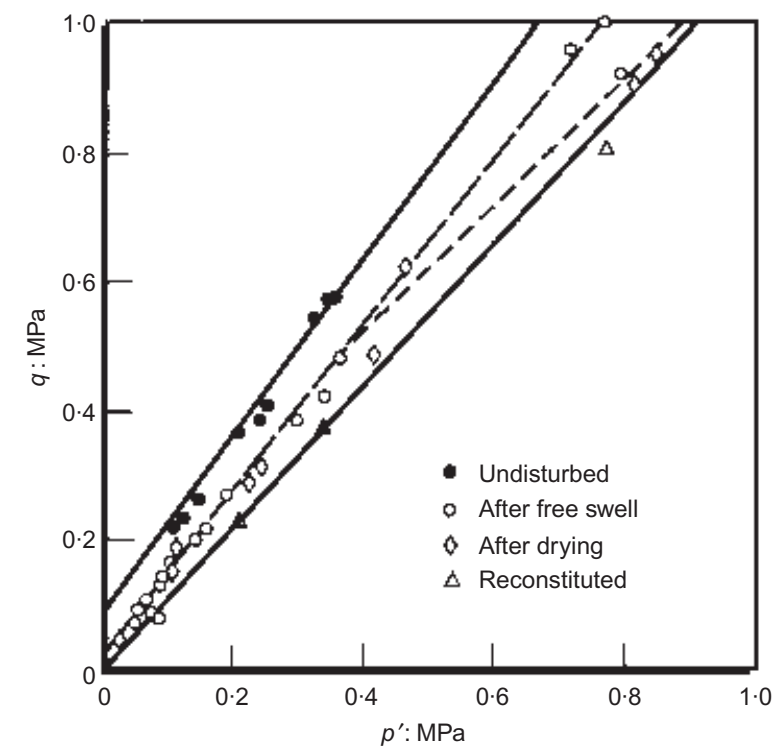

(a)

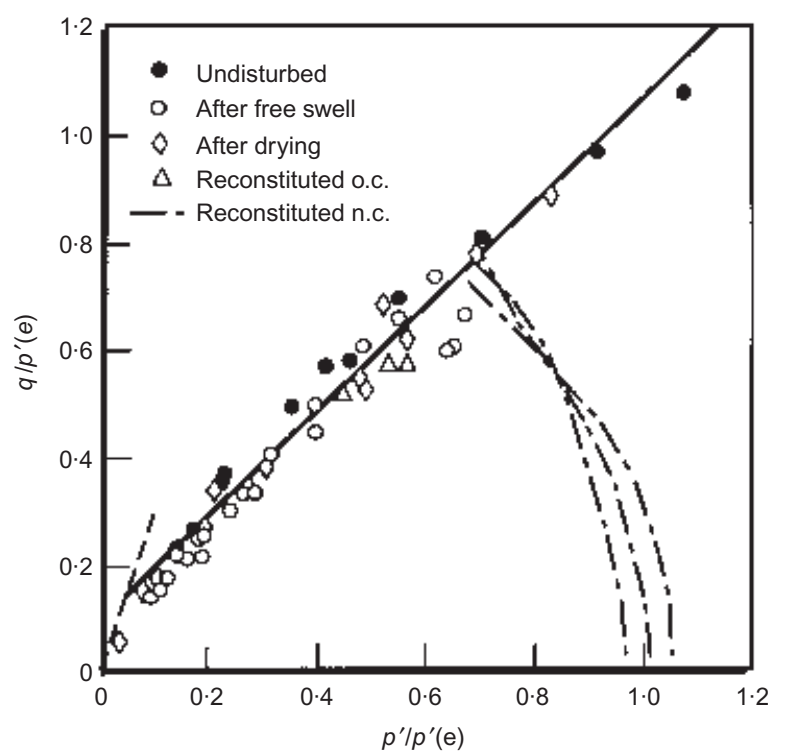

(b)

Fig. 13. Failure envelopes for undisturbed, free swollen and dried-wetted samples of Todi clay; (a) in a normal stress diagram; (b) normalised with respect to the equivalent pressure at failure, $p^{\prime}(\mathrm{e})$ (from Rampello, 1989, 1991)

reconstituted material at the same void ratio as at failure (Fig. 13(b)). The normalised strength envelope of the undisturbed soil is only slightly above those of the soil after free swelling, drying-wetting, or of the reconstituted soil, indicating that interparticle bonding is existent but not strong in Todi clay. However, for practical implications in in situ conditions, it is the envelopes of the soil including the effect of void ratio (those shown in Fig. 13(a)) that is relevant. Thus, even if bond strength is not high in this case, it provides the intact Todi clay with an enhanced strength corresponding to a cohesion on the order of $50 \mathrm{kPa}$. So, if field observations indicate strength at shallow depths and in gentle slopes to be smaller than the strength of the intact clay at Todi, this is probably due to a combination of factors, but destructuration by swelling and drying-wetting cycles certainly comes into the process, as indicated by Calabresi \& Rampello (1987). More generally, for clays close to the surface and in contact with water, there can be primary and secondary swelling, destructuration by swelling or drying-wetting, chemical weathering, and, in marine clays, a progressive decrease in salinity, all factors that contribute to a decrease in strength and thus to instability.

Weathering. Weathering is a destructive process due to both physical and chemical phenomena in which air and water play a major role. The weathering phenomena generally produce a decrease in particle size, changes in mineralogy, and a decrease of interparticle bond strength. From the mechanical point of view, weathering generally results in a lowering of the peak strength envelope of the geomaterial considered (Taylor \& Cripps, 1987; Chandler \& Apted, 1988). This is evidenced by the comparison shown in Table 2 of strength parameters obtained on the intact material and those obtained on the same material when weathered. There is systematically a decrease in cohesion and, for most of the time, a reduction of the friction angle.

Partial saturation. Alonso et al. (1990) defined a constitutive model in which they extended the concepts of limit and critical states applied to saturated materials (Roscoe \& Burland, 1968) to unsaturated soils. As previously established by Fredlund et al. (1978), the controlling factor is matric suction, defined as $S=\left(u_{\mathrm{a}}-u_{\mathrm{w}}\right)$, in which $u_{\mathrm{a}}$ and $u_{\mathrm{w}}$ are respectively the pore air pressure and the pore water pressure in the unsaturated material. The concepts have since been confirmed experimentally on a variety of soils (Maâtouk et al., 1995; Zakaria et al., 1995; Cui \& Delage, 1996; and others since), and can be described as follows (Fig. 14). If the limit state curve corresponding to zero suction (saturated conditions) is $Y_{0}$, as the matric suction increases the entire limit state curve swells, generating in particular an increase in peak strength and in critical state strength of the soil. On the other hand, if an unsaturated soil is subjected to progressive wetting and decrease in matric suction, the entire limit state curve shrinks and the strength decreases. Fredlund et al. (1978) described the strength of unsaturated soils with the two stress components $\left(\sigma_{\mathrm{n}}-u_{\mathrm{a}}\right)$ and $\left(u_{\mathrm{a}}-u_{\mathrm{w}}\right)$ as follows:

$$
\tau_{\mathrm{f}}=c^{\prime}+\left(\sigma_{\mathrm{n}}-u_{\mathrm{a}}\right) \tan \phi^{\prime}+\left(u_{\mathrm{a}}-u_{\mathrm{w}}\right) \tan \phi^{\mathrm{b}}
$$

where $c^{\prime}$ and $\phi^{\prime}$ are respectively the effective cohesion and effective friction angle of the soil, and $\phi^{\mathrm{b}}$ is the friction angle with respect to changes in $\left(u_{\mathrm{a}}-u_{\mathrm{w}}\right)$ when $\left(\sigma_{\mathrm{n}}-u_{\mathrm{a}}\right)$ is held constant.

Table 2. Strength characteristics of selected fresh and weathered mudrocks and overconsolidated clays

\begin{tabular}{l|c|c|c|c}
\hline \multirow{2}{*}{} & \multicolumn{2}{|c|}{ Fresh: } & \multicolumn{2}{c}{ Weathered: } \\
\cline { 2 - 5 } & $\phi^{\prime}:$ degrees & $c^{\prime}: \mathrm{kPa}$ & $\phi^{\prime}:$ degrees & $c^{\prime}: \mathrm{kPa}$ \\
\hline London Clay & $20-29$ & $31-252$ & $17-23$ & $1-18$ \\
Bearpaw shale & $25-30$ & $10-152$ & $20-28$ & $0-41$ \\
Lower Oxford clay & $23-40$ & $10-216$ & $21-28$ & $0-20$ \\
Upper Lias clay & 24 & 27 & $18-25$ & $1-17$ \\
Keuper Marl & $>40$ & $>30$ & $25-42$ & $2-80$ \\
Coal Measures Mudrock & 46 & 131 & $26-39$ & $0-25$ \\
\hline
\end{tabular}

After Taylor \& Cripps (1987) 


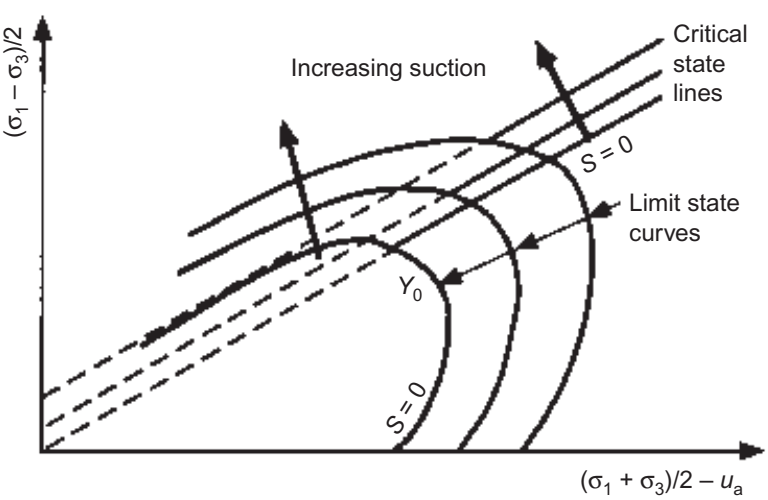

Fig. 14. Influence of matric suction on the limit state curve and strength envelope of soils

\section{Swelling}

Swelling due to unloading and secondary swelling. When stresses applied to soil are decreased, swelling occurs. There is the primary swelling associated with pore water pressure equilibration, and the secondary swelling associated with the readjustment of soil particles and aggregates to the new stresses (Mesri et al., 1978; Gens \& Alonso, 1992; Urciuoli, 1992)

Osmotic swelling. It has been shown on several clays, particularly smectites and montmorillonites, that exposure to liquid of chemical composition different from that of the pore liquid can cause a change in void ratio (Mitchell et al., 1973; Barbour \& Fredlund, 1989; Di Maio, 1996a, b; Picarelli et al., 1998). This phenomenon can exist in particular when a marine clay is exposed to fresh water. Di Maio (1996a, b) and Picarelli et al. (1998) examined this point. Fig. 15 shows the change in void ratio under one-dimensional conditions of Bisaccia clay, reconstituted with $1 \mathrm{M} \mathrm{NaCl}$, compressed to high stresses, then unloaded to a vertical stress of $10 \mathrm{kPa}$, and finally exposed to distilled water under the same vertical stress. As seen in Fig. 15, osmotic swelling can be very important; it was about $34 \%$ in this case (A to B).

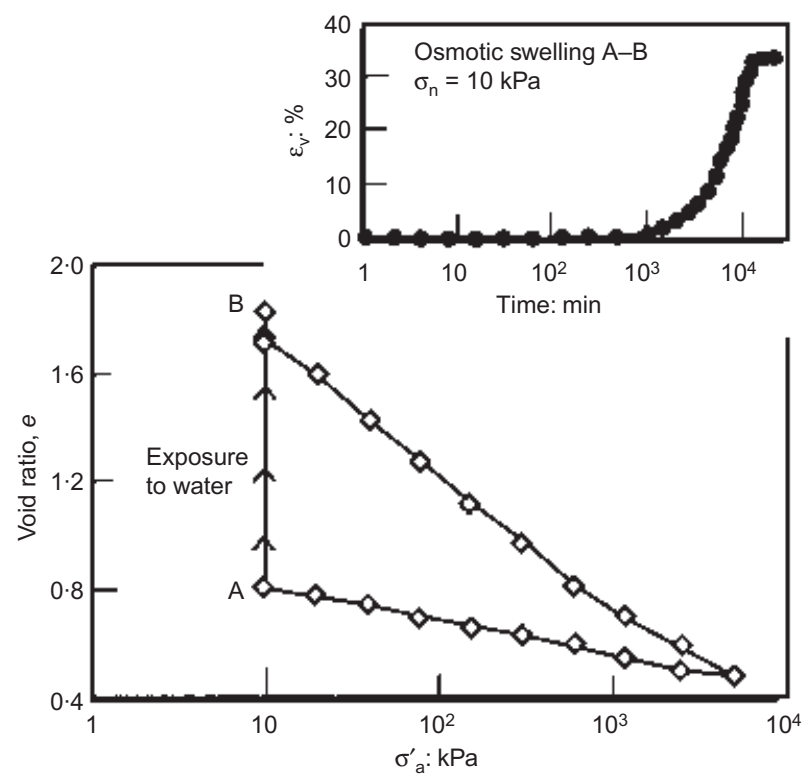

Fig. 15. One-dimensional compression and swelling curves of a specimen of Bisaccia clay reconsituted with and immersed in a $1 \mathrm{M} \mathrm{NaCl}$ solution. Exposed to distilled water, the specimen swelled from A to B (after Picarelli et al., 1998)
Large deformation strength in microstructured soils

Calabresi (1980), Burland (1990) and Burland et al. (1996) observed that shear tests on stiff clays give a peak with formation of rupture surfaces, followed by a rapid drop in strength towards what they call 'post-rupture' strength reached after a displacement along the shear surface of 1 to a few millimetres. They also found that the 'post-rupture' strength envelope lies close to the critical state line obtained on the reconstituted soil. As further displacements take place, there is a progressive orientation of clay particles and a reduction of the angle of shearing resistance towards its residual value.

Leroueil et al. (1997) reported large deformation strengths obtained in triaxial tests, in the overconsolidated range of the material, that lie well above the critical state line obtained on the reconstituted material. The materials studied were sensitive eastern Canada clays and softened clay shales from southern Italy. Fig. 16 shows typical results for eastern Canada clays. Whereas the friction angle obtained at the critical state, on the reconstituted or normally consolidated clay, is typically around $30^{\circ}$, the large deformation strength corresponds to a friction angle of about $44^{\circ}$. This was explained by the fact that these clays are made up of aggregates that are at a water content close to the plastic limit, and thus very stiff and very angular. As for the Italian softened clay shales, it was explained by the presence of hard lithorelicts (bonded aggregates of clay particles from the parent shale) in the clayey matrix. The results obtained by Burland et al. (1996) are thus not general. It is thought, however, that, if displacements larger than those allowed in triaxial testing were possible, the aggregates or lithorelicts would be progressively destroyed and the angle of shearing resistance would progressively decrease towards its residual value (Picarelli, 1993; Leroueil et al., 1997).

\section{Residual strength}

When considering slopes in general, residual strength is a major factor. It is reached after large displacements and reorientation of platy particles in a direction parallel to the direction of shearing. The behaviour then observed is influenced by the mineralogy and the shape of the particles, and by several other factors: applied stress; type of shearing; rate of displacement; and pore water chemistry. These aspects are briefly examined below, but it is worth mentioning that Stark \& Eid (1994) proposed a general correlation between the residual friction angle, $\phi_{\mathrm{r}}^{\prime}$, mineralogy (through the liquid limit), clay size fraction and normal effective stress.

Influence of applied stress. For many clayey soils, the relation between residual strength and normal effective stress is nonlinear (Skempton, 1985; Picarelli, 1991; Stark \& Eid, 1994). This is illustrated by the data obtained by Picarelli (1991) on reconstituted specimens of Laviano clay (circles in Fig. 17).

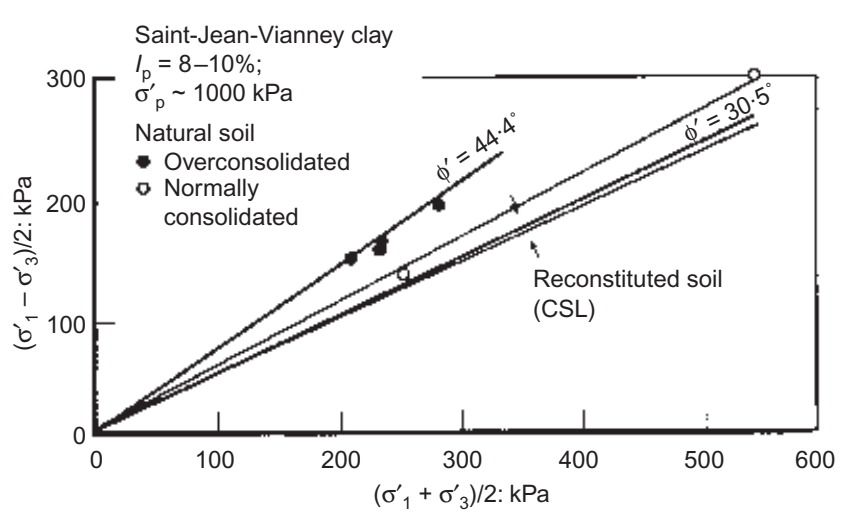

Fig. 16. Large deformation strength of the natural and reconstituted Saint-Jean-Vianney clay (after Saihi, 1997) 


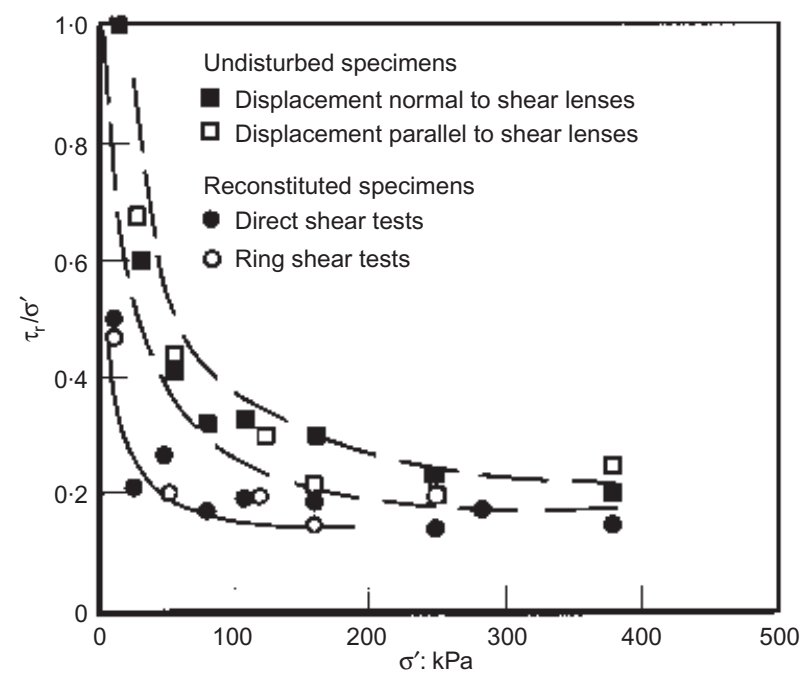

Fig. 17. Residual shear strength of Laviano clay (from Picarelli, 1991)

Influence of shear mode (rolling against sliding). The behaviour at large displacements of soils containing both rotund and platy particles has been studied by Lupini et al. (1981). Their main conclusion can be illustrated by Fig. 18 that presents the residual friction angle, $\phi_{\mathrm{r}}{ }_{\mathrm{r}}$, and the critical state friction angle, $\phi_{\mathrm{cr}}{ }_{\mathrm{cr}}$, of sand-bentonite mixtures. When the percentage of platy particles (bentonite) is small, there is no reorientation of particles, shear can be described as turbulent shear or rolling shear, and $\phi_{r}^{\prime}$ is only slightly smaller than $\phi_{\text {cr. }}^{\prime}$. When the percentage of platy particles is large, there is reorientation of these particles, shear is described as sliding shear, and $\phi_{\mathrm{r}}^{\prime}$ is significantly smaller than $\phi^{\prime}{ }_{\text {cr. }}$. In between, the behaviour is transitional, with rotund particles impeding the development of a continuous and perfectly smooth shear surface.

These phenomena can be reflected when testing undisturbed specimens of soils. On Laviano clay shale, Picarelli (1991) observed that the residual strength of the undisturbed material is substantially greater than that measured on reconstituted soil specimens (Fig. 17). This has been attributed to the coarser grain size distribution of the undisturbed specimens, whose shear lenses are constituted of bonded clayey aggregates. In reference to Fig. 18, the behaviour of Laviano clay probably changes from a 'sliding shear' mode when the reconstituted material is considered to a 'transitional' mode when the undisturbed material is considered. Picarelli (1999, personal commu-

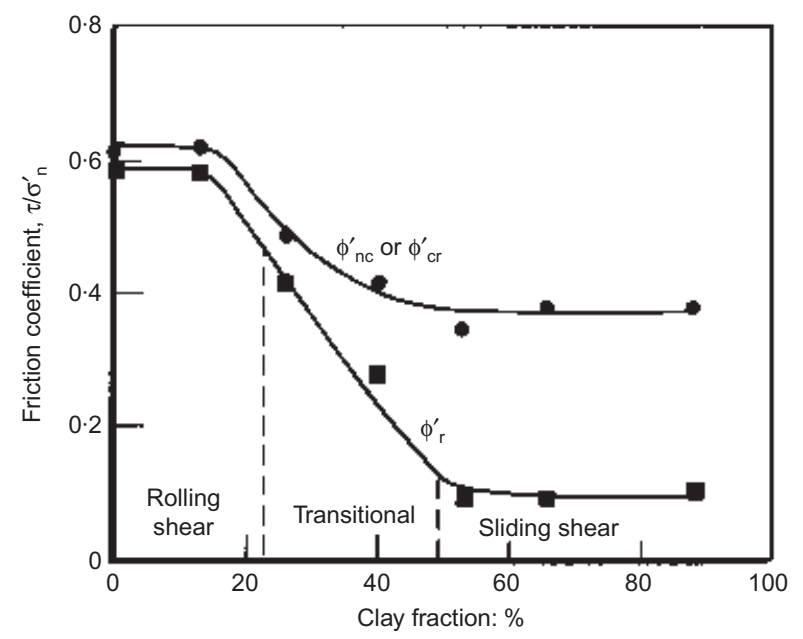

Fig. 18. Ring shear tests on sand-bentonite mixtures (after Lupini et al., 1981, and Skempton, 1985) nication) also attributes the behaviour shown in Fig. 17 to the rugosity of the shear lenses.

Influence of the rate of displacement. Figure 19 shows the variation of residual strength as a function of time for displacement for various clays. Residual strength increases by a few percent when the rate of displacement increases by one order of magnitude. This is not significant when stability of slopes is considered (Skempton, 1985), but, as seen later on, it has significant consequences for the rate of slope movements at their reactivation stage. Fig. 19 considers rates of shearing smaller than $10^{-1} \mathrm{~mm} / \mathrm{min}$. At faster rates of shearing (larger than $1-10 \mathrm{~mm} / \mathrm{min}$ ), the residual strength under a constant normal stress has been observed to remain constant or to increase or to decrease, depending on the soil and testing conditions. Tika et al. (1996) studied these phenomena, and concluded that decrease in residual strength at fast rates would be due to an increase in void ratio in the shear zone, and would exist if free water was available.

Influence of pore water chemistry. Di Maio (1996a, b) showed that the effect of pore water chemistry on residual friction angle can be important. Fig. 20 shows results obtained on three southern Italy clays and on Ponza bentonite prepared either with saturated $\mathrm{NaCl}$ solution or with distilled water. It can be seen

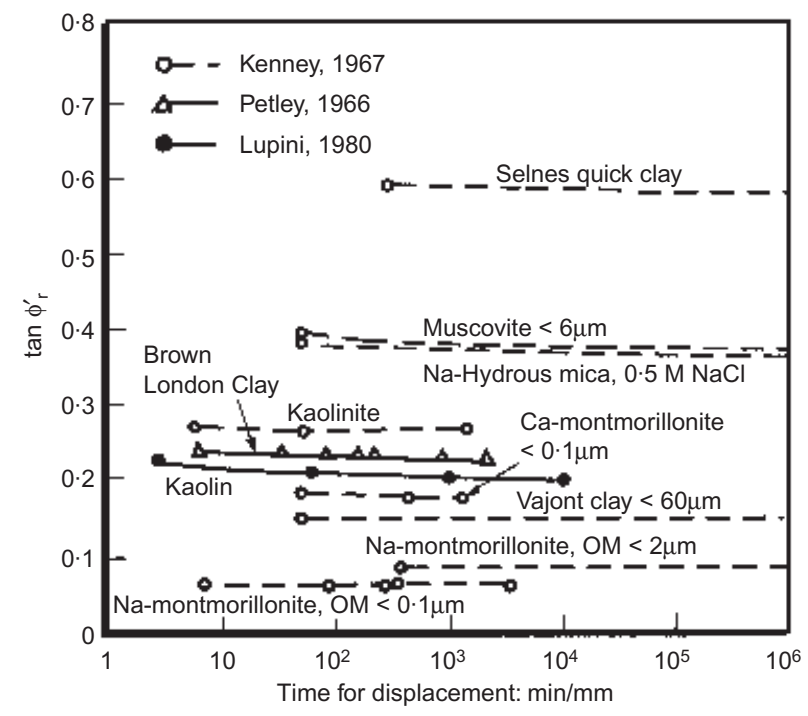

Fig. 19. Influence of rate of shearing on residual strength

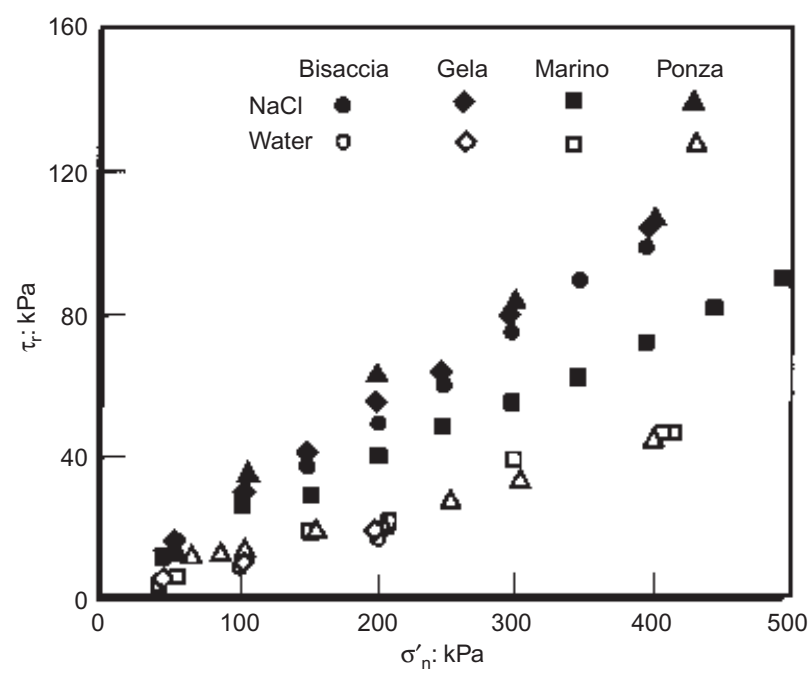

Fig. 20. Residual shear strength plotted against normal stress of specimens reconstituted with water and specimens reconstituted with saturated NaCl solution (from Di Maio, 1996a) 
that, with the exception of Marino clay, $\phi^{\prime}{ }_{r}$ changes from about $14^{\circ}$ with the saturated $\mathrm{NaCl}$ solution to $6^{\circ}$ with distilled water, which may be extremely important from a practical point of view. Fig. 21 shows the variation of $\phi^{\prime}{ }_{r}$ with concentration of $\mathrm{NaCl}$ solution for Ponza bentonite; all the change in $\phi^{\prime}{ }_{\mathrm{r}}$ occurs for concentrations between 0 and $35 \mathrm{~g} / 1 \mathrm{NaCl}$, which should be an encouragement to evaluate residual friction angle in laboratory with pore water having a chemistry close to that existing in situ.

\section{WATER IN SOIL MASSES}

Water is, without any doubt, the factor that influences slope movements the most, and it is worth having a section to examine its influence on several aspects of the behaviour of natural slopes and cuts.

\section{Pore pressure variations in saturated deposits}

In saturated conditions, owing to the compressibility of soils and the fact that total stresses in a slope, or for a horizontal ground surface, change only slightly when pore pressures vary at the boundaries; a change in pore pressure at a given depth is associated with a change in effective stress and, consequently, a change in void ratio. This is illustrated for one-dimensional conditions in Fig. 22. This process, which involves water flow and swelling or compression of the soil, requires time, and is controlled by the following swelling/consolidation differential equation for two-dimensional conditions:

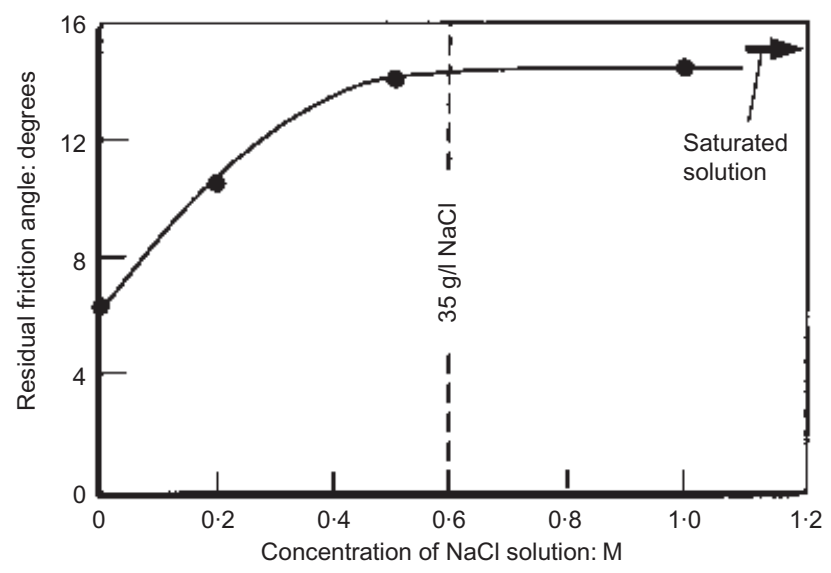

Fig. 21. Residual friction angle, $\phi^{\prime}{ }_{r}$, of Ponza bentonite under normal stresses of $250-400 \mathrm{kPa}$ for various concentrations of $\mathrm{NaCl}$ solution (after Di Maio, 1996b)

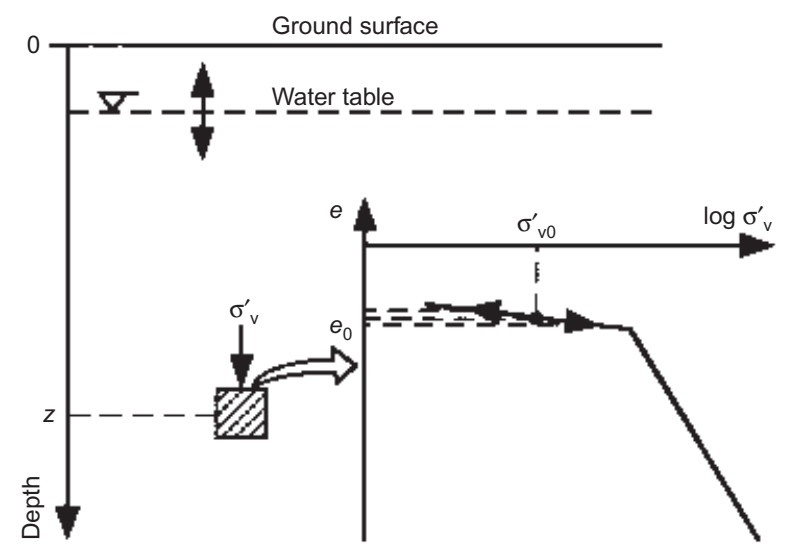

Fig. 22. Changes in void ratio with changes in pore pressure conditions in compressible material

$$
\frac{\partial u_{w}}{\partial t}=\frac{1}{m \gamma_{\mathrm{w}}}\left(k_{\mathrm{x}} \frac{\partial^{2} u_{\mathrm{w}}}{\partial x^{2}}+k_{z} \frac{\partial^{2} u_{\mathrm{w}}}{\partial z^{2}}\right)
$$

where $t$ is time, $x$ and $z$ are coordinate axes in the plane of flow, $k_{x}$ and $k_{z}$ are the hydraulic conductivities in the $x$ and $z$ directions respectively, $\gamma_{\mathrm{w}}$ is the unit weight of water, and $m$ is the coefficient of volume change of clay expressed as change of porosity per unit change of effective stress (Kenney \& Lau, 1984). In the case of equal hydraulic conductivities in the horizontal and vertical directions, equation (3) can be written:

$$
\frac{\partial u_{\mathrm{w}}}{\partial t}=\frac{k}{m \gamma_{\mathrm{w}}}\left(\frac{\partial^{2} u_{\mathrm{w}}}{\partial x^{2}}+\frac{\partial^{2} u_{\mathrm{w}}}{\partial z^{2}}\right)=c_{\mathrm{vs}}\left(\frac{\partial^{2} u_{\mathrm{w}}}{\partial x^{2}}+\frac{\partial^{2} u_{\mathrm{w}}}{\partial z^{2}}\right)
$$

where $c_{\mathrm{vs}}$ is the coefficient of swelling/consolidation of the soil, generally in its overconsolidated domain.

As a consequence of this swelling/consolidation process, the seasonal variation of pore pressures at the upper and lower boundaries of a saturated soil deposit is not entirely reflected in the deposit (Berntson \& Sällfors, 1984; Kenney \& Lau, 1984; Vaughan, 1994; Demers et al., 1999). This can be illustrated by observations made at Wabi Creek in Ontario, in a soft clay deposit (Kenney \& Lau, 1984; Fig. 23). At some distance from the slope the annual variation of the water table level is in excess of $2 \mathrm{~m}$, but the variation in pore pressure at depths larger than $10 \mathrm{~m}$ or so is less than $0.5 \mathrm{~m}$, as indicated in Fig. 23 . Kenney \& Lau (1984) indicate a coefficient of consolidation for the clay at Wabi Creek on the order of $1.2 \times 10^{-6} \mathrm{~m}^{2} / \mathrm{s}$. This latter value can, however, be considered as a minimum value since, as shown by Kenney \& Lau (1984), it would give no pore pressure variation at depths larger than $5.5 \mathrm{~m}$.

The upper part of clay deposits is often fissured and acts as an open aquifer in which the water level varies by a maximum amount corresponding to $\Delta u_{z=0}$. Fig. 24 shows the relative amplitude of pore pressure at a depth $z,\left(\Delta u_{z} / \Delta u_{z=0}\right)$, in which $\Delta u_{z}$ is the amplitude of pore pressure variation at depth $z$, as a function of $z^{2} / c_{\mathrm{vs}}$ for a sinusoidal variation of the pore pressure at the boundary between zero and $\Delta u_{z=0}$ (solution given by Carlslaw \& Jaeger, 1959). The soil deposit is assumed saturated and semi-infinite with a horizontal surface. The figure shows two curves: the continuous one corresponds to one sinusoidal cycle per year, which is the most common case with a dry season and a wet season, and the other corresponds to two sinusoidal cycles per year, as observed under some nordic climates.

As it is difficult in practice to estimate the coefficient of consolidation of clays in in situ conditions (Berntson \& Sällfors, 1984), observation of pore pressures and use of Fig. 24 can easily provide an approximate value of this parameter. If more accurate values are required, a computer program based on oneor two-dimensional consolidation equation can be used (Berntson \& Sällfors, 1984). Applied to Wabi Creek observations (Fig. 23), with the assumptions that there is a $2 \mathrm{~m}$ clay crust and one cycle of water table variation per year, Fig. 24 indicates a coefficient of swelling/consolidation for the overconsolidated clay of $3 \times 10^{-6} \mathrm{~m}^{2} / \mathrm{s}$, which is in reasonable agreement with the results reported by Kenney \& Lau (1984). According to Vaughan (1994), the seasonal fluctuations in pore pressure in stiff clays from the UK extend down to about $4 \mathrm{~m}$, which indicates a much smaller coefficient of swelling as consolidation.

\section{Infiltration in unsaturated soils}

Infiltration in unsaturated soil is more complex than in saturated soils since: (a) initial conditions, represented by profiles of degree of saturation and pore pressure, depend on antecedent hydrologic conditions and are generally not simple; as these conditions control the hydraulic conductivity, the quantity of water required to reach full saturation and the hydraulic gradient, they play an important role in the saturation process and the development of positive pore pressures; (b) relationships between degree of saturation, matric suction 


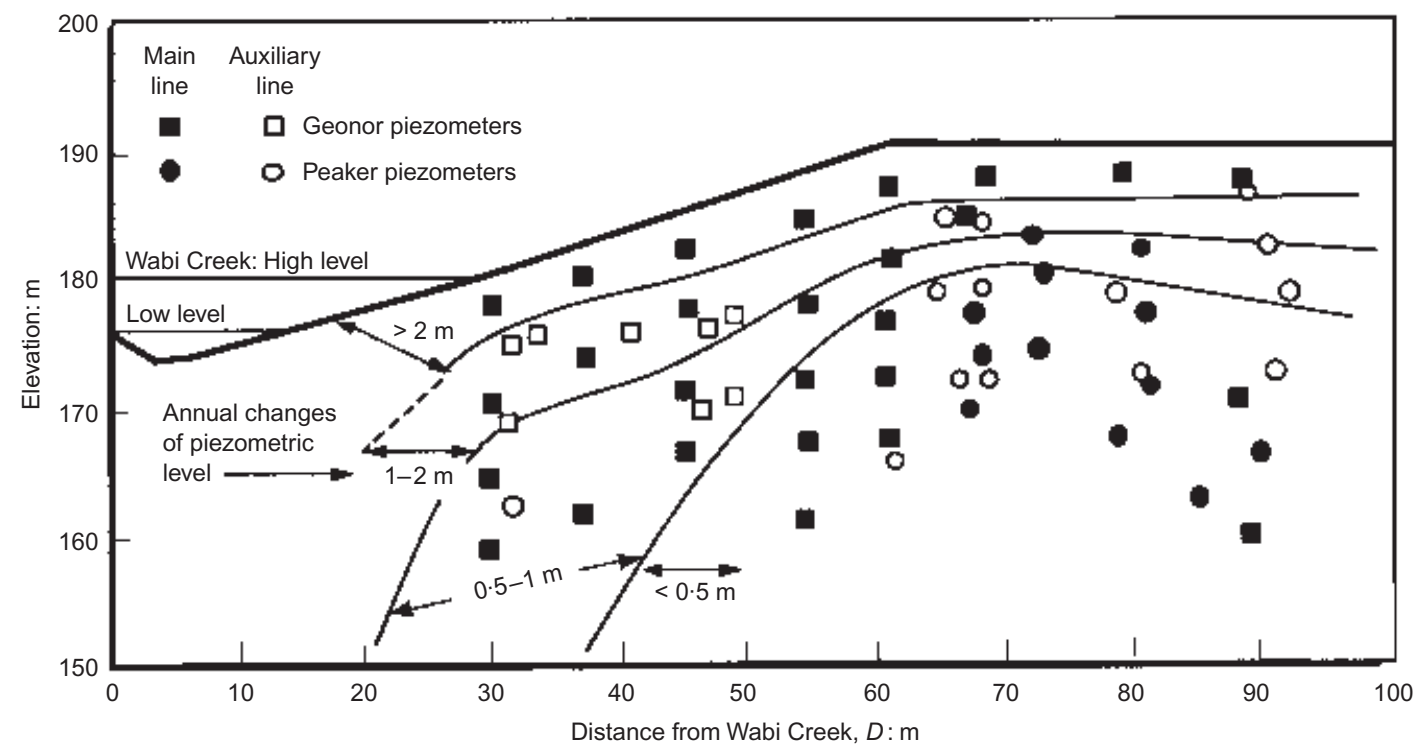

Fig. 23. Location of piezometers and annual changes of piezometric level (from Kenney \& Lau, 1984)

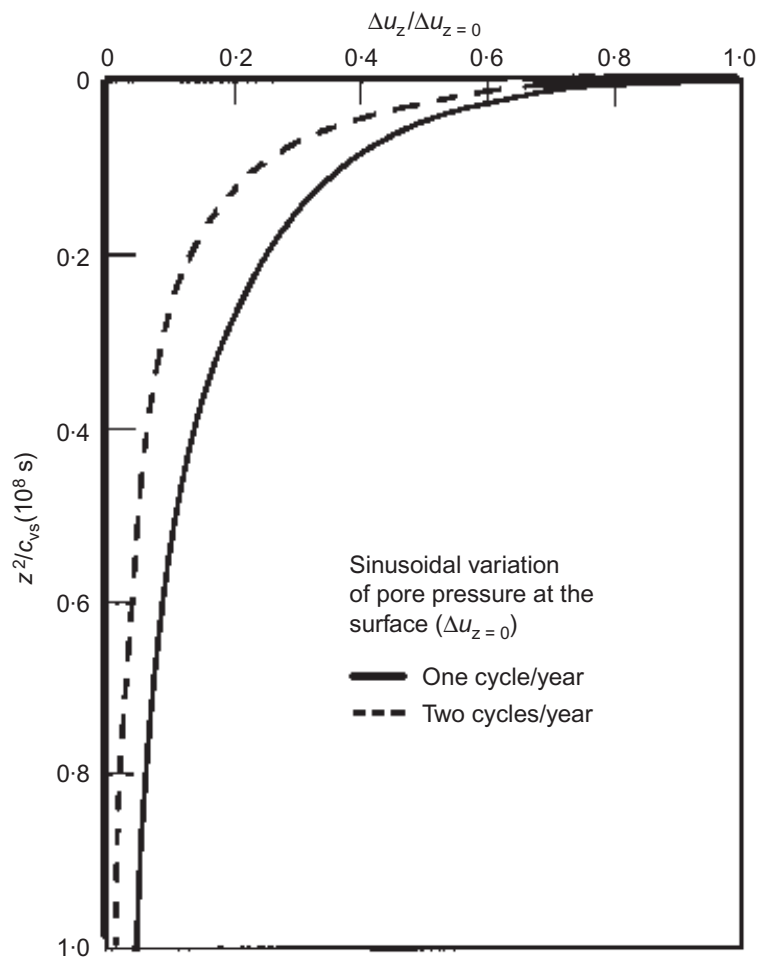

Fig. 24. Variation of pore pressure in a soil deposit due to a sinusoidal variation of pore pressure at the surface

$\left(u_{\mathrm{a}}-u_{\mathrm{w}}\right)$ and hydraulic conductivity are not simple either (see Fredlund \& Rahardjo, 1993).

Water infiltration in unsaturated soil deposits has been the object of several theoretical and numerical studies. Works by Alonso et al. (1995), Collins \& Znidarcic (1997, 1998), and Sun et al. (1998) can be mentioned. Brand (1982) and Vaughan (1985) pointed out that pore pressures in the slope may increase rapidly when the descending water front meets the in situ water table. Wolle (1998) reports that this kind of process has been observed in some Brazilian natural slopes. Such a rapid change in pore pressure may rapidly decrease the factor of safety of a slope and trigger a landslide, which may then start with an initial acceleration.

Gullà \& Sorbino (1996) present pore water pressure measurements at a site of the Western Sila Massif, southern Italy. In a relatively thick (apparently on the order of $10 \mathrm{~m}$ ) layer of residual soil from gneiss, piezometers-tensiometers were installed at different depths, up to $3.58 \mathrm{~m}$. The measured pore pressures are shown in Fig. 25. They show seasonal variations with damped and delayed pore pressures as depth increases, as expected from theory. Also, there are periods (September to November 1993 and 1994) during which pore pressures in the shallowest tensiometer $(0.81 \mathrm{~m})$ remain essentially constant and very low, although rainfall intensity was close to the maximum
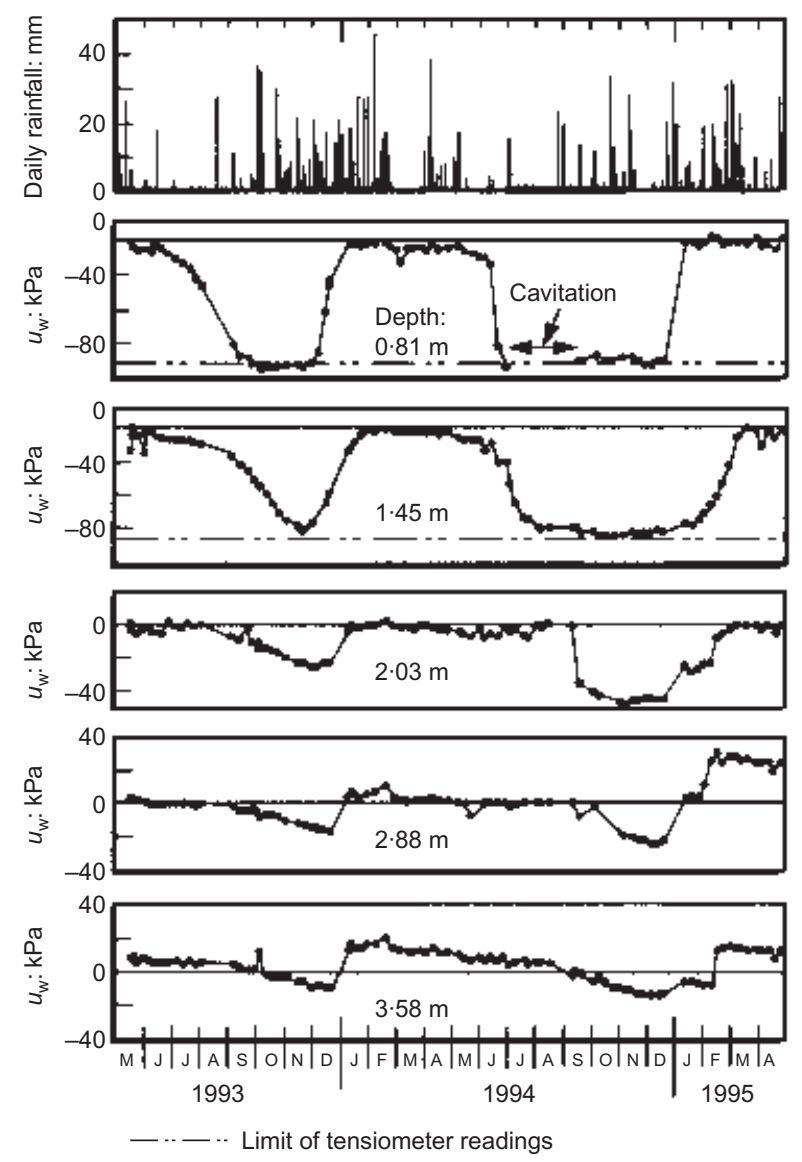

Fig. 25. Daily rainfall and pore pressure measurements in Western Sila Massif (after Gullà \& Sorbino, 1996) 
values measured during the observation period. This indicates that the wetting front did not propagate to this depth during these periods, and that it is also necessary to consider evapotranspiration and runoff to relate precipitation and pore pressure response.

Similar measurements made by Johnson \& Sitar (1990) in the Briones Regional Park, close to San Francisco, in an area prone to debris flows show a much more rapid response to rainfall events. These authors report pore water pressures measured during two specific rainfall events: the storm of 24 November 1985 and the storms of 12-20 February 1986. Fig. 26 shows the pressure heads measured in one nest of piezometers-tensiometers together with the cumulative rainfall and the hourly rainfall intensity. The conditions before 24 November 1985 event were considered as 'dry', with suctions of about $60 \mathrm{kPa}$ (Fig. 26(a)). The pore pressure response to the storm was very rapid at the shallowest depth and gradually propagated with some delay (12-24 hours) at larger depths. Also, the deepest instrument responded earlier than the intermediate one, which, according to Johnson \& Sitar (1990), suggests that a lateral source contributes to the increase in moisture at this latter level. Johnson \& Sitar (1990) concluded: 'In general, for the dry storms (storms appearing during a dry period), locally saturated areas with positive pore pressures developed in the shallow region as the advance of the infiltration front was impeded by the low hydraulic conductivity of the unsaturated, drier soil below.' The conditions before 14 February 1986 were considered to be 'wet', with initial suction values generally smaller than $5 \mathrm{kPa}(50 \mathrm{~cm}$ of water, Fig. 26(b)). Johnson \& Sitar (1990) generally observed that the piezometers-tensiometers at $30 \mathrm{~cm}$ depth did not show significant peaks whereas, as shown in Fig. 26(b), deeper instruments do. The pore pressure increase is followed by a rapid decrease, and Johnson \& Sitar (1990) concluded that 'intensities between 0.2 and $0.4 \mathrm{~cm} / \mathrm{h}$ are required to sustain positive pore pressures at this site'. This study evidences the influence of antecedent conditions on pore pressure response to rainfalls, and, in comparison with observations at Western Sila Massif (Fig. 25), that pore pressure response can vary considerably from site to site.

Observations made by Lacerda (1989), Johnson \& Sitar (1990), Montgomery et al. (1997) and others show that the development of pore pressures and the initiation of debris flows may not result from vertical infiltration only, but also from flows of water through more permeable soil layers and fractured bedrock; water flow into slopes may also be influenced by animal burrows, desiccation cracks and root holes. The hydrologic and hydrogeologic response of a hillslope to rainfall may thus be complex, as schematised in Fig. 27, and complicates the prediction of locations of debris flows.

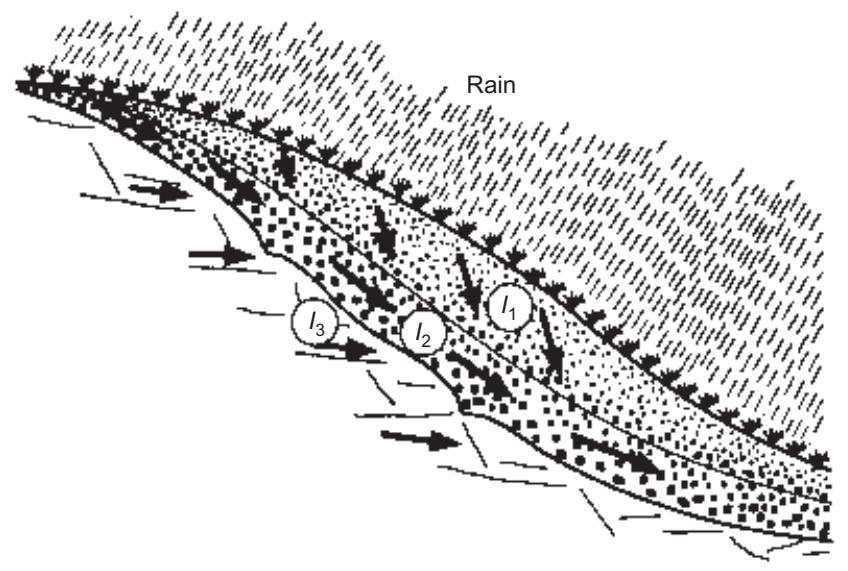

Fig. 27. Schematic diagram of hillslope hydrologic response to rainfall; arrows indicate groundwater flow directions (after Lacerda, 1989; Johnson \& Sitar, 1990; and Sitar, personal communication, 1998)

Relations between climatic conditions and the nature and frequency of slides

Because of the complexity of the infiltration processes of water in soils, one of the biggest challenges for the geotechnical engineer is to establish relationships existing between hydrologic conditions, pore pressures, strength, factor of safety, and, possibly, rate of movement (Fig. 28). This will be illustrated later on with the Sallèdes case history. Hydrologic conditions relevant to slopes include rainfall, runoff and evapo-transpiration (see Blight, 1997, and Wilson, 1999, for details).

Hydrologic conditions have two main effects on landslides: first, they influence their occurrence; second, they influence the type of landslide triggered. Very schematically, intense rainfall over a short period of time generally triggers shallow slides, whereas the triggering of deep-seated landslides generally requires rainfall of long duration. Also, as infiltration of water into unsaturated soils depends on the degree of saturation and permeability characteristics that are related to antecedent rainfall, this latter parameter also influences the occurrence of landslides (Johnson \& Sitar, 1990). Finally, as changes in pore pressure at depth are delayed compared with changes in pore pressure close to boundaries, failures are generally delayed in comparison with rainfall. These aspects can be illustrated by the following reported experiences.


(b)

(d)

Fig. 26. Rainfall characteristics and pore pressure response at the Briones Hills field site (piezometer nest 4): (a), (b) storm of November 1985; (c), and (d) storms of 12-20 February 1986 (after Johnson \& Sitar, 1990) 


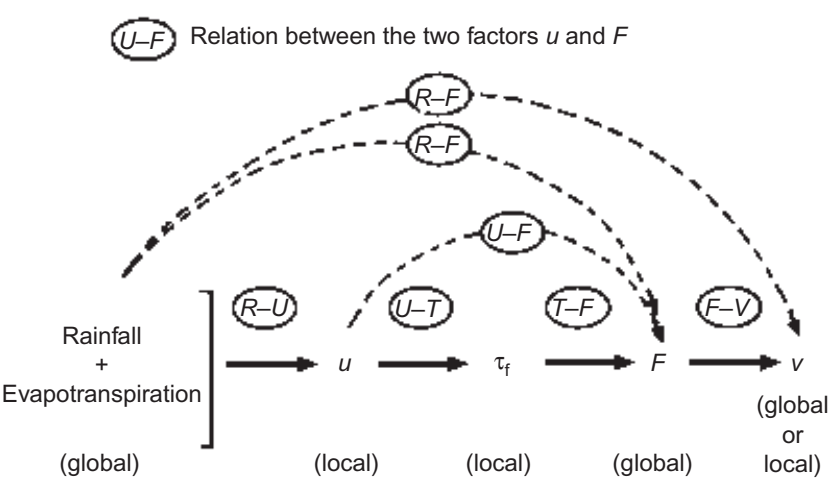

Fig. 28. From hydrologic conditions to factor of safety and rate of displacement, and related relations

London Clay cliffs at Southend-on-Sea, England. In zones where rainfalls are not intense, infiltration and pore water pressures in the soil mass result from a combination of rainfall characteristics and evapo-transpiration, more precisely with the soil water deficit (SWD). This is well illustrated by the occurrence of landslides in London Clay cliffs at Southend-on-Sea, England. Examining this occurrence during the period 1967-1976, Hutchinson (1995) observed that landslides were occurring when the SWD became smaller than a threshold level of about $10 \mathrm{~mm}$ (Fig. 29).

Rio de Janeiro, Brazil. In many areas rainfalls are abundant, and their characteristics dominate the occurrence of landslides over evapo-transpiration. This is particularly the case in tropical areas. In such cases, direct relationships between rainfall characteristics and occurrence of landslides have been empirically established by many authors, in many geological and climatic environments. Fig. 30 shows the relationship established for the Rio de Janeiro area over the period 1966-1996 (d'Orsi et al., 1997); it indicates that landslide occurrence is related to a combination of daily rainfall and accumulated rainfall over the 96 hours preceding the landslide. This figure is used as a warning in the Rio de Janeiro Landslide Watch System (d'Orsi et al., 1997); it is also of particular interest to mention that such a safety approach can benefit from weather forecasts.

Salvador, Brazil. De Campos \& Menezes (1992) report landslides that occurred in Salvador, Brazil, in residual clayey silts or silty clays, and which evidence possible delay between rainfall and landslides. Annual rainfall there ranged from $1500 \mathrm{~mm}$ to $2700 \mathrm{~mm}$ during the period $1978-1988$, and on average during this period close to $50 \%$ of the landslides occurred during the month of April. In 1985, the total annual rainfall was $2702 \mathrm{~mm}$ and the total number of slope failures was 1427 . Fig. 31 shows the cumulative percentage of slope failures during the month of

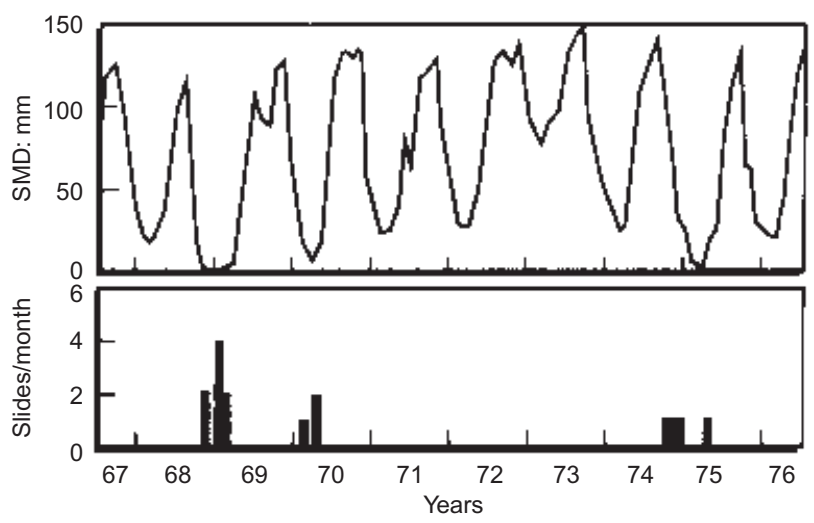

Fig. 29. Landslide occurrence in relation to variations of soil moisture deficit (SMD) for defended London Clay cliffs at Southend-on-Sea, England, 1967-1976 (from Hutchinson, 1995)

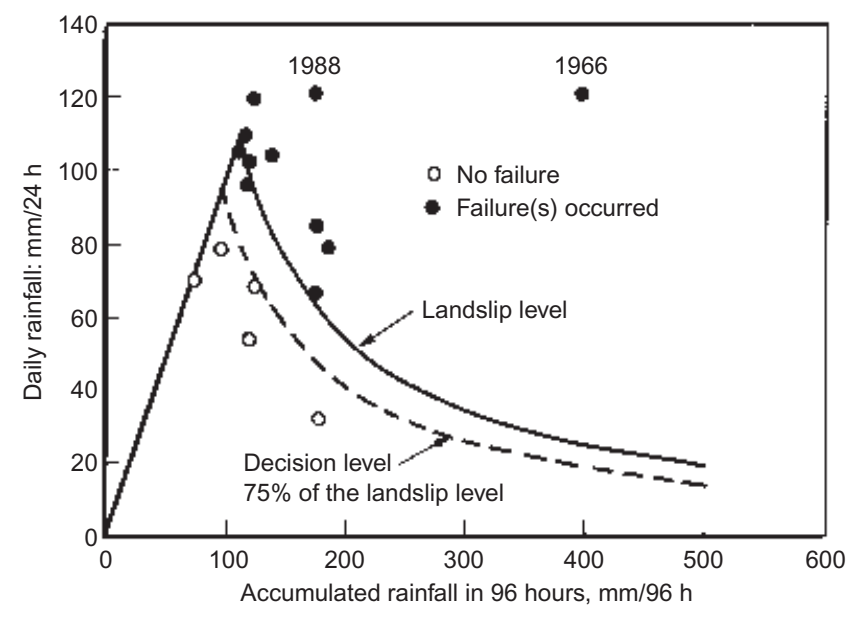

Fig. 30. Landslides and decision criteria based on the daily rate against accumulated rainfall in 96 hours at Rio de Janeiro (after d'Orsi et al., 1997)

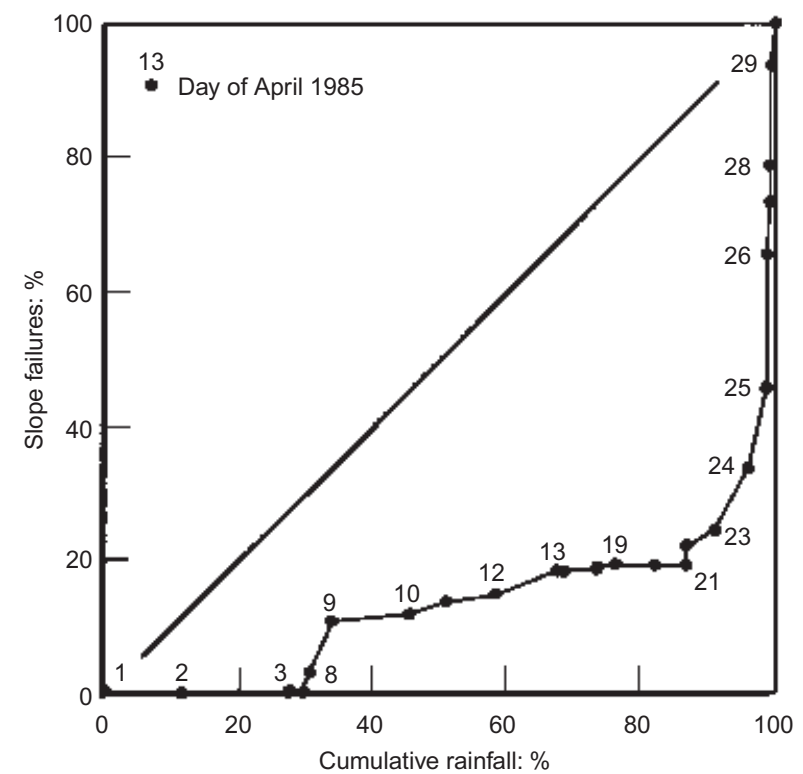

Fig. 31. Percentage of total landslides plotted against the percentage of total rainfall during the month of April 1985 at Salvador, Brazil (after De Campos \& Menezes, 1992)

April 1985 as a function of the cumulative percentage of total rainfall during the same month. Numbers shown on the figure are the days of the month. On days 2 and 3 rainfall was very intense, but no failures were observed until days 8 and 9. Rainfall was then intense from day 9 to day 13, and decreased from day 13 to day 23. Some landslides were observed during this period, but most of them-about $80 \%$ of all the failures of the monthoccurred in the following week, even though essentially it did not rain during that period.

Hong Kong. The slope response to rainfall is quite different in Hong Kong. Brand et al. (1984) and Brand (1995) demonstrated that the antecedent rainfall has no significant influence on the occurrence of landslides in Hong Kong, and that rainfall intensity is the triggering factor. According to Brand (1995), 'a rainfall of the intensity of about $70 \mathrm{~mm} /$ hour appears to be the threshold value above which landslides occur'. This seems to be true for small slides-less than $50 \mathrm{~m}^{3}$ - which represent more than $90-95 \%$ of all the reported landslides in cuts and fills in Hong Kong (Malone, 1998, personal communication). The occurrence of these small-volume landslides is shown as a function of the 15-day (or 16-2-day, excluding the two days just before the landslides) antecedent rainfall in Fig. 32 from Pun et 


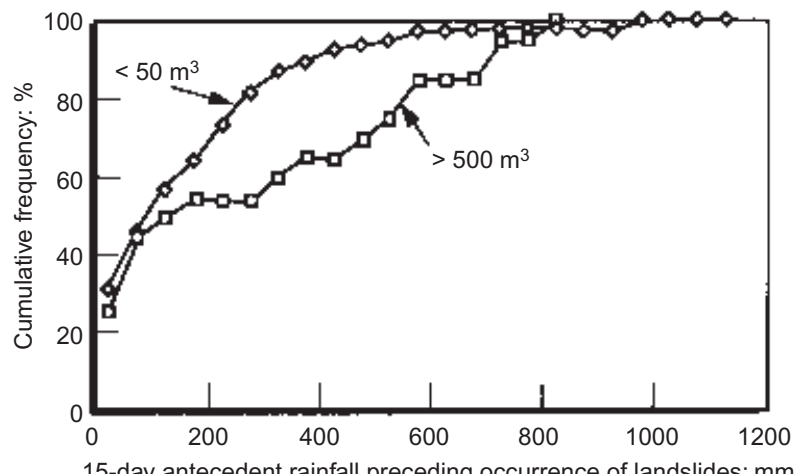

Fig. 32. Cumulative frequency of landslides in Hong Kong as a function of the 15-day (exluding the 2 days just before the landslide) antecedent rainfall preceding occurrence of landslides (after Pun et $a l .$, 1999). Landslides with volume in between 50 and $500 \mathrm{~m}^{3}$ have a cumulative frequency in between the two curves

al. (1999). The occurrence of large-volume and deeper landslides (with a volume larger than $500 \mathrm{~m}^{3}$ ) shows a different distribution, indicating an influence of antecedent rainfall on their occurrence, and confirming that the characteristics of rainfalls influence both the occurrence and the type of landslide.

All these examples show that the responses of slopes to hydrologic conditions are highly variable from one place to another, and in fact can only be examined locally.

Pore pressure variations due to cuts in clays

Pore pressure equilibration in excavations. Another area where water plays an important role is in cuts in clayey materials. As indicated in Fig. 33 from Bishop \& Bjerrum (1960), associated with the reduction in the mean stress and the development of shear stresses due to excavation, there is a decrease in pore pressure in the soil mass:
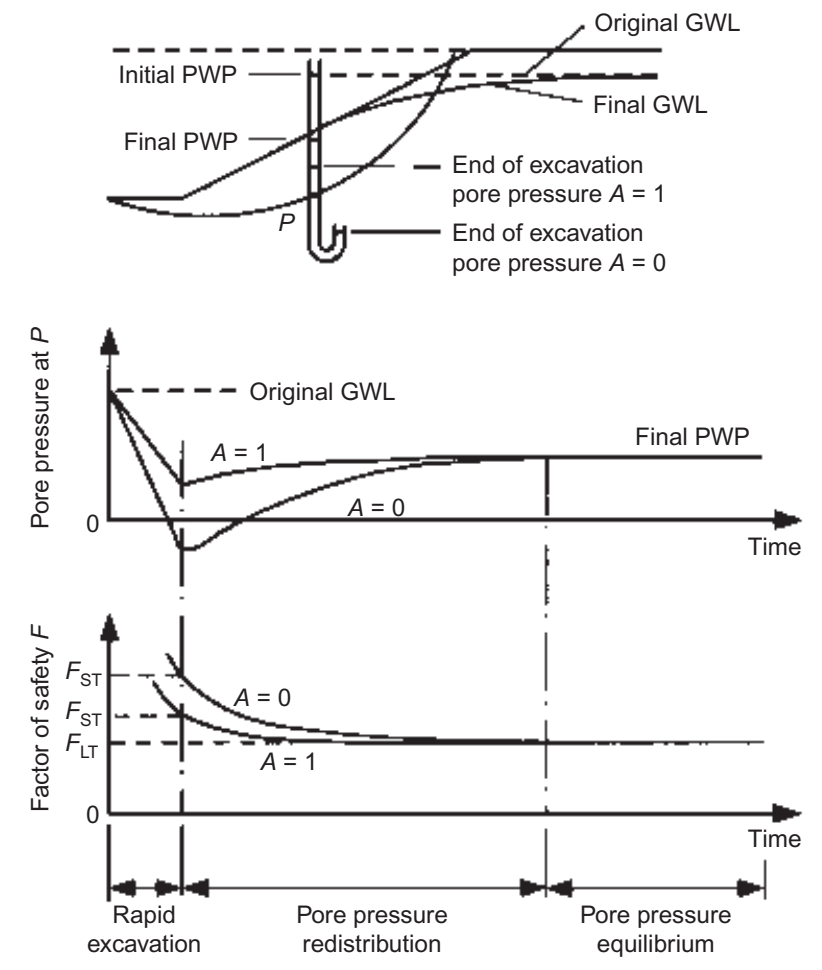

Fig. 33. Changes in pore pressure and factor of safety during an excavation of a cut in clay (after Bishop \& Bjerrum, 1960)

$$
\begin{aligned}
\Delta u_{\mathrm{w}}= & \beta\left(\Delta \sigma_{1}+\Delta \sigma_{2}+\Delta \sigma_{3}\right) / 3 \\
& +\alpha \sqrt{\left(\Delta \sigma_{1}-\Delta \sigma_{2}\right)^{2}+\left(\Delta \sigma_{2}-\Delta \sigma_{3}\right)^{2}+\left(\Delta \sigma_{3}-\Delta \sigma_{1}\right)^{2}}
\end{aligned}
$$

where $\Delta \sigma_{i}$ are the changes in total principal stresses, and $\alpha$ and $\beta$ are the pore pressure parameters proposed by Henkel (1960).

If the soil is linear elastic, perfectly saturated and undrained, $\beta=1.0$ and $\alpha=0$, and the change in pore pressure is equal to the change in mean stress. Assuming that the period of excavation is short enough not to allow significant pore-pressure redistribution, the excavation is undrained and the factor of safety is $F_{\mathrm{ST}}$, ST being used for short-term. With time, clay swells, pore pressures progressively come to an equilibrium, and the factor of safety decreases towards the long-term factor of safety, $F_{\mathrm{LT}}$. Fig. 34 shows the average pore pressure ratio, $r_{\mathrm{u}}$, given as the ratio between pore pressure and total vertical stress, as a function of age of cutting in brown London Clay (most of the cuts were $6-12 \mathrm{~m}$ high); it can be seen that pore pressures in these conditions progressively increase to reach full pore pressure equilibration after about 50 years.

Experience shows that the time necessary for pore pressures to reach steady-state conditions after excavation is highly variable from site to site, as indicated in Fig. 35. It was on the order of a few days at La Bosse-Galin (Blondeau \& Queyroi, 1976); about 10 days in Bangkok clay (Phien-Wej, 1993, personal communication); one month in Mexico City clay for excavation depths of 4.5-8 m (Alberro, 1979); about 2 months at Hede, Sweden, for a $5.5 \mathrm{~m}$ deep cut (Rankka, 1994); 3 months at Kimola, Finland, for a $12 \mathrm{~m}$ deep cut (Kankare, 1969); 6 months at Saint-Hilaire, Québec, for an excavation depth of $8 \mathrm{~m}$ (Lafleur et al., 1988a, b) and at Rivière Vachon, Québec, for a $24 \mathrm{~m}$ high cut (Laflamme \& Leroueil, 1999), and thus rather rapid and less than one year in these recent clays of very different origins. Experience with stiff London Clay shows much longer periods of equilibration of about 50 years for $6-$ $12 \mathrm{~m}$ deep excavations (Skempton, 1977; Chandler, 1984; Fig. 34) and on the order of 2000 years for $44 \mathrm{~m}$ high cliffs at Warden Point, Isle of Sheppey, England (Bromhead \& Dixon, 1984). From pore pressure measurements made by Fenelli \& Picarelli (1990) and Neuzil (1993), the time for equilibration could be hundreds of thousands or millions of years in thick deposits of low permeability clay shales.

The time necessary to reach pore pressure equilibration depends on the swelling properties of the soil, its hydraulic conductivity, the detailed stratigraphy of the soil deposit, and the geometry of the excavation. On the basis of numerical

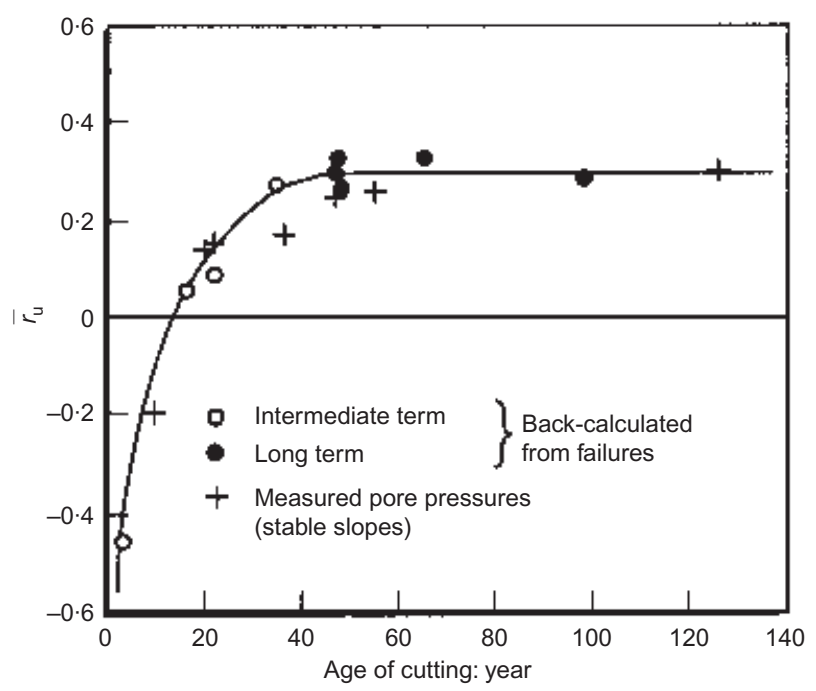

Fig. 34. Pore pressure equilibrium, Brown London Clay cuttings (after Chandler, 1984) 


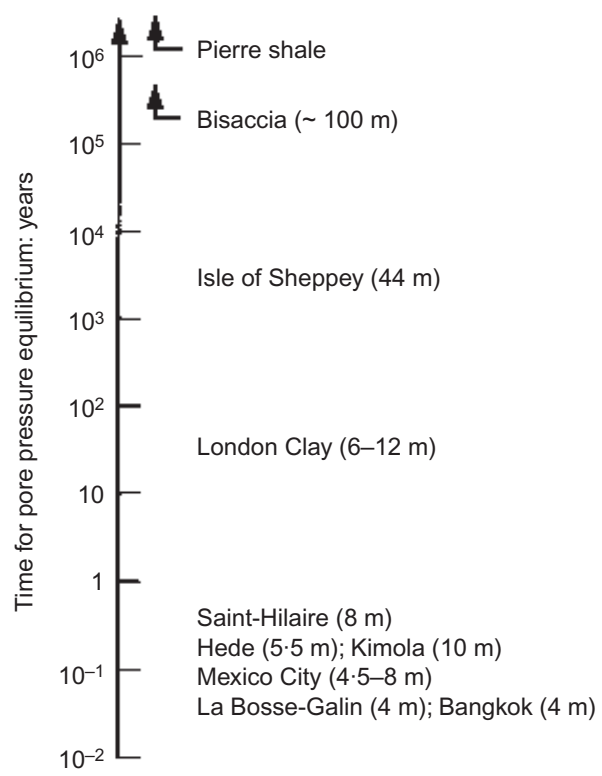

Fig. 35. Time for pore pressure equilibrium after excavation in clayey deposits

analysis of cuts in a clay deposit excavated up to an impervious substratum, Eigenbrod (1975) concluded that full equilibration of pore pressures is obtained for a time factor

$$
T=c_{\mathrm{vs}} t / H^{2}=0.33
$$

where $c_{\mathrm{vs}}$ is the coefficient of swelling/consolidation, $t$ is the time and $H$ is the height of the cut.

Experience indicates, however, that the time for full pore pressure equilibration can be different from that given by equation (6) if the geometry of the problem, in particular the thickness of the clay deposit and the position of the substratum, differs from the case studied by Eigenbrod (1975).

Test excavation at Saint-Hilaire. The case of the Saint-Hilaire excavation in a soft clay deposit from the Province of Québec is used to illustrate pore pressure variations with time. The excavation is $8 \mathrm{~m}$ deep, and is a $62 \mathrm{~m}$ square with four slopes of $18^{\circ}, 27^{\circ}, 34^{\circ}$ and $45^{\circ}$ to the horizontal. There is, on this site, $0.6 \mathrm{~m}$ of sand covering $33 \mathrm{~m}$ of Champlain Sea clays. This latter has a plasticity index of about 30 , a liquidity index on the order of $1 \cdot 2$, and a vane shear strength regularly increasing with depth from about $30 \mathrm{kPa}$ at $4 \mathrm{~m}$ to about $77 \mathrm{kPa}$ at $20 \mathrm{~m}$. Several failures occurred in the $45^{\circ}$ and $34^{\circ}$ slopes during or shortly after excavation; in the $27^{\circ}$ slope only shallow soil movements, occurring in particular upon thawing of the soil, were observed. Pore pressure observations are reported by Lafleur et al. (1988a, b).

Laflamme \& Leroueil (1999) simulated the pore pressure variations in the $27^{\circ}$ and $18^{\circ}$ slopes that have not been affected by failures. Figure 36 shows a section of the excavation with the location of the piezometers. The finite element program used was Abaqus software with the assumption of linear elasti- city and undrained conditions $(\beta=1$ and $\alpha=0$ in equation (5)). First considered were coefficients of permeability measured in the laboratory and in situ with a self-boring permeameter, small strain shear moduli $G_{\max }$ measured in cross-hole tests or deduced from piezocone tests at large depths, and a Poisson ratio of $0 \cdot 25$. However, to get the best fit, the resulting coefficient of swelling $\left(c_{\mathrm{vs}}\right)$ had to be multiplied by a factor of $2 \cdot 3$. Typical results are shown in Fig. 37 for the first 300 days, a sufficiently long period to get full pore pressure equilibrium. It can be seen that there is a good agreement between the measured and computed pore pressure variations, both during excavation and during pore pressure equilibration. This indicates that the rate of pore pressure equilibration is controlled by a shear modulus close to the small strain shear modulus, a factor of $2 \cdot 3$ being relatively small when coefficients of swelling/consolidation are considered.

The excavation at Saint-Hilaire was performed from 5 August to 9 September 1986. The simulation made by Laflamme \& Leroueil (1999) with constant boundary conditions $(u=0$ on the faces of the excavation) gave good results for the first 300 days: that is, to the end of May 1987. During this period there were no significant variations in ground water table and evaporation, so that the assumption of constant boundary conditions was reasonable. Quite often, owing to evapo-transpiration and seasonal changes of the water table, boundary conditions vary with time and influence the pore pressure equilibration process. This is well illustrated by the Rivière-Vachon cut described below.

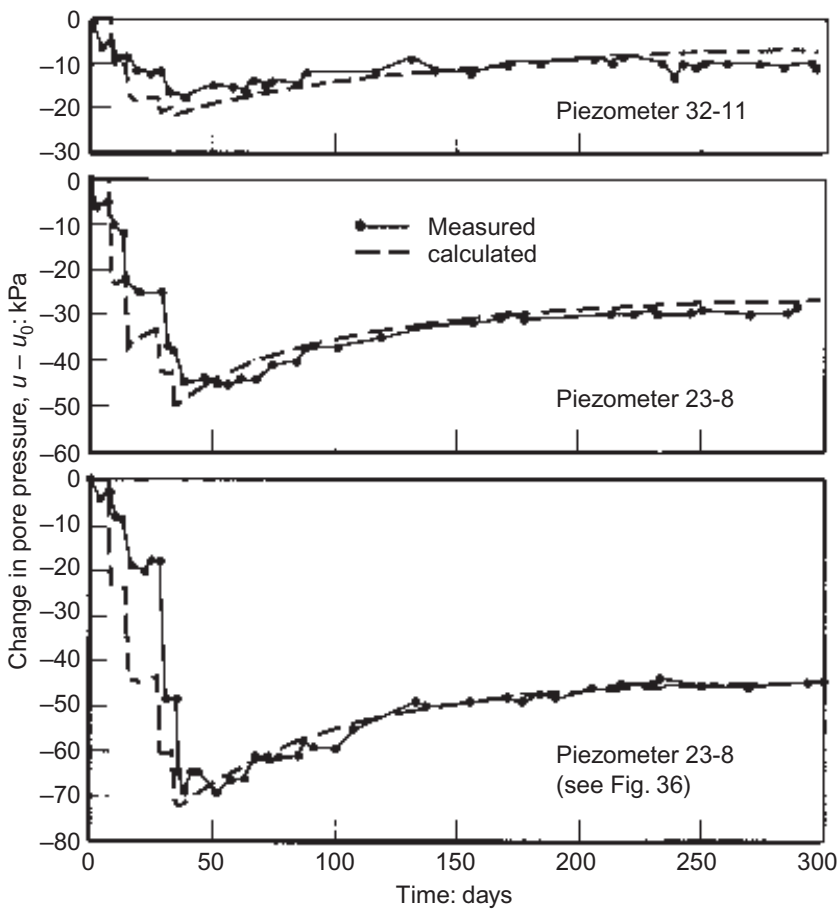

Fig. 37. Measured and calculated changes in pore pressure with time at Saint-Hilaire (after Lafleur et al., 1988a, b; Laflamme \& Leroueil, 1999)

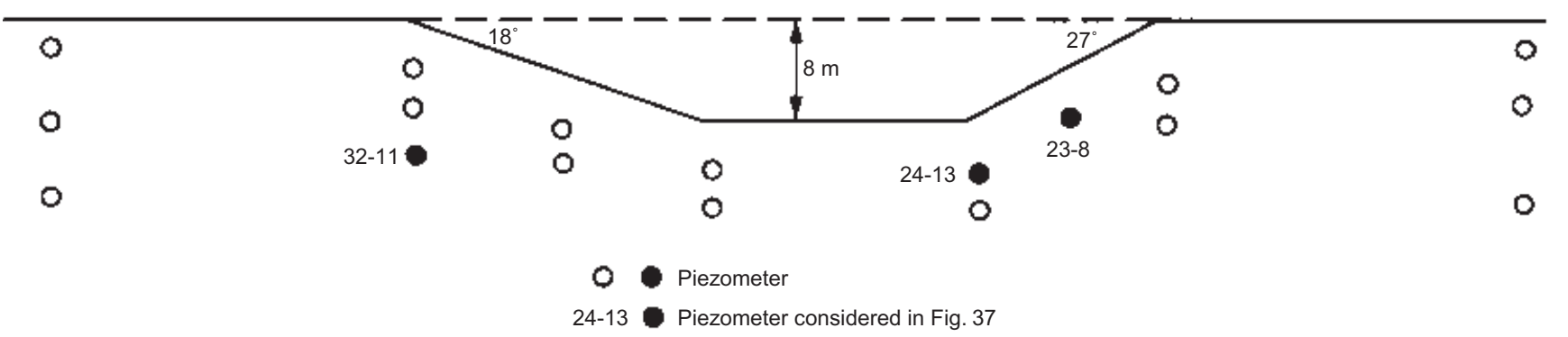

Fig. 36. Test excavation at Saint-Hilaire (after Lafleur et al., 1988a, and b) 
Excavation at Rivière-Vachon and the influence of clay crust formation on pore pressures. Excavations in soft to stiff clays (liquidity index typically larger than 0.5 ) set a particular problem, owing to the formation of a clay crust on the new face of the excavation (Laflamme \& Leroueil, 1999). Evaporation increases the effective stresses isotropically to values in excess of the isotropic yield stress, $\sigma^{\prime}{ }_{\mathrm{pi}}$, of the clay (about 0.6 times the preconsolidation pressure of the clay; Diaz-Rodriguez et al., 1992), represented by points $\mathrm{P}_{i}$ in Fig. 38. When stresses become larger than those at points $\mathrm{P}_{i}$, the clay progressively dries to form a clay crust, whereas the clay remains overconsolidated when the effective stresses are smaller than $\sigma^{\prime}$ pi. With time, the crust progresses downwards and point $\mathrm{P}_{i}$ becomes deeper. Owing to the change in compressibility of most natural clays at the passage of the isotropic yield stress, the effective stress profile must show a knee at the corresponding point $\mathrm{P}_{i}$, as indicated in Fig. 38. At the scale of most excavations, all these points $\mathrm{P}_{i}$ are close to the surface (tens of centimetres compared with metres or tens of metres for the slope) and can in practice be considered at this boundary. Consequently, when evaporation is larger than infiltration and thus the clay crust is deepening, the soil mass behaves as though there would be a suction equal to $\sigma^{\prime}$ pi at the surface; conversely, when infiltration is higher than evaporation the development of the clay crust stops, and the soil behaves as though there is no suction applied at the surface. In fact, owing to the development of cracks with drying and the threedimensional aspect of the problem (Konrad \& Ayad, 1997), the 'average efficient suction' at the boundary during drying cannot be $\sigma_{\text {pi }}^{\prime}$ but only a fraction of it, say $\alpha . \sigma^{\prime}{ }_{\text {pi }}$. This approach thus transforms a complex atmosphere-soil interaction problem into a relatively simple on/off mechanical problem. The pore pressure at the surface would in practice be $u_{\mathrm{w}}=0$ when it rains and $u_{\mathrm{w}}=-\alpha \cdot \sigma_{\mathrm{pi}}^{\prime}$ when it does not.

Laflamme \& Leroueil (1999) applied this approach to the Rivière-Vachon cut, about $600 \mathrm{~km}$ east of Québec City. To improve safety in a curve of Road 138, the Ministère des Transports du Québec decided to make the cut shown with the hatched area in Fig. 39. This cut is about $24 \mathrm{~m}$ high and is in a low plasticity clay and silt deposit showing a preconsolidation

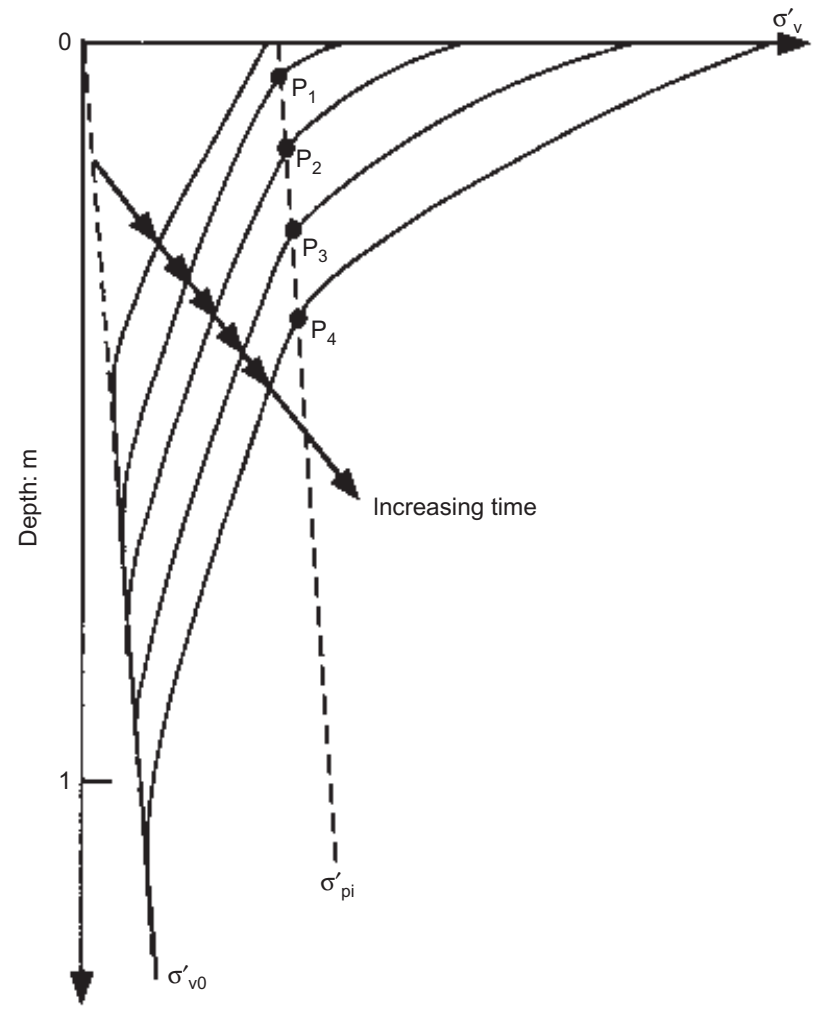

Fig. 38. Schematic development of a clay crust due to evaporation pressure almost constant with depth and equal to $400 \mathrm{kPa}$. The hydraulic conductivity is equal to about $10^{-9} \mathrm{~m} / \mathrm{s}$.

Numerical simulation of the cut was performed with the Abaqus software, considering a linear elastic behaviour of the soil (Laflamme \& Leroueil, 1999). Several observations were made:

(a) The pore pressures generated during excavation were smaller than those predicted by an undrained linear elastic analysis; this has been attributed to partial saturation of the clay and silt $\$$, which could result from the downward water flow associated with a high hydraulic gradient of about $0 \cdot 75$.

(b) Pore pressure equilibration seems to be controlled by a coefficient of consolidation based on the small strain shear modulus.

(c) As shown in Fig. 40, the simulation of pore pressures gives reasonable agreement with measured ones on the basis of the following hypotheses:

(i) $u_{\mathrm{w}}=-\alpha . \sigma_{\mathrm{pi}}^{\prime}$ with $\alpha=0.27$ at the surface when the crust progresses.

(ii) Changes of boundary condition $\left(u_{\mathrm{w}}=0\right.$ when it rains or $u_{\mathrm{w}}=-\alpha \cdot \sigma_{\mathrm{pi}}^{\prime}$ during periods of drought at the surface) are delayed by about 15 days after the beginning of rain or drought.

Contrary to the Saint-Hilaire case history, the Rivière-Vachon cut shows that pore pressures are not always easy to predict, and that clay crust formation has a tendency to delay the equilibration period and thus the decrease in factor of safety towards its minimum value, $F_{\text {LT }}$. More generally, and as mentioned by Chandler (1984), when evapo-transpiration is higher than infiltration, the long-term flow net and the resulting long-term factor of safety can be significantly influenced.

From these two case histories it also seems that a representative in situ coefficient of swelling/consolidation can be deduced approximately from hydraulic conductivity and small strain shear modulus reliably measured on site. As indicated by Berntson \& Sällfors (1984), $c_{\mathrm{vs}}$ values deduced from laboratory tests often underestimate in situ values in the overconsolidated range.

\section{Swelling following erosion}

Unloadings previously considered were associated with cuts, generally man-made. Unloading on large areas also exists naturally at larger scales and over longer periods of time. Behaviour in terms of pore pressures has been observed in such conditions, in particular by Fenelli \& Picarelli (1990) and Di Nocera et al. (1995) at Bisaccia, southern Italy, and by Neuzil (1993) for the Pierre shale formation in South Dakota, USA.

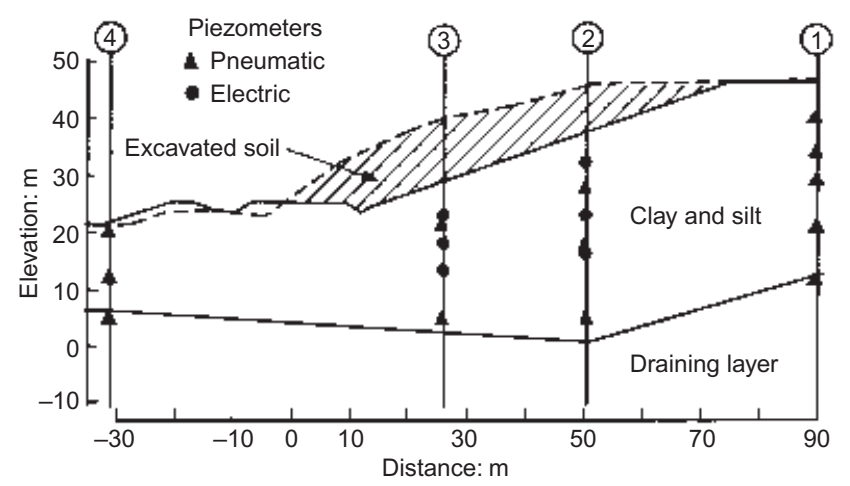

Fig. 39. Excavation at Rivière-Vachon, Québec (from Laflamme \& Leroueil, 1999)

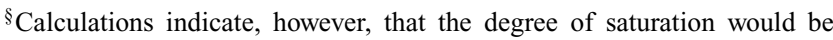
larger than $99 \%$ 


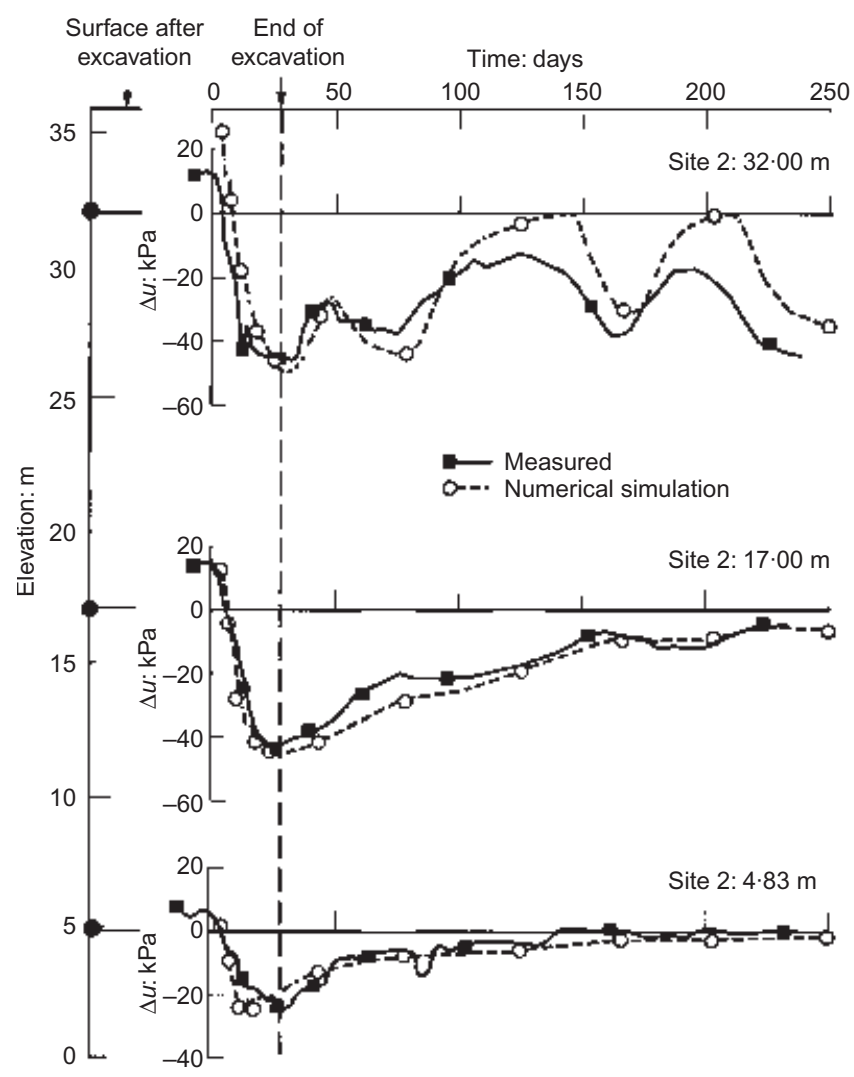

Fig. 40. Variations with time of pore pressures in piezometers from site 2 at Rivière-Vachon (from Laflamme \& Leroueil, 1999). Pore pressure variations are given with reference to long-term conditions

The name of Bisaccia has already been mentioned (Figs 15 and 20). It is an Italian town that stands on a hill consisting of a conglomerate slab resting on a deposit more than $200 \mathrm{~m}$ thick, of plastic and tectonised clay shale (Fig. 41). This clay shale is of marine origin, and has a plasticity index of about 70 and a hydraulic conductivity in the order of $10^{-12} \mathrm{~m} / \mathrm{s}$. The valleys on both sides of the hill result from erosion, which probably began about 300000 years ago. Fenelli \& Picarelli (1990) and Di Nocera et al. (1995) present information obtained at site B (see Fig. 41). Water contents and pore pressures measured at that site are shown in Figs 42(a) and (b) respectively. Water contents evidence swelling in the upper part of the clay shale deposit. It can also be seen that the pore pressures are extremely low, even negative, and much lower than the expected steady-state conditions. This is certainly due to swelling associated with erosion, as indicated by Koppula \& Morgenstern (1984). This process may also be amplified and delayed by secondary swelling, which has been shown to be very significant in these clays (Urciuoli, 1992), progressive destructuration of the shales, and a possible decrease in salinity of pore water at shallow depths (see Fig. 15), all factors that have a tendency to increase void ratio with time.

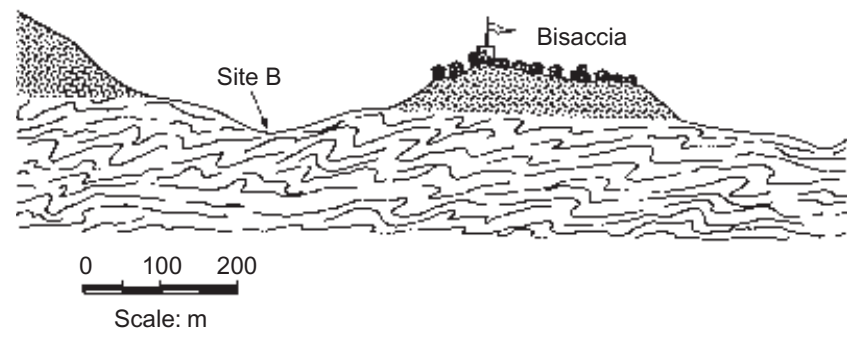

Fig. 41. Cross-section of Bisaccia Hill (after Fenelli \& Picarelli, 1990)
The deficient pore pressures have important consequences for the stability of Bisaccia Hill. Di Nocera et al. (1995) estimate that the factor of safety against deep-seated slides is currently close to $1 \cdot 0$, and would be as low as 0.86 if steady-state conditions would exist. Thanks to delayed swelling, Bisaccia still proudly stands on the top of the hill.

Neuzil (1993) reports very similar pore pressure measurements in the Pierre Shale formation in South Dakota. The thickness of the formation is about $325 \mathrm{~m}$, and the shale is characterised by a hydraulic conductivity in the order of $10^{-13}-10^{-14} \mathrm{~m} / \mathrm{s}$. This formation has been covered by $360-$ $400 \mathrm{~m}$ of materials that have been eroded in the past 4.5 million years. As observed by Neuzil (1993), pore pressure is close to zero at a depth of about $140 \mathrm{~m}$, meaning a pore pressure deficit in the order of $1000 \mathrm{kPa}$ at that depth.

\section{PRE-FAILURE}

Pre-failure movements include all the movements that occur before a first-time failure. They can result from a combination of phenomena: elasto-plastic deformations associated with changes in effective stresses; viscous deformations; and strains and displacements associated with progressive failure.

\section{Creep movements at the pre-failure stage}

Evidence of creep in slopes of precarious stability at the prefailure stage exists in soft clays (Eden, 1977; Tavenas, 1984; Moller et al., 1989; Ottosson \& Johansson, 1995; Demers et al. $1999)$ but also in stiff clays and rock masses, as described by Terzaghi (1950), Nemčok et al. (1972) and other authors (see Varnes, 1978).

The deformations of the Santa Barbara open-pit mine in Italy (D'Elia, 1984; D'Elia, 1991; D'Elia et al., 1998) provide another interesting observation of creep in an intensely fissured and sheared clay shale, the 'Argille Scagliose'. The excavation started in 1978 and ended in 1991, with failure at a cut height exceeding $200 \mathrm{~m}$. From pore pressure measurements and other considerations, D'Elia (1991) concluded that the behaviour during excavation was essentially drained. As the cut reached the height of $50 \mathrm{~m}$, and thus at a relatively low shear stress level, excavation was stopped for over one year. As seen in Fig. 43 , the settlement rate of reference points located uphill from the cut edge decreased with time from $0.2 \mathrm{~mm} / \mathrm{d}$ to $0.013 \mathrm{~mm} / \mathrm{d}$ in a relationship very similar to the relationships of axial strain rate against time obtained from laboratory creep tests performed on the same material (Fig. 5(b)). It is also worth noting that, owing to the ductile behaviour of the 'Argille Scagliose', these strains cannot be attributed to progressive failure.

When approaching failure, as observed in the laboratory (Fig. 4 , tests $D, F$, and G), the strain rate progressively increases. As evidenced in Fig. 44, such a behaviour has been observed in situ in a variety of materials.

Another characteristic of pre-failure creep movements is that their rate varies with seasons. According to viscous models, as the stress path gets closer to the limit state curve (or to the peak strength envelope) of the soil, creep deformations develop at increasing strain rates, as indicated in Fig. 45. As, with the seasonal variations of pore pressures, the effective stress conditions fluctuate between limits such as HW, when pore pressures are high, and LW, when pore pressures are low, creep rates vary accordingly from high values (when at HW) to smaller values (when at LW). Such variations have been observed in slopes in eastern Canada clays by Mitchell \& Eden (1972); the creep rates observed during the spring season, when the water table is at its higher level, were 8 to 33 times larger than the average creep rates measured over a 3 year period.

\section{Progressive failure}

The conditions necessary to the development of progressive failure are: 


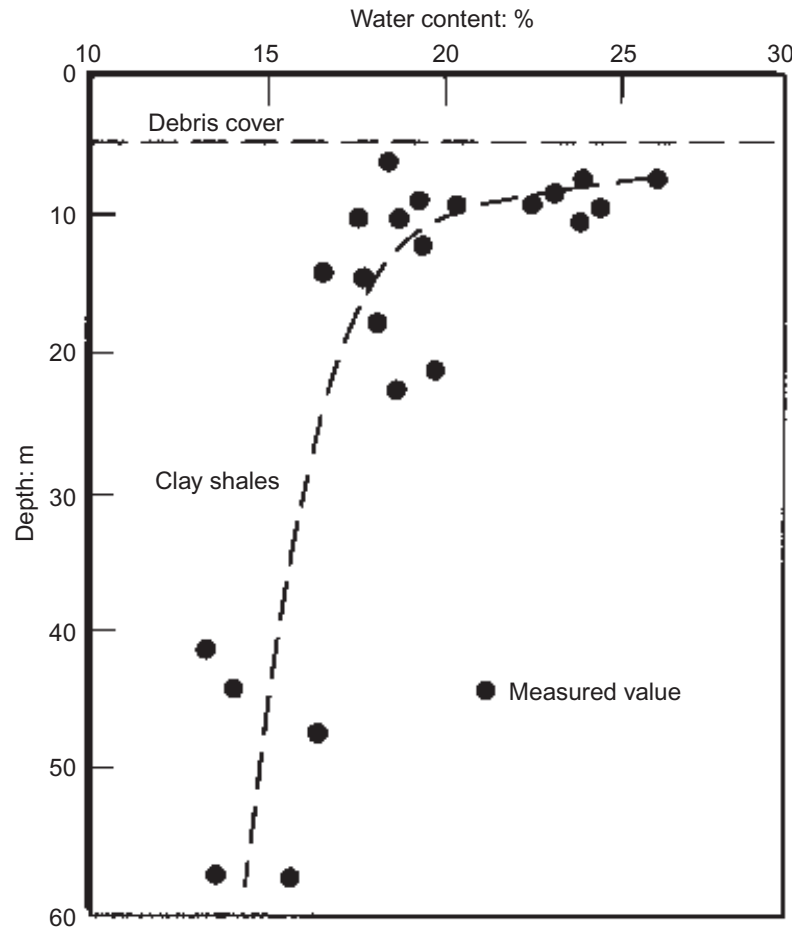

(a)

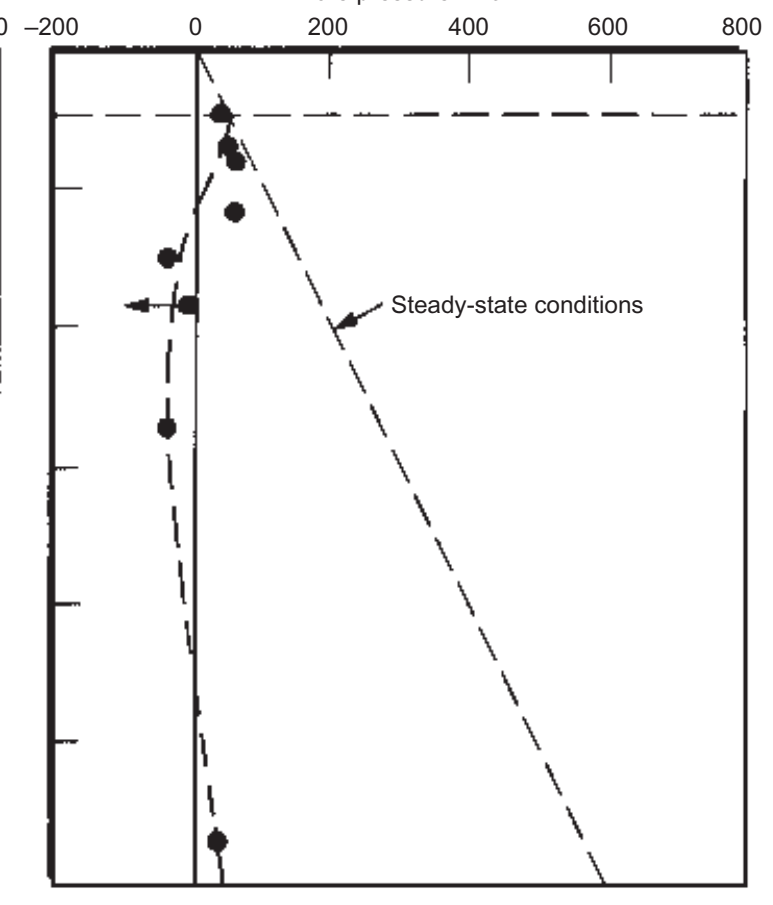

(b)

Fig. 42. Soil conditions at site B (Bisaccia; see Fig. 41): (a) water content; (b) pore pressure (after Fenelli \& Picarelli, 1990; Di Nocera et al., 1995)

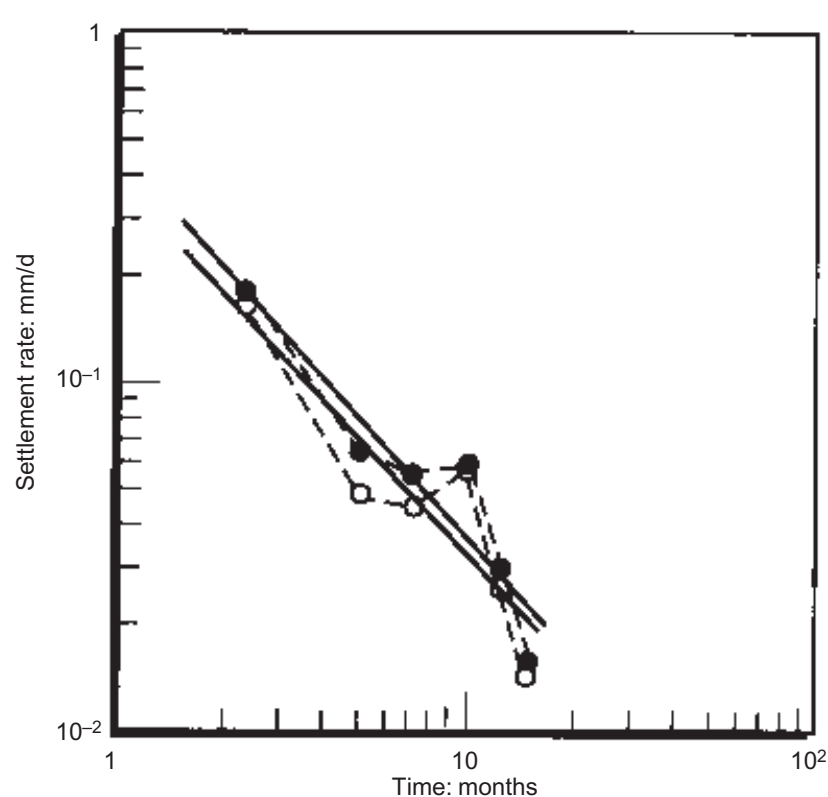

Fig. 43. Santa Barbara open-pit mine: Argille Scagliose. Settlement rate versus time for two reference points uphill from the $50 \mathrm{~m}$ high cut edge in conditions of essentially constant effective stresses (from D’Elia, 1991)

(a) brittleness of soil

(b) non-uniformity in the distribution of shear stresses

(c) local shear stresses that exceed the peak strength of the soil

(d) boundary conditions such that strains exceeding that at failure may develop.

Brittleness is a characteristic of most natural soils in their overconsolidated range, and of weak rocks; also, owing to the geometry of the problem, shear stresses are generally not uniform in a slope, and in particular along a potential failure surface. As a result, progressive failure plays a major role in

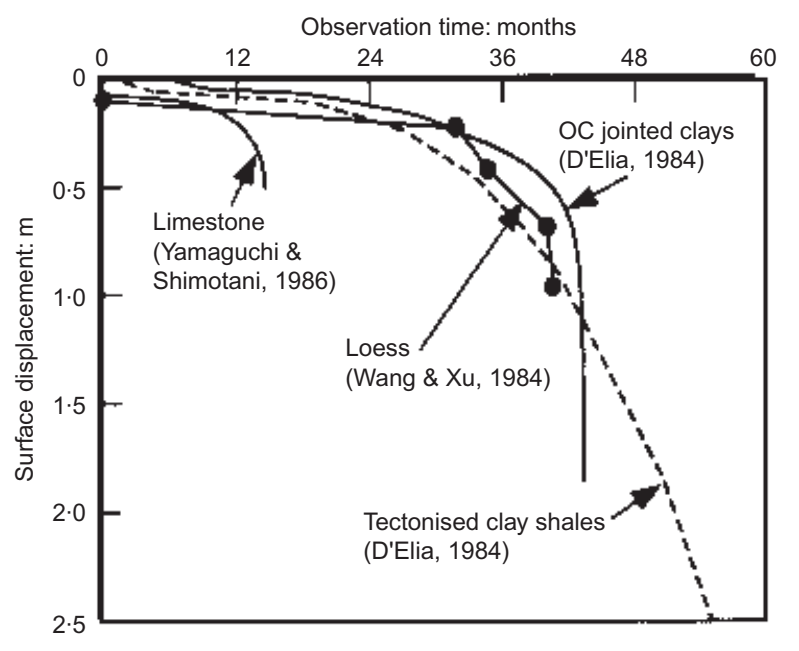

Fig. 44. Pre-failure movements in different geomaterials

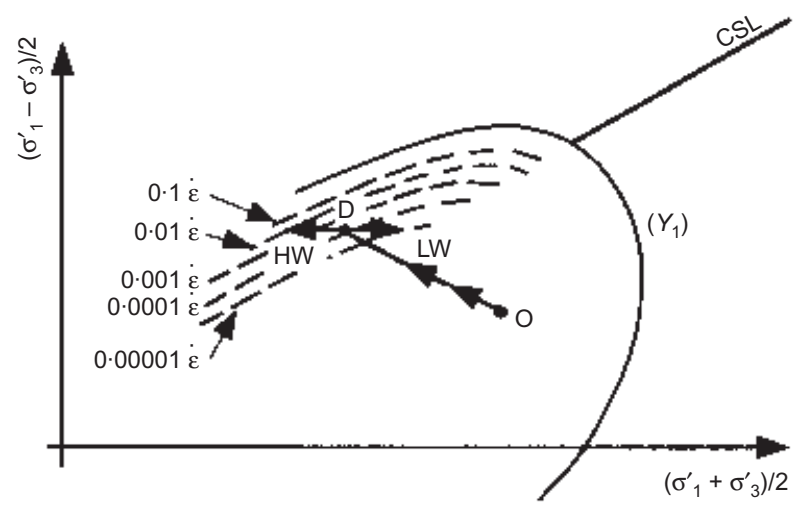

Fig. 45. Creep model for natural slopes in clay (from Tavenas \& Leroueil, 1981) 
pre-failure phenomena. The mechanisms of progressive failure were recognised by Terzaghi \& Peck (1948) and Taylor (1948). It was not, however, until the 1960s that they were clearly understood and discussed in the context of overconsolidated clays and clay shales (Skempton, 1964; Bjerrum, 1967; Bishop, 1967). They are summarised below.

If shear stresses locally reach the peak shear strength of the material, there is local failure. If soil presents some strainsoftening behaviour, the failed soil elements will support a decreasing shear stress as strain increases. The part of the shear stress that is no longer supported by the failed elements is then transferred to the neighbouring soil elements, which can fail in turn. The process, which may be accompanied by local variations in water content, continues until an equilibrium between shear stresses and strains has been reached. At that time, along a potential failure surface, part of it can exceed the peak, with possibly some elements at large deformation or residual strength, whereas another part of the potential surface has not reached the peak. If such equilibrium cannot be obtained, the process will continue until failure conditions extend along the entire failure surface.

Even if some equilibrium seems to exist at a given time, it can be modified and the process of progressive failure can resume or continue. The main factors leading to this situation are:

(a) a change in the geometry of the problem and in shear stresses (e.g. erosion at the toe or loading at the top of a slope)

(b) a decrease in normal effective stress, and thus in peak and residual strengths (e.g. excavation during pore pressure equilibration or pore pressure increase in general)

(c) a decrease in strength parameters (e.g. lowering of the peak strength envelope due to creep, fatigue or weathering).

Bjerrum (1967) particularly emphasised the importance of bonds and weathering, and of the possible release of stored energy, in the process of progressive failure.

Brittleness, which constitutes a major factor in the development of progressive failure, has been characterised by the brittleness index, $I_{\mathrm{B}}$, as follows (Bishop, 1967):

$$
I_{\mathrm{B}}=\frac{\tau_{\mathrm{p}}-\tau_{\mathrm{r}}}{\tau_{\mathrm{p}}}, \%
$$

where $\tau_{\mathrm{p}}$ and $\tau_{\mathrm{r}}$ are the peak and residual strengths defined under the same effective normal stress.

However, as indicated by Vaughan \& Hamza (1977) and by Chandler (1984), the brittleness index alone is not sufficient to characterise the susceptibility of a soil to progressive failure; the rate at which the strength decreases from peak strength to ultimate strength is also important. D'Elia et al. (1998) propose a generalised brittleness index, $I_{\mathrm{GB}}$, defined as follows:

$$
I_{\mathrm{GB}}=\frac{\tau_{\mathrm{p}}-\tau_{\mathrm{mob}}}{\tau_{\mathrm{p}}}, \%
$$

in which $\tau_{\text {mob }}$ is the mobilised shear stress at the considered strain or displacement. $I_{\mathrm{GB}}$ thus varies with strain or displacement from 0 at the peak to a value equal to $I_{\mathrm{B}}$ at large displacements (Fig. 46). Also, in the context of slopes, $I_{\mathrm{GB}}$ must be associated with stress paths that are representative of those followed in situ, and must thus not be seen as a fundamental characteristic of a soil. With this extended definition, not only overconsolidated clays, clay shales, sensitive clays, residual soils and loess may appear brittle, but also cohesionless soils such as loose sands in undrained conditions (as suggested by Sladen et al., 1985).

The process of progressive failure was confirmed by direct field observations, in particular by Burland et al. (1977), who observed the propagation of a horizontal shear band near the base of an excavation in overconsolidated Oxford Clay, and by Cooper et al. (1998), who brought to failure a well-instrumented experimental cut by increasing pore pressures within the slope. The development of the failure surface in this latter case is described in the following paragraphs.

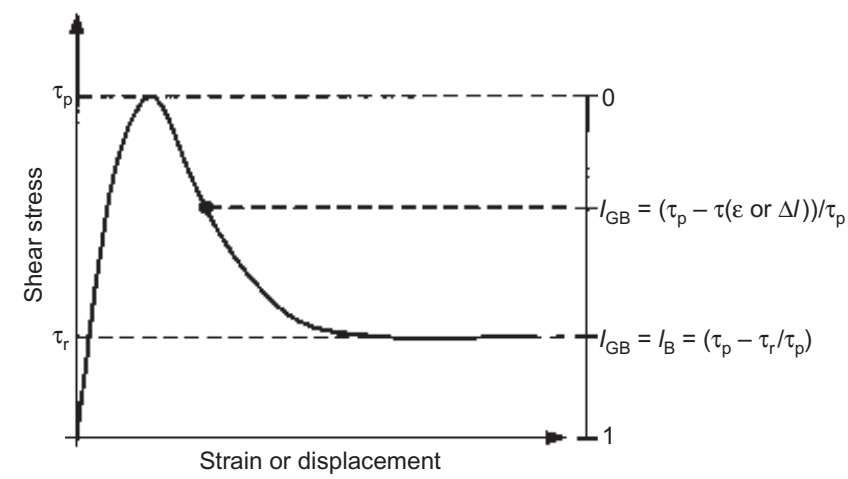

Fig. 46. Brittleness of soils

The Selborne cut is shown in Fig. 47. It is a $9 \mathrm{~m}$ high, 2:1 cut slope in overconsolidated Gault Clay. Instrumentation, survey results and interpretations have been presented in papers by Muir Wood et al. (1995), Cooper (1996) and Cooper et al. (1998), as well as in a CD-ROM (Bromhead et al., 1998). Fig. 47 shows some of the installed inclinometers and the recharge zone in which pore pressures were increased. Failure occurred on 16 July 1989 (day 196 in the time scale used by Cooper et al., 1998) along the failure surface (dotted line) shown on the figure and corresponding to observations made along the centre line of the slip mass.

The first readings were taken shortly after the end of excavation, approximately on day -400 . Fig. 48 shows lateral displacement profiles in inclinometers I-04, I-06 and I-08 at selected times. These results, as well as observations reported by Cooper and co-workers, give interesting indications on the development of progressive failure:

(a) All the inclinometers show a progressive deformation of the soil mass with occurrence of local shearing at some time. This is quite clear for inclinometer I.06, which shows continuous deformations on day 88 (reading $\mathrm{C}$ in Fig. 48(b)), initiation of localisation of displacement on day 175 (reading D), and clear localisation on day 186 (reading E).

(b) Shortly after excavation, localised shearing appeared at the toe of the cut, whereas the overall factor of safety was larger than 1.26. As shown in Fig. 48(c), localisation was already evident on day -171 in inclinometer I.08, at a depth of about $2 \mathrm{~m}$. Fig. 49(a) shows the part of the final slip surface on which failure had already been reached at that time.

(c) At the time of reading $\mathrm{C}$ (days 88-96), the profile in I.06 is continuous whereas localisations were observed at a depth of about $2 \mathrm{~m}$ in I.04 and I.08. Fig. 49(b) shows the localisations at the higher and lower parts of the final slip surface.

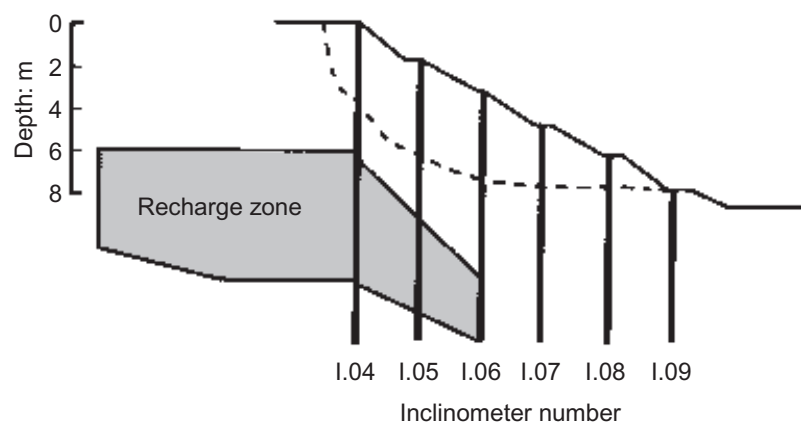

Fig. 47. Selborne cut, with recharge zone and inclinometers (from Cooper et al., 1998) 


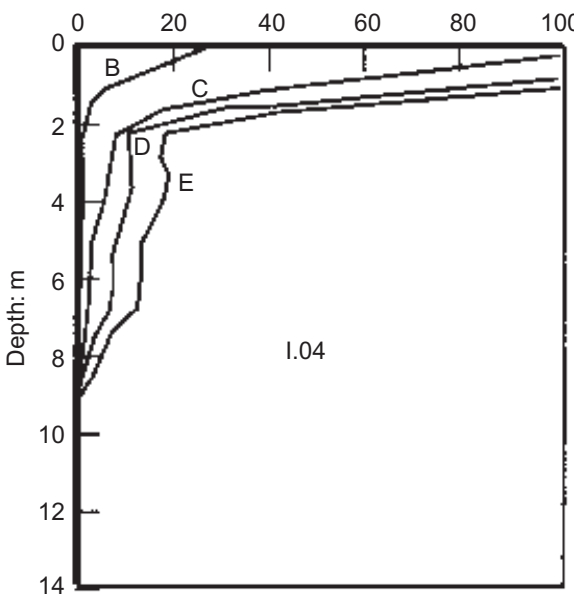

(a)

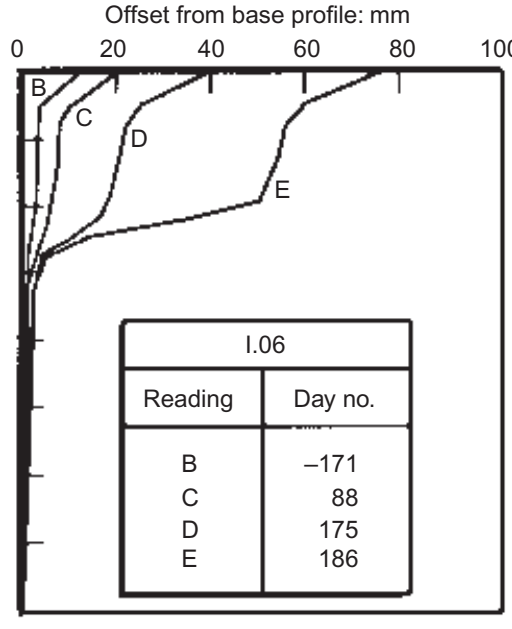

(b)

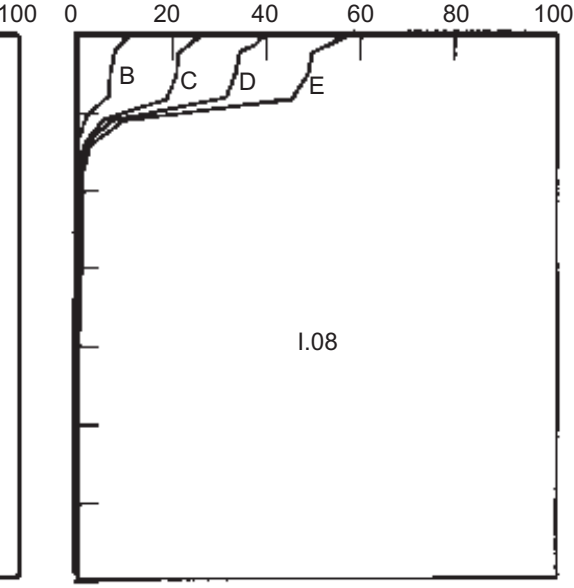

(c)

Fig. 48. Inclinometer profiles at different times, at Selborne (from Bromhead et al., 1998)

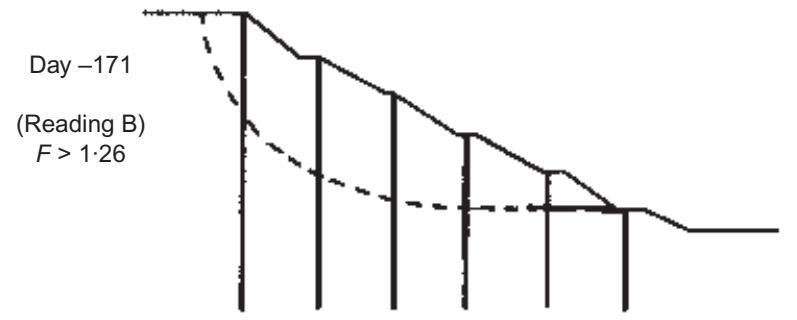

(a)

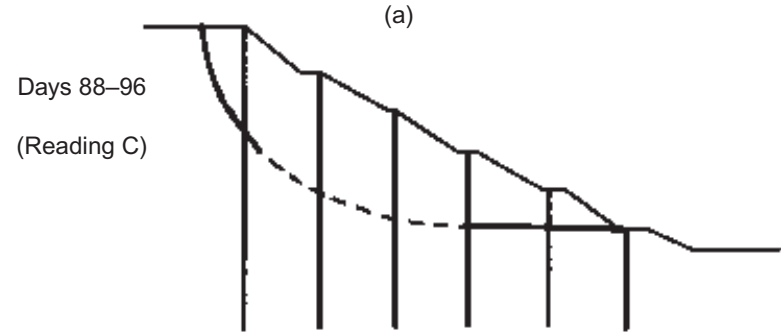

(b)

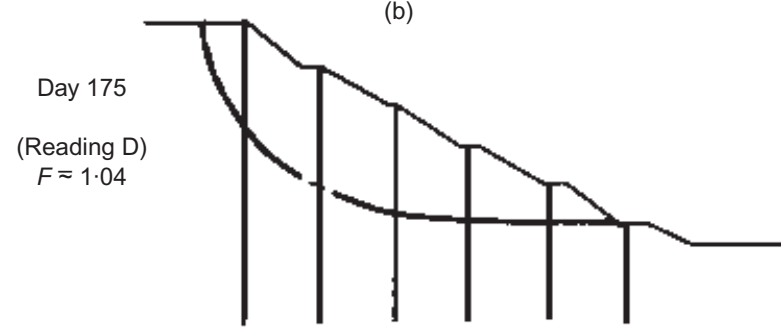

(c)

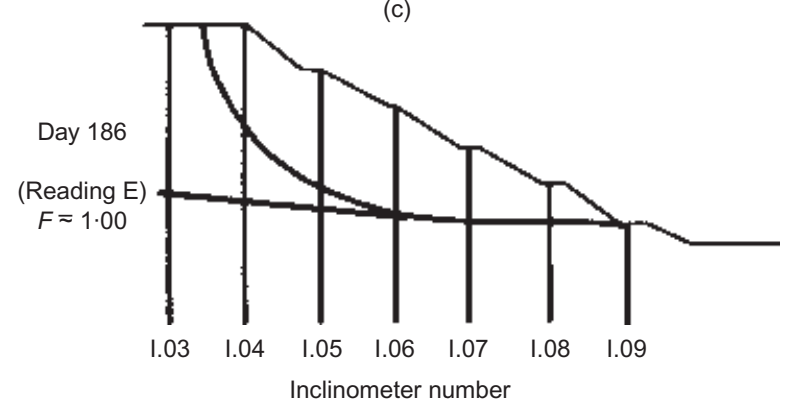

(d)

- - Final slip surface (failure on day 196) Localization

Fig. 49. Development of the slip surface at Selborne (after Bromhead et al., 1998) (d) At the time of reading D (day 175), localisation was discernible in all the inclinometers, except inclinometer I.05 (Fig. 49(c)). According to Cooper et al. (1998), the global factor of safety was close to 1.04 at that time.

(e) The last reading (reading E on day 186) shows localisation along the entire slip surface, and failure occurred 10 days later (Fig. 49(d)). Fig. 48a (I.04) also shows that another slip surface is developing, about $5 \mathrm{~m}$ below the first one (Fig. 49(d)).

To this author's knowledge, it is the first time that the development of progressive failure up to generalised failure has been observed in an excavation. This constitutes an important step forward. However, owing to the complexity of the processes involved, a complete understanding of progressive failure will come only from representative numerical modelling.

Potts et al. (1997) examined delayed failures of cuts in overconsolidated London Clay, using a soil model previously used by Potts et al. (1990). It is an elasto-plastic model in which softening behaviour is accounted for by allowing the angle of friction, $\phi^{\prime}$, and the effective cohesion, $c^{\prime}$, to vary with the deviatoric plastic strain invariant $\varepsilon_{\mathrm{D}}^{\mathrm{p}}$ as shown in Fig. 50. The deviatoric plastic strain invariant is defined as:

$$
\left(\varepsilon_{\mathrm{D}}^{\mathrm{p}}\right)^{2}=2\left[\left(\varepsilon_{1}^{\mathrm{p}}-\varepsilon_{2}^{\mathrm{p}}\right)^{2}+\left(\varepsilon_{2}^{\mathrm{p}}-\varepsilon_{3}^{\mathrm{p}}\right)^{2}+\left(\varepsilon_{3}^{\mathrm{p}}-\varepsilon_{1}^{\mathrm{p}}\right)^{2}\right] / 3
$$

In Fig. 50, $\phi^{\prime}{ }_{\mathrm{p}}$ and $c_{\mathrm{p}}^{\prime}$ are the peak strength parameters and $\phi^{\prime}{ }_{\mathrm{r}}$ and $c^{\prime}{ }_{\mathrm{r}}$ are the residual strength parameters. For the London

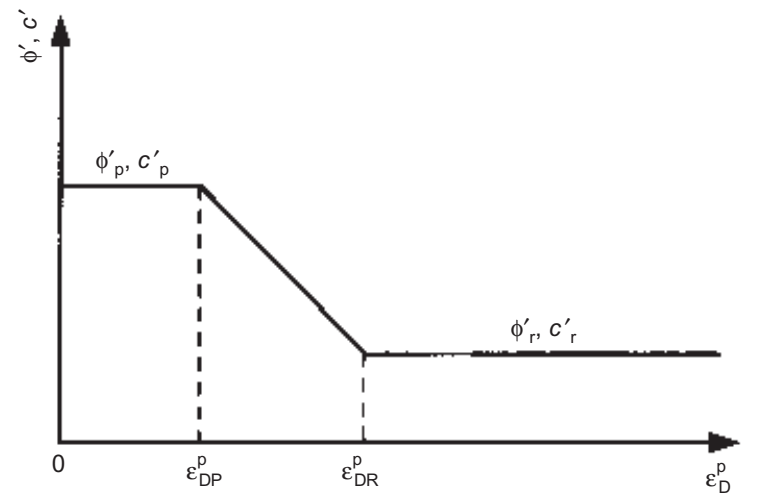

Fig. 50. Variation of the angle of shearing resistance, $\phi^{\prime}$, and the cohesion intercept, $c^{\prime}$, with the deviatoric plastic strain invariant, $\varepsilon_{\mathrm{D}}^{\mathrm{p}}$, used by Potts et al. (1997) 
Clay, Potts et al. (1997) considered $\phi_{\mathrm{p}}^{\prime}=20^{\circ}, \quad c_{\mathrm{p}}^{\prime}=7 \mathrm{kPa}$, $\phi_{\mathrm{r}}^{\prime}=13^{\circ}, c^{\prime}{ }_{\mathrm{r}}=2 \mathrm{kPa}$, and peak strength prevailing up to $\varepsilon_{\mathrm{D}}^{\mathrm{p}}$ values of $5 \%$ and residual strength prevailing for $\varepsilon_{\mathrm{D}}^{\mathrm{p}}$ values larger than $20 \%$.

Figures 51 and 52 refer to a $10 \mathrm{~m}$ high and 3:1 cut excavated in three months in a clay deposit with an initial coefficient of
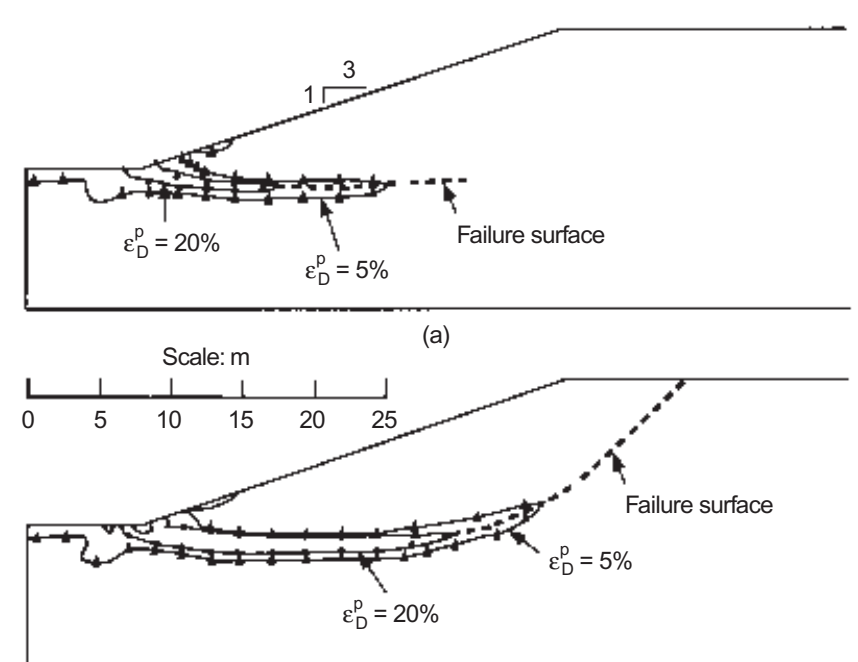

(b)

Fig. 51. Finite element analysis of an excavation, $3: 1$ slope, $10 \mathrm{~m}$ high, $K_{0}=1.5$, surface suction $10 \mathrm{kPa}$ : (a) 9 years after excavation; (b) $\mathbf{1 4 . 5}$ years after excavation, just before collapse. Contours of accumulated deviatoric plastic strain, $\varepsilon_{\mathrm{D}}^{\mathrm{p}}$ (after Potts et al., 1997). Strain softening starts when $\varepsilon_{D}^{p}=5 \%$; it is complete when $\varepsilon_{D}^{p}=20 \%$ (see Fig. 50)
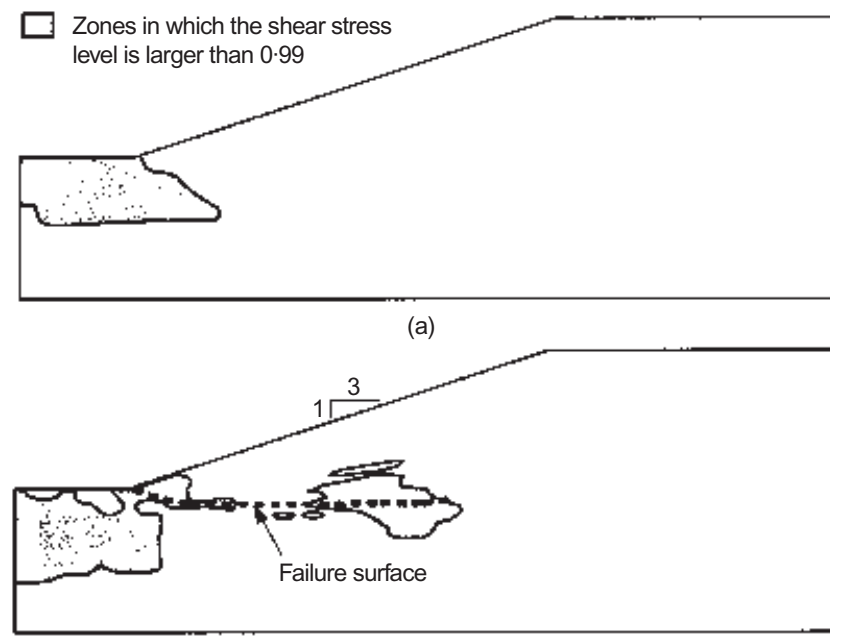

(b)

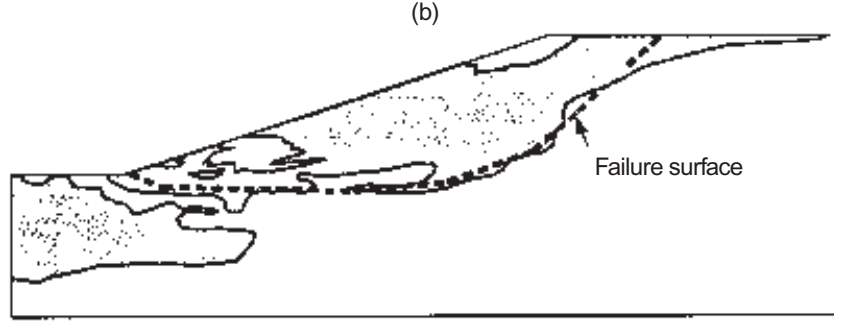

(c)

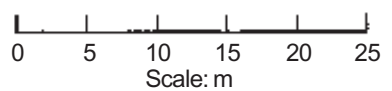

Fig. 52. Finite element analysis of an excavation, $3: 1$ slope, $10 \mathrm{~m}$ high, $K_{0}=1.5$, surface suction $10 \mathrm{kPa}$ : (a) after excavation; (b) 9 years after excavation; (c) 14.5 years after excavation, just before collapse. Shaded areas show zones in which the shear stress level is larger than 0.99 (after Kovacevic, 1994) earth pressure at rest, $K_{0}=1 \cdot 5$. Fig. 51 shows the contours of the deviatoric plastic strain, $\varepsilon_{\mathrm{D}}^{\mathrm{p}}$, for the values $5 \%$ and $20 \%$ at which strain softening starts and ends. They evidence the propagation of an essentially horizontal shear zone from just below the toe of the slope. Nine years after excavation, the failure surface is only below the slope (Fig. 51(a)), but 14.5 years after excavation (Fig. 51(b)), just before collapse, the failure surface is completely defined. The development of the failure surface obtained by Potts et al. (1997) seems to correspond well to field observations made by Bjerrum (1967), James (1970), Burland et al. (1977) and Cooper et al. (1998). In particular, the development of a second, almost horizontal, failure surface observed at Selborne when approaching collapse (Fig. 49(d)) is predicted by Potts et al. (1997) when $K_{0}$ is equal or larger than $2 \cdot 0$.

Figure 52, from Kovacevic (1994), shows the zones in which a shear stress level larger than 0.99 has been reached or, practically reached, in which local failure occurred. At the end of excavation (Fig. 52(a)), local failure has occurred only below the bottom of the excavation but, just before collapse, 14.5 years after excavation (Fig. 52(c)), local failure into the slope has occurred in a significant part of the soil mass.

Figure 53 presents data similar to those shown in Fig. 52, but for a 4:1 slope that, according to the numerical model and the input parameters considered, remains stable in the long term. It can be seen that, even in this stable slope, local failure has been reached in a large part of the slope.

The numerical work performed by Dunlop \& Duncan (1970), Lo \& Lee (1973), Deschamps \& Leonards (1992) and Potts et al. (1997) indicates a strong influence of initial stress conditions $\left(K_{0}\right)$ on the zone of local failure (weakened zone) that develops in cuts. While in strongly overconsolidated clays (say $K_{0}>1 \cdot 0$ ), it always includes the toe of the slope (as confirmed by field observations: De Beer, 1969; Burland et al., 1977; Cooper et al., 1998), it could in some cases be confined below the crest of the slope in nearly normally consolidated or slightly overconsolidated clays (say $K_{0}<1 \cdot 0$ ).

\section{Field evidence of soil weakening}

As previously indicated (Fig. 53), a significant part of a slope may have reached local without or before the occurrence of a general failure. Reaching the peak means destructuration in most geomaterials and thus a decrease in strength (Leroueil \& Vaughan, 1990). This must thus be observable in natural slopes of precarious stability, which has been confirmed by several recent field investigations. The corresponding zones will be described herein as weakened zones.

Maskinongé. Several first-time landslides occurred during the period 1990-1992 along the left bank of Maskinongé river, close to and in the Maskinongé village, about $90 \mathrm{~km}$ northeast of Montréal, Québec (Fig. 54). The Maskinongé river there flows in the upper part of a very homogeneous deposit of sensitive clay $60-70 \mathrm{~m}$ thick. The banks are about $11 \mathrm{~m}$ high; the geometry of the left bank is essentially the same all along the part of the river shown in Fig. 54.

Demers et al. (1999) investigated in detail the landslide that

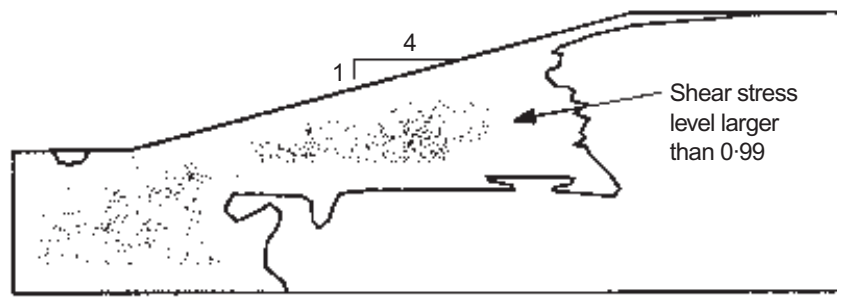

Fig. 53. Finite element analysis of an excavation, $4: 1$ slope, $10 \mathrm{~m}$ high, in London Clay. Shaded area shows zones in which the shear stress level is larger than $\mathbf{0 . 9 9}$ (after Kovacevic, 1999, personal communication) 


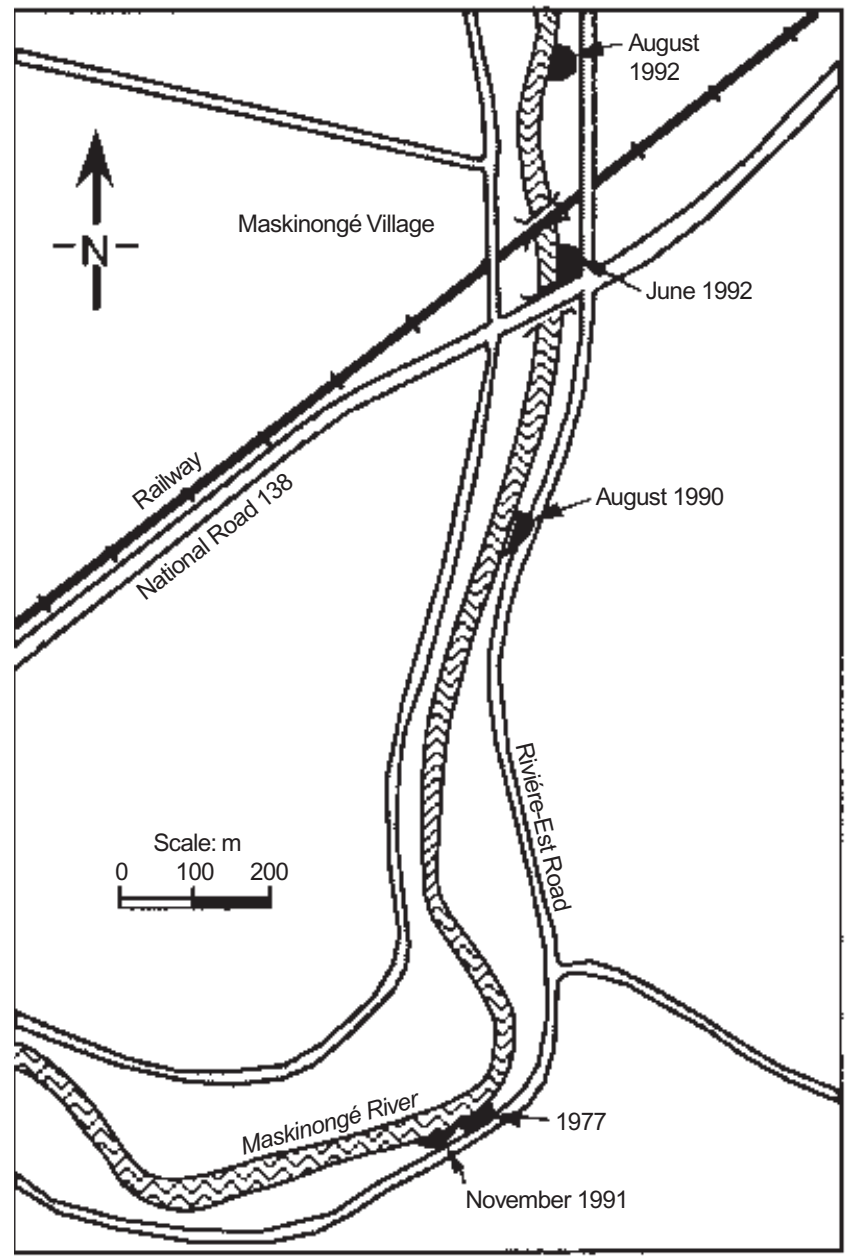

Fig. 54. Location of recent landslides in Maskinongé area (after Demers et al., 1999)

occurred in August 1990 (Fig. 54). The upper part of the deposit consists of $2.7 \mathrm{~m}$ of stratified silty sand with silty and clayey layers. Below this unit is a homogeneous deposit of soft to firm grey and plastic silty clay. The overconsolidation ratio is about 1.35 over the entire deposit.

Vane and piezocone profiles obtained in the slide crater allowed the definition of the failure surface, as shown in Fig. 55.

Two sections perpendicular to the river and at a distance from the landslide of $10 \mathrm{~m}$ for section $\mathrm{A}$ and $50 \mathrm{~m}$ for section $\mathrm{B}$ were investigated with the piezocone. These sections were in areas that were stable but probably with a low factor of safety, as indicated by the nearby failure and by deformations of the

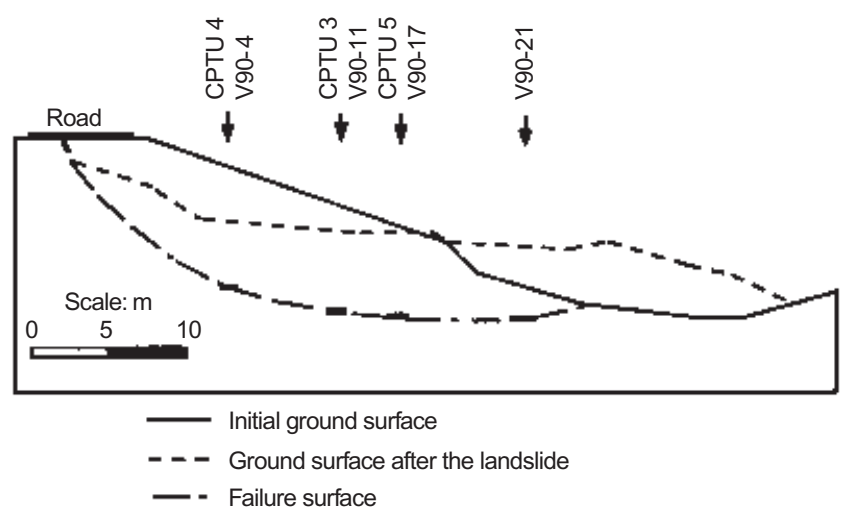

Fig. 55. Sections before and after the second stage of the 1990 landslide (from Demers et al., 1999) pavement of the road at the crest of the slope. Similar results were obtained in both sections. Those obtained in section A are shown in Fig. 56. It can be seen that:

(a) The CPTU7 profile confirms the homogeneity of the intact clay deposit, with tip resistance and pore pressure increasing linearly with depth.

(b) The CPTU12, 9 and 8 profiles show irregularities. The difference from a reference $q_{\mathrm{T}}$ profile, also shown by the shaded zones in Fig. 56(a), is an indication of a local loss of tip resistance, and thus of a local degree of weakening of the clay in the slope.

(c) The difference in tip resistance is also reported as shaded zones in the cross-section shown in Fig. 56(a). It can be seen that the weakening is not localised, but generalised to the entire clay mass close to the slope, in a manner similar to the numerical results shown in Fig. 53.

(d) The failure surface observed in the nearby landslide (Fig. 55 ) is well inside the weakened zone (Fig. 56(a)).

It is worth noting that a piezocone profile obtained outside the zone where deformations in the pavement were observed did not show any weakened zone, indicating that weakening is associated with phenomena such as creep and progressive failure.

Other eastern Canada cases. Delisle \& Leroueil (2000) report several other sites from the Province of Québec where some weakening of sensitive clay constituting the slope (that had not failed before) was detected with the piezocone. The example of La Baie is shown in Fig. 57. The deposit is composed of very stiff clay and silt, but with a liquidity index only slightly smaller than $1 \cdot 0$. It can be seen that the piezocone profile established $32 \mathrm{~m}$ behind the crest is regular, increasing slightly with depth, while those obtained closer to the slope are very irregular and with smaller $\left(q_{\mathrm{T}}-\sigma_{\text {vo }}\right)$ values in their upper part. There is a clear weakening of the soil mass.

Demers et al. (1999) and Delisle \& Leroueil (2000) compared clay samples taken in intact zones and in weakened zones on several of the sites studied. The general conclusion is that there are more fissures and the clay is slightly less microstructured in weakened zones. It was, however, concluded that the decrease in tip resistance and pore pressure observed with the piezocone in the weakened zones mostly reflects the presence of fissures.

Chieti. Totani et al. (1997) present the results of an investigation performed at Chieti, central Italy. A cross-section of the slope, which is about $30 \mathrm{~m}$ high, is shown in Fig. 58. Three different soil layers can be distinguished: fill material over a maximum thickness of $10 \mathrm{~m}$ below the crest of the slope; light brown clay; and grey clay. The clay is of medium plasticity, and is considered as highly overconsolidated but with a small brittleness, the residual strength envelope being only slightly below the peak strength envelope.

Several dilatometer (DMT) and cone penetration (CPT) profiles were obtained. Results obtained in the zone of interest are shown in Fig. 58. Outside the zone indicated as 'weak' on the figure, the tip resistance, $q_{\mathrm{c}}$, increases regularly with depth, and the profiles of the horizontal stress index deduced from dilatometer tests, $K_{\mathrm{D}}$, are regular. On the other hand, within the 'weak' zone the $q_{\mathrm{c}}$ and $K_{\mathrm{D}}$ profiles are very irregular, with values smaller than the corresponding values in the surrounding soil. Totani et al. (1997) have no clear explanation for this weakening, but the observations made are very similar to those made on the previously mentioned sites from Québec, which could indicate that the Chieti slope is also destructured owing to creep and progressive failure phenomena.

\section{Instability indications prior to main landslides}

There are other indications that something may happen to slopes prior to a first-time failure.

In connection with two deep-seated landslides that occurred in Hong Kong following the passage of Typhoon Helen in 

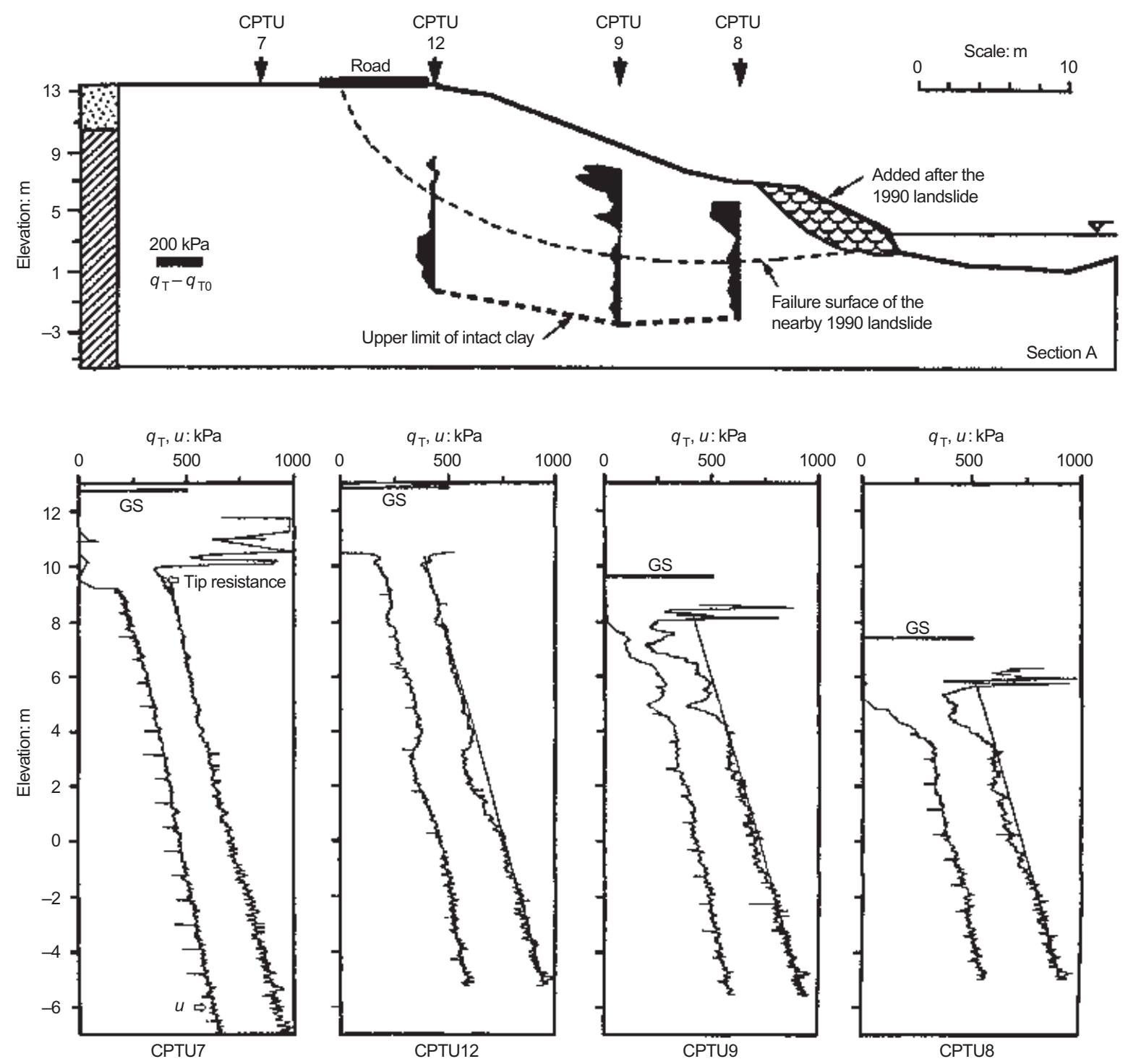

Fig. 56. CPTU profiles in section A, close to the 1990 Maskinongé landslide, GS-ground surface (from Demers et al., 1999)

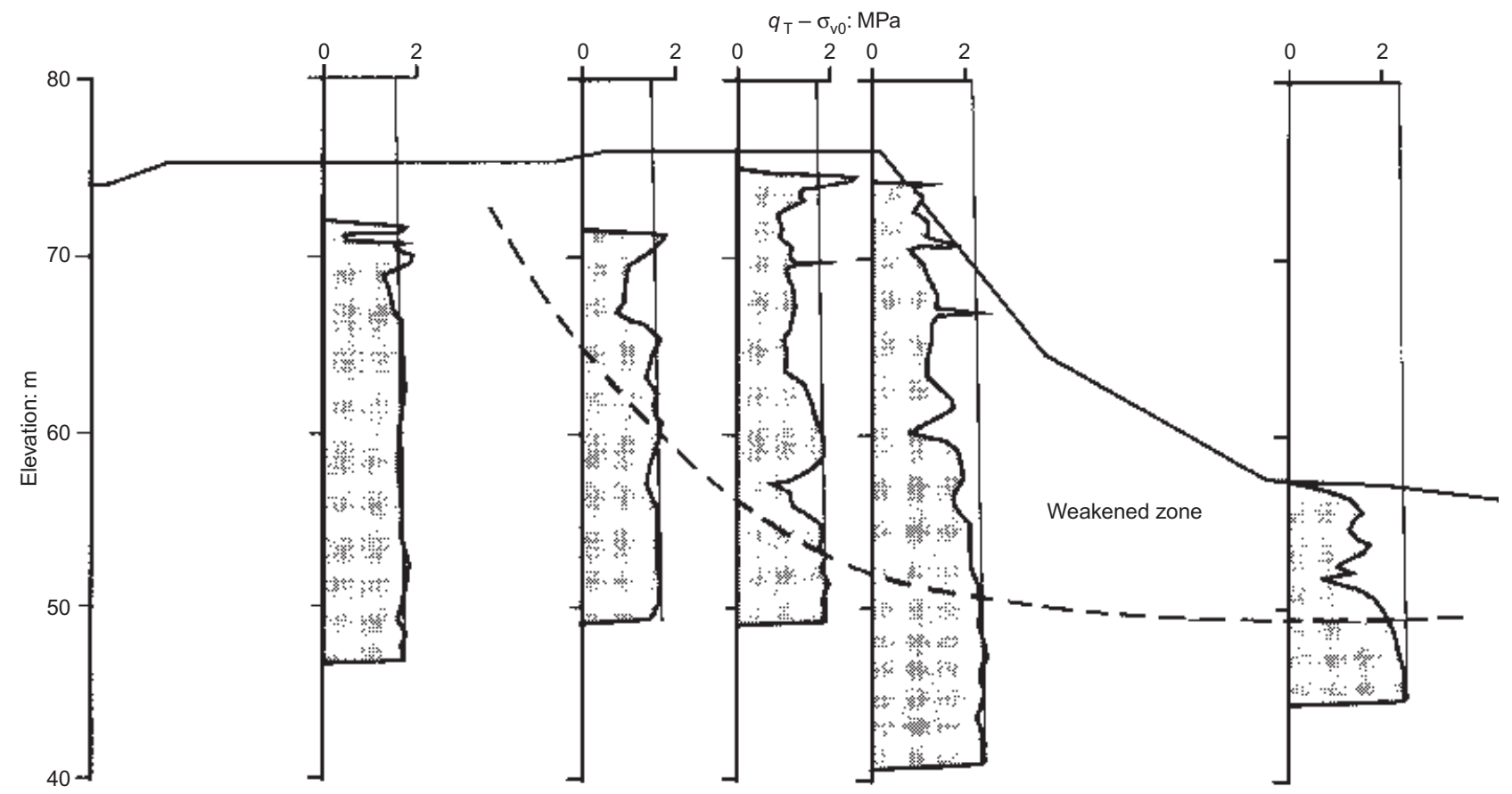

Fig. 57. CPTU profiles at La Baie (from Delisle \& Leroueil, 2000) 


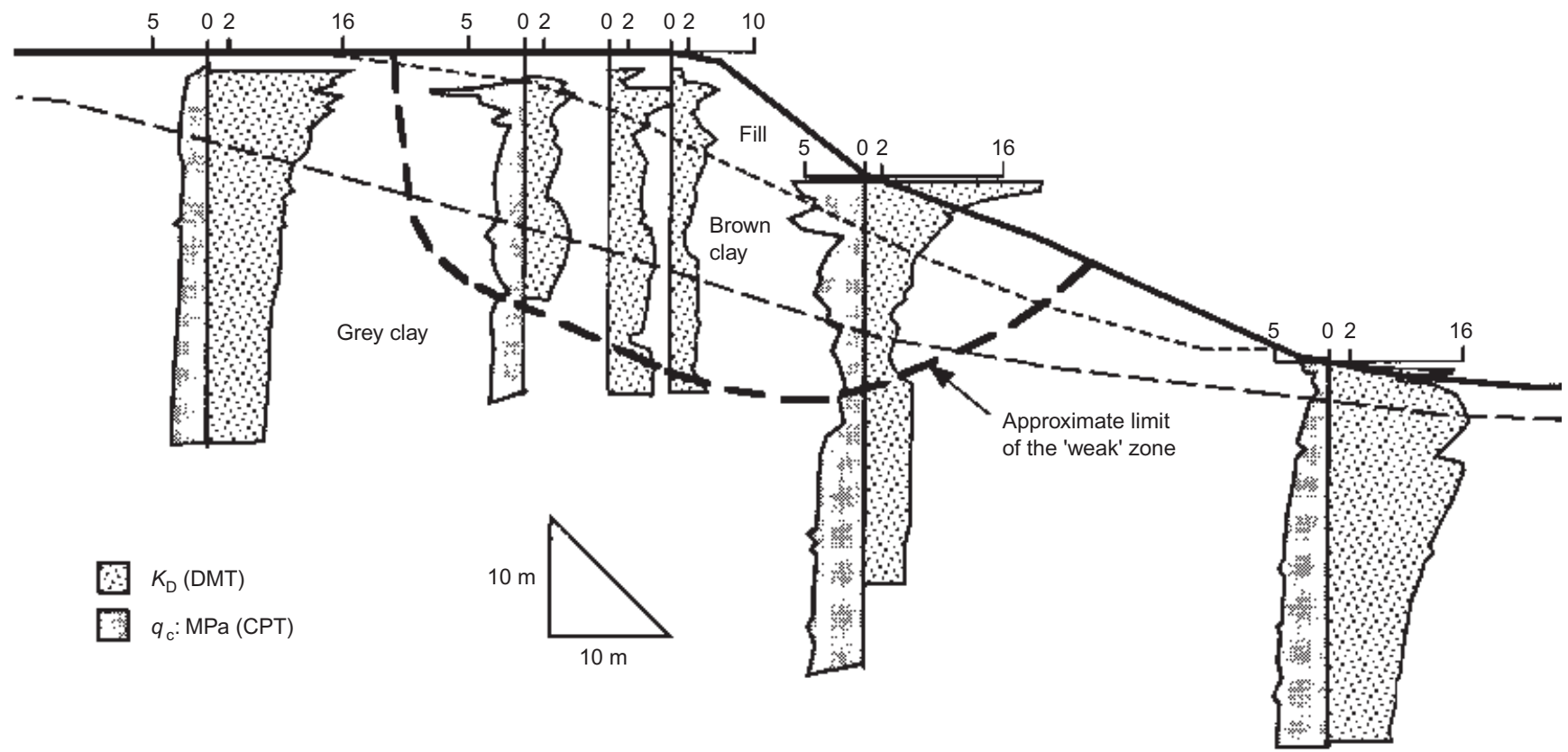

Fig. 58. CPT $\left(q_{\mathrm{c}}\right)$ and DMT $\left(K_{\mathrm{D}}\right)$ profiles at Chieti, Italy (after Totani et al., 1997)

August 1995, Kirk et al. (1997) examined in great detail the slip surface and joints close to it. The materials involved were partially weathered rocks comprising predominantly fine ash tuff. The observations made by Kirk et al. (1997) evidenced complex joint infilling with alternations of kaolin of varying composition and todorokite. This was seen as an indication that the actual opening of the joints results from a succession of small movements that had occurred at different times prior to the main slide. Malone (1998, personal communication) indicates that kaolinite/todorokite alternations have been observed and documented at two other sites. Also, Malone (1998) reviewed detailed reports concerning major failures in igneous rock saprolites in Hong Kong and found evidence of movements preceding the main failure in nine of the twelve large-volume landslide cases studied (volume equal to or greater than $1500 \mathrm{~m}^{3}$ ).

Terzaghi (1950) also mentions the slide of Goldau 'that took the villagers by surprise, but the horses and cattle became restless several hours before the slide, and the bees deserted their hives.' Tavenas et al. (1971) report similar facts in relation to the Saint-Jean-Vianney landslide, which occurred in extremely sensitive clays and caused the loss of 31 lives. As indicated by witnesses, in the hours preceding the slide, dogs became extremely nervous as during a thunderstorm and cows, though usually docile, refused to go to their usual grazing land - which was, a few hours later, completely washed away by the slide. Pilot (1984) also mentions several cases in which acoustic emission measurments show increasing activity as failure approached.

It thus appears that many slope failures are preceded by prefailure phenomena, and movements. As a consequence, and as well indicated by Terzaghi (1950), 'if a landslide comes as a surprise to the eyewitnesses, it would be more accurate to say that the observers failed to detect the phenomena which preceded the slide.' Another consequence is certainly that we should pay attention to precursory signs of landslides more than we usually do, and learn how to detect them, interpret them and react.

\section{FAILURE}

Failure is characterised by the formation of a continuous failure or slip surface through the entire soil or rock mass. As defined here it is thus the onset of the landslide.
Weakened zone, shear zone and slip surface

From the previous section, it appears that the failure or slip surface in a slope develops within a weakened zone. Observations, however, show that there is, an intermediate structure surrounding the slip surface, usually called the shear zone (Fig. 59).

According to the Mohr-Coulomb theory, shear surfaces form at an inclination of $\left(45^{\circ}+\phi^{\prime} / 2\right)$ to the direction of the minor principal stress. When such shear surfaces cannot develop, owing to kinematic constraints, there is at first the formation of a shear zone (described below) and then the development, within this shear zone, of a slip surface that is kinematically possible. This is particularly the case in direct shear tests and in many slopes.

Riedel (1929) was the first to describe such a process, which was observed during a kind of shear test on a clay specimen. According to Riedel's observations (Fig. 60), the mechanism of rupture is characterised by initial formation of single separate shear surfaces, called Riedel shears $(R)$, that are slightly inclined to the direction of main shear, and by some conjugate discontinuities (Fig. 60(a)). Then another set of discontinuities, the thrust shears $(P)$, are formed at locations almost symmetrical to the $R$ shears (Fig. 60(b)). None of these minor shears allows for significant displacements (Skempton \& Petley, 1967). Finally, the displacement discontinuities $(D)$ are formed in the direction of the imposed shear (Fig. 60(c)). In the final stage, these latter link to form a unique principal displacement dis-

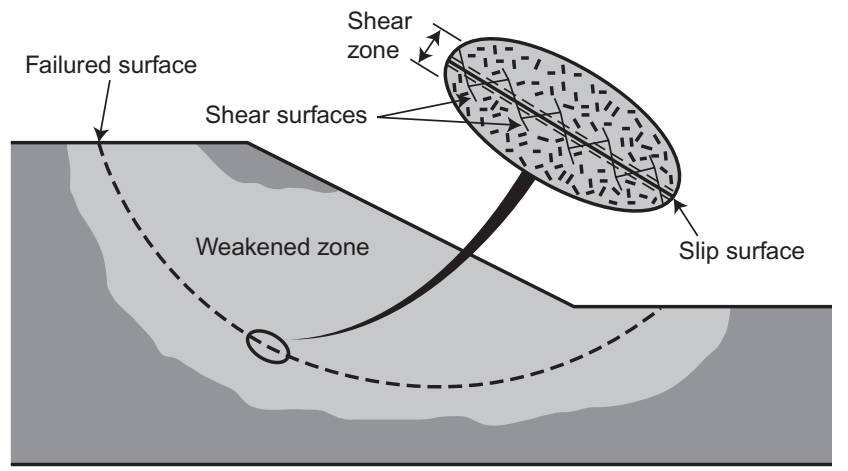

Fig. 59. Weakened zone, shear zone and slip surface in a slope 


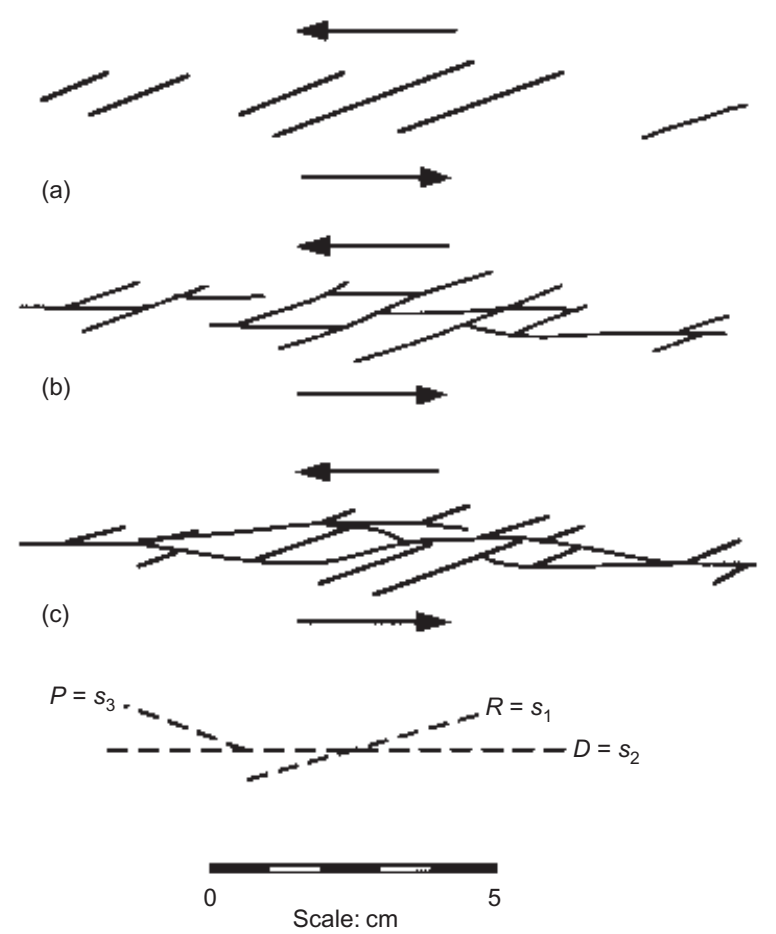

Fig. 60. Sketch showing three successive stages in the development of slip surfaces in clay subjected to shear (from Riedel, 1929, and Skempton, 1967)

continuity (Skempton \& Petley, 1967). This process was confirmed by laboratory experiments (Morgenstern \& Tchalenko, 1967a; Wilcox et al., 1973). The described zone of discrete thickness, including the system of minor shears and more or less disturbed lenses, is the shear zone (Skempton, 1967). The occurrence and features of shear zones in in situ conditions were recently reviewed by Picarelli et al. (1997). In particular, structures similar to the one shown in Fig. 60(c) were observed along faults and folds over thicknesses varying from tens of centimetres to hundred of metres (Skempton, 1964, 1967; Tchalenko, 1970; Archambault et al., 1990; Tani \& Ueta, 1998). Another shear zone, associated with ice-thrusting, was also well documented by Tsui et al. (1988) and Cruden et al. (1989). In slopes, observations made by Morgenstern \& Tchalenko (1967b), Skempton \& Petley (1967) and Hayashi et al. (1992) indicate shear zones with a thickness of a few centimetres and presenting several sets of shears with different directions. Fig. 61 shows the details of a shear zone observed by Morgenstern \& Tchalenko (1967b) in an old landslide that

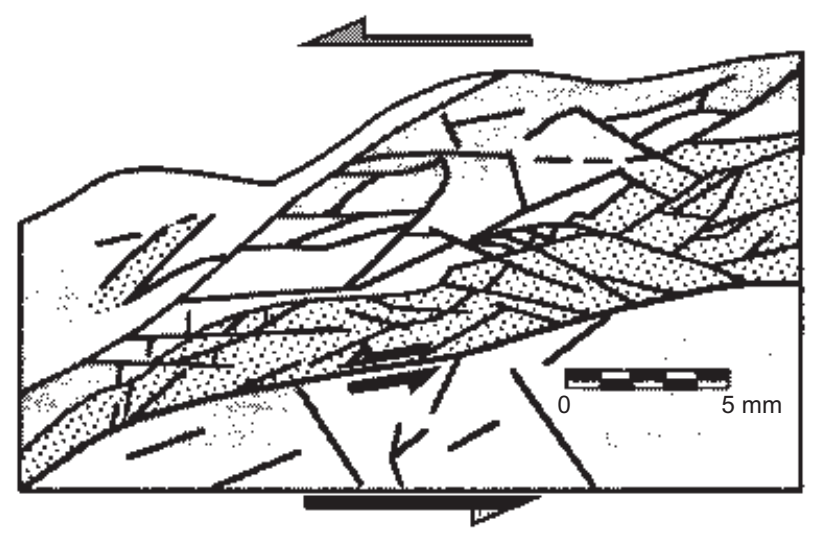

Fig. 61. Details of shear zone in old landslide near Guildford (after Morgenstern \& Tchalenko, 1967b) occurred in London Clay. Picarelli (1993) and Guerriero (1995) report data on earthflows involving intensely fissured clay shales in southern Italy. They observed at the bottom of several earthflows shear zones $4-40 \mathrm{~cm}$ thick, including one or several slip surfaces. The shear zone is constituted of small lithorelicts in a softer clay matrix, and reflects an important destructuration of the parent material that probably has to be related to the large displacements experienced in earthflows.

Observations of water contents around slip surfaces developed in overconsolidated clays and clay shales show a local increase in water content, as evidenced in Figs 62(a) and 63, which can be related to dilatancy induced by shearing. In contrast, Lefebvre (1981) observed in sensitive eastern Canada clays that water content close to the slip surface is smaller than in the surrounding soil (Fig. 62(b)).

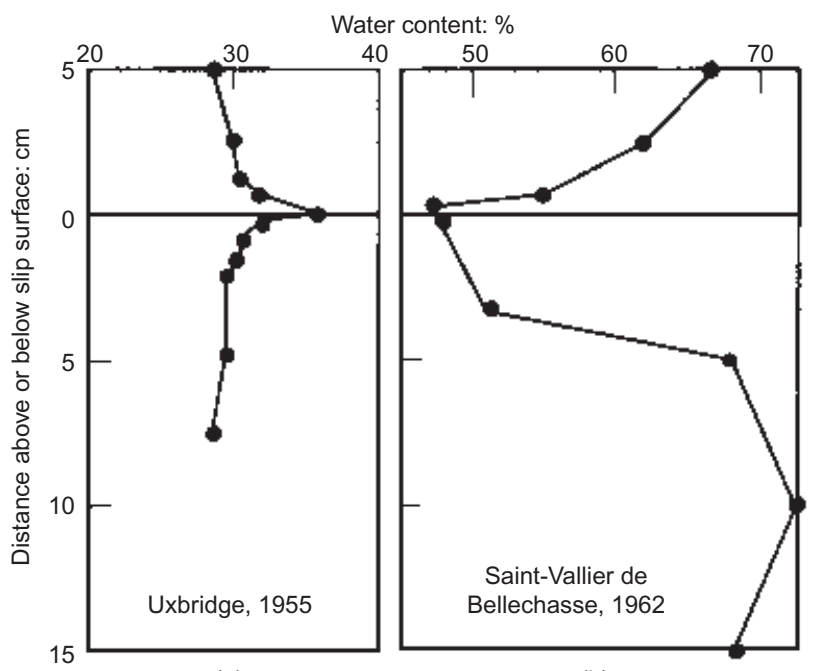

(a)

(b)

Fig. 62. Variation of water content around slip surfaces: (a) in overconsolidated clay (after Skempton, 1964); (b) in sensitive clay (after Lefebvre, 1981)

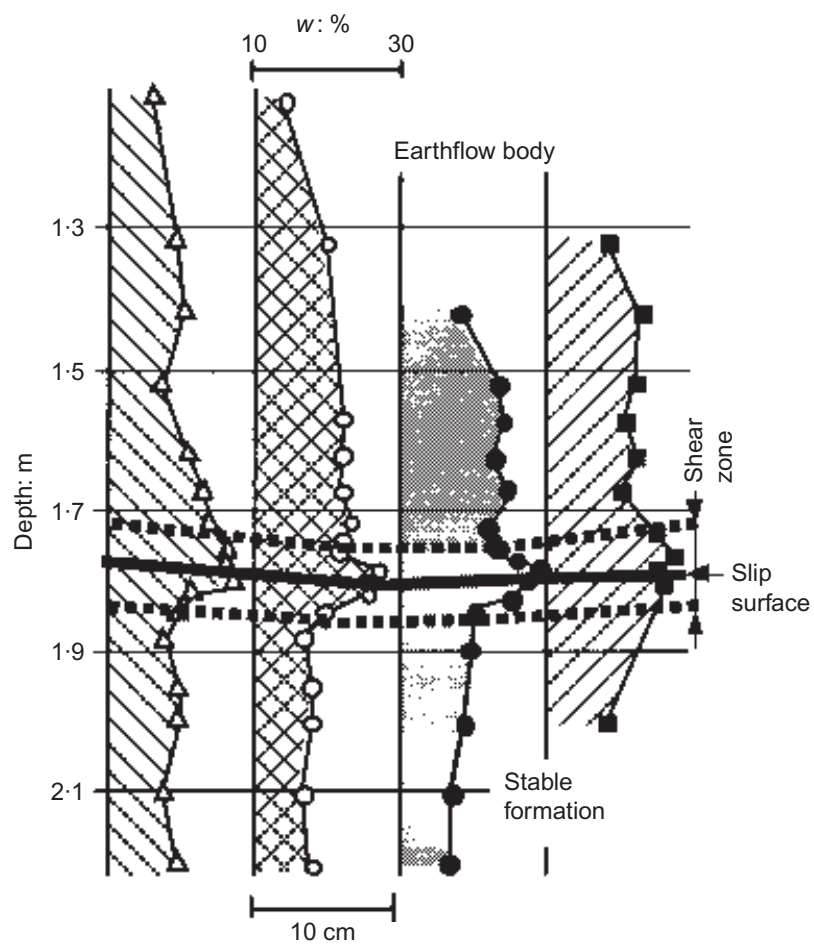

Fig. 63. Water content profiles at the base of earthflows in Basento Valley, Italy (from Picarelli, 1993) 
So, as already indicated (Fig. 59), there are several 'structures' associated with failure (local and/or general) in slopes:

(a) a weakened zone in which soil has reached local failure and should be generally destructured

(b) a shear zone, surrounding the shear surface, with a thickness varying from a few centimetres to a few decimetres and including shears and lenses of soil, more or less disturbed, depending on the material and on the displacements involved

(c) the failure surface itself, along which there is localisation and possible particle orientation.

It is worth noting, however, that there is no evidence that weakened zones and shear zones develop or can be observed in all cases.

\section{Brittleness and in situ strength}

As previously indicated, progressive failure and failure itself depend to a large extent on the brittleness of the material, and this brittleness can be characterised by a generalised brittleness index $I_{\mathrm{GB}}$ defined, as a function of strain or displacement, as indicated in Fig. 46. An important aspect is that this generalised brittleness index has to be defined for the stress path really followed in situ. For example, as indicated by Brand (1981), in rainfall-induced failures stress paths are under approximately constant shear stress and decreasing effective mean stress. Two important factors are associated with the generalised brittleness index: the peak strength and the ultimate strength. As previously indicated, peak strength is influenced by several factors:

(a) swelling, destructuration, strain rate and accumulation of strain, fatigue and weathering, which progressively lower peak strength value with time (time-softening process: Popescu, 1993)

(b) changes in effective stress or matric suction

(c) anisotropy and stress axis rotation.

The ultimate strength depends on the nature of the material and on the effective stress conditions existing under ultimate conditions, which includes the influence of void ratio and applied stresses. The influence of some of the above-mentioned factors influencing peak strength will be examined later on in this section; factors influencing the ultimate strength will be discussed in next section on post-failure.

Owing to the process of progressive failure, the average strength mobilised in a slope at failure will generally be intermediate between the peak and the ultimate strengths (Skempton, 1964; Tavenas \& Leroueil, 1981; Duncan, 1992; Vaughan, 1994). This is well documented for London Clay and Upper Lias (Skempton, 1977; Chandler, 1984), Norwegian clays (Janbu, 1977) and eastern Canada clays (Lefebvre, 1981; Tavenas \& Leroueil, 1981). As shown in Fig. 64, the strength mobilised for first-time slides in London Clay is characterised by a friction angle of $20^{\circ}$ and a small cohesion of about $1 \mathrm{kPa}$, well below the peak strength envelope deduced from laboratory tests, and well above the residual strength envelope, here deduced from back-calculated analyses of reactivated landslides. Fig. 65 presents results deduced from a back-analysed first-time

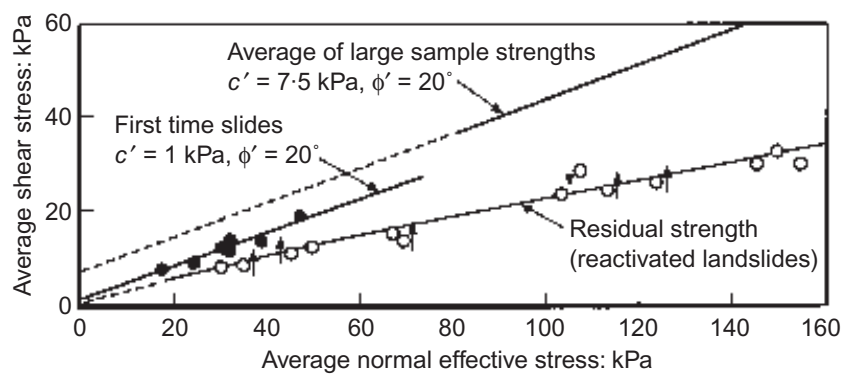

Fig. 64. Strength envelopes in London Clay (from Chandler, 1984)

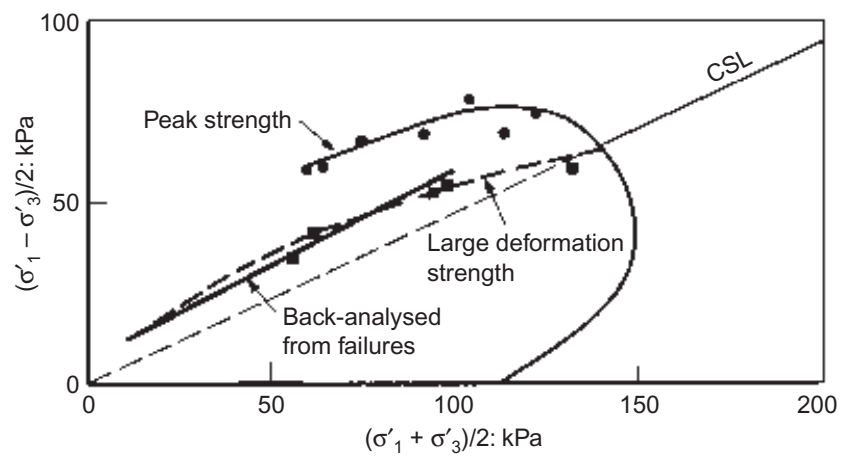

Fig. 65. Strength envelopes for Saint-Vallier clay (after Lefebvre \& La Rochelle, 1974; Lefebvre, 1970)

slope failure at Saint-Vallier, Québec (Lefebvre \& La Rochelle, 1974). The mobilised strength envelope is much lower than the peak strength envelope determined in the laboratory, and close to the large deformation strength envelope determined in the overconsolidated range. In fact, the upper strength envelope obtained in the laboratory is representative of in situ strength only when the soil has a ductile behaviour $\left(I_{\mathrm{GB}}\right.$ remaining close to 0 ).

Back-analyses of slope failures present some weaknesses. The geometry of the slope and of the failure surface are not always well known; pore pressures at the time of failure are generally unknown (an error of $10 \mathrm{kPa}$ on pore pressure results in an error of $4-6 \mathrm{kPa}$ in the back-calculated effective cohesion); and the three-dimensional geometry of most failures is generally neglected, which results in an overestimation of backcalculated strength parameters (e.g. for 3-D analyses: Hungr, 1987; Gens et al. 1988). It is thus important to recognise that back-calculated strength parameters reflect the assumptions made for the calculations.

Also, progressive failure seriously questions the meaning of the factor of safety usually determined by limit equilibrium analysis (Tavenas et al., 1980). In their simulation of the 3:1 cut in London Clay (Figs 50-52), Kovacevic (1994) and Potts et al. (1997) conclude that the average strength parameters at failure would be a friction angle of $18^{\circ}$ and a cohesion of 0 , which are parameters close to those back-calculated from firsttime failures (see Fig. 64). However, as indicated in Fig. 51(b), at the time of failure, part of the failure surface is at the peak whereas about half of the failure surface is at the residual. Observations at Selborne show that localisation occurs at the toe of the cut (Fig. 49(a)) while the global factor of safety is equal to about $1 \cdot 26$. Finally, piezocone testing at different sites (Figs 56-58) indicates that local failure may occur in large parts of slopes, even if their global factor of safety is higher than 1.0. So, when used for first-time failures, limit equilibrium methods have to be seen as empirical tools that, however, are extremely useful in practice and work well when calibrated. However, it is obvious that a better understanding of what really happens in slopes will come from simulations with 'deformation methods' such as finite element methods. A good example is provided by Potts et al. (1997).

Influence of anisotropy and stress axis rotation on failure

These are factors that have been examined in the 38th Rankine Lecture (Hight, 1998) and which will not be considered in detail here. Their influence on the stability of slopes is recognised, however. Evidence of that has been provided by Hight (1998) and Hight et al. (1998), in relation to failures in micaceous sand that occurred at the Bangabandhu Bridge, Bangladesh.

\section{Fatigue and slope failures}

Among the causes of landslides, Terzaghi (1950) mentioned the progressive structural changes in the slope-forming materials 
that would be associated with a loss of cohesion caused by slow plastic deformation, and thus a reduction with time of the factor of safety. He presented several examples, among which was the Frank slide, Alberta, in April 1903, which involved about 30 million $\mathrm{m}^{3}$ of rock, mostly Palaeozoic limestone, and resulted in the loss of approximately 70 lives. This failure has been the subject of numerous investigations, but the precise mechanisms involved remain uncertain (Cruden \& Krahn, 1978; Benko \& Stead, 1998). About this landslide, Terzaghi (1950) wrote: 'The slope failed when it was ripe for failure.'

In this author's mind, this apparently trivial but very significant statement made by Terzaghi (1950) well describes failures resulting from creep-fatigue phenomena. Such failures surely exist. However, probably because creep-fatigue phenomena are difficult to evidence and difficult to explain with classical soil mechanics concepts, they are poorly documented in the literature. In the following paragraphs, two cases that are thought to be caused by creep-fatigue phenomena, namely the Maskinongé landslides previously mentioned (Figs 54 and 55) and the Cabrito's Hill landslide, will be described.

Maskinongé landslides. Figure 54 shows the situation of the four landslides that occurred at Maskinongé, Québec, during the period 1990-1992, over a distance of about $1.5 \mathrm{~km}$. Of these four landslides, three occurred during the summer season, which is unusual: most landslides in the Province of Québec occur during the spring season, when snow melts and the water table is high (Lebuis et al., 1983). Moreover, these landslides were not associated with unusual rainfalls: the August 1990 landslide occurred after three rainy days $(38 \mathrm{~mm})$ following a drought of two weeks; the November 1991 landslide occurred after three weeks during which rainfalls were below average; the June 1992 landslide occurred during a relatively dry period; and the August 1992 landslide occurred after two rainy days and a rainy month. As a result of these conditions, it is very probable that, with the possible exception of the August 1992 landslide, the pore pressures in the slopes were low at the time of failure, and certainly lower than those experienced by the slopes before, in particular during the spring periods (Demers et al., 1999). Other explanations for failures had thus to be found. Demers et al. (1999) explain that, about 20 years prior to the landslides, dredging works were carried out in this part of the river in order to facilitate the navigation of small boats. This change in the longitudinal profile of the river probably modified the geometry of the banks, but in an unknown manner. These works are probably partly responsible for the sliding activity observed in the years 1990-1992. However, it cannot be in relation with pore pressure equilibration following excavation since, from the experience gained by Lafleur et al. (1988b) at Saint-Hilaire, Québec, in very similar soil conditions, pore pressures should equilibrate in about 6 months, and thus much less than 20 years. Demers et al. (1999) concluded that these failures had to be explained by creep-fatigue phenomena.

Cabrito's Hill landslide. In February 1988 there were exceptional rainfalls over Rio de Janeiro that triggered hundreds of slides and caused many casualties. The accumulated rainfall was $660 \mathrm{~mm}$ in 18 days and $240 \mathrm{~mm}$ in 5 days. Nine months later rainfalls were much less significant, with $230 \mathrm{~mm}$ in 18 days and $137 \mathrm{~mm}$ in 5 days. However, on 7 November 1988 an important landslide occurred in the residual soils from gneiss at Cabrito's Hill (De Campos et al., 1997). According to Lacerda (1998, personal communication), the Cabrito's Hill landslide is an illustration of the consequence of creep-fatigue phenomena, as he indicated in 1989.

It can be added that many environments have landslides every year, even if every year is obviously not exceptional in hydrologic terms, and creep-fatigue phenomena could be a possible explanation for failures. In fact, fatigue is a wellaccepted phenomenon in mechanical engineering, and even in rock mechanics. So, if we accept that most natural soils are microstructured we have to accept at the same time that natural slopes and cuts can be affected by creep-fatigue phenomena, and possibly 'fail when they are ripe for failure'.

\section{Failures associated with a loss of suction}

Brand (1981) emphasised that the stress paths followed in a natural slope subjected to infiltration are different from the stress paths followed in conventional triaxial tests. The shear and deviatoric stresses are essentially constant with a possible small increase during infiltration as the unit weight of the soil increases.

Neglecting strain rate effects and progressive failure, the behaviour of the soil in terms of stress path and strength can be summarised as shown in Fig. 66. It shows the shear stress, $\tau$, versus the total net normal stress, $\left(\sigma_{\mathrm{n}}-u_{\mathrm{a}}\right)=\sigma_{\mathrm{n}}$ (assuming the air pressure is at atmospheric pressure), when the soil is unsaturated and pore water pressure negative; when the soil is essentially saturated and the pore water pressure is larger or equal to the atmospheric pressure, $\tau$ is considered against the effective normal stress $\sigma_{\mathrm{n}}^{\prime}=\left(\sigma_{\mathrm{n}}-u_{\mathrm{w}}\right)$.

Let us consider a soil element in an unsaturated natural slope, with a negative pore pressure $u_{\mathrm{w}}=-S_{\mathrm{a}}$, and represented by point 0 in Fig. 66. The mobilised shear stress is $\tau_{\mathrm{m} 0}$ and the strength, a function of the suction $S_{\mathrm{a}}$, is equal to $\tau_{\mathrm{f} 0}$. With infiltration, the suction progressively decreases and the stress and strength conditions move towards points 1 in Fig. 66 . Owing to the slight increase in unit weight of the soil, the mobilised shear stress increases to $\tau_{\mathrm{m}}$ and the available strength decreases to $\tau_{\mathrm{fl}}$. When the soil becomes close to $100 \%$ saturation at point 1 , its strength becomes controlled by effective stresses. As pore water pressure increases in the positive range, the normal effective stress decreases from point (1) towards F, and failure is reached at this latter point when the effective stress path reaches the strength envelope of the saturated soil $\left(S=S_{\mathrm{c}}=0\right)$. All this process, from 0 to $\mathrm{F}$, is drained: that is, the soil adapts to the new conditions by changing its water content and void ratio.

To understand and analyse the stability of unsaturated slopes it is thus essential to know the variation of shear strength with suction (e.g. Fredlund \& Rahardjo, 1993) and matric suction in slopes. Measurement of this latter parameter is increasingly performed (Pitts \& Cy, 1987; Fredlund, 1989; Öberg, 1995; Lim et al., 1996; Bressani, 1997). Fig. 67(a) shows an example of a cut in Hong Kong that has been studied by Sweeney (1982) and Fredlund \& Rahardjo (1993). The slope, localised in weathered granite, has been protected from surface infiltration by a layer

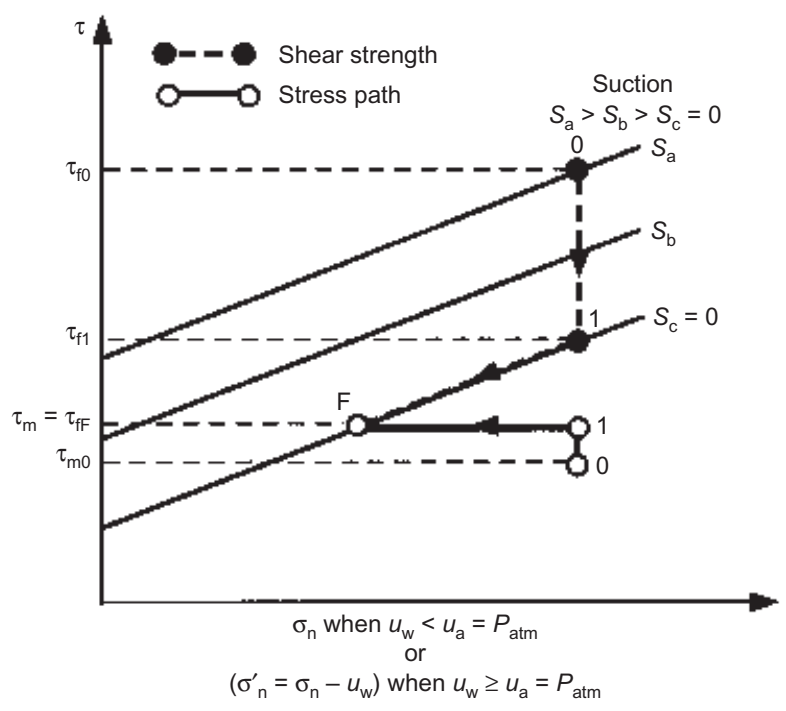

Fig. 66. Variation of shear stress and shear strength when suction deceases $(0-1)$ and when pore water pressure increases from zero to its value at failure $(1-F)$ in an initially unsaturated slope subjected to infiltration 


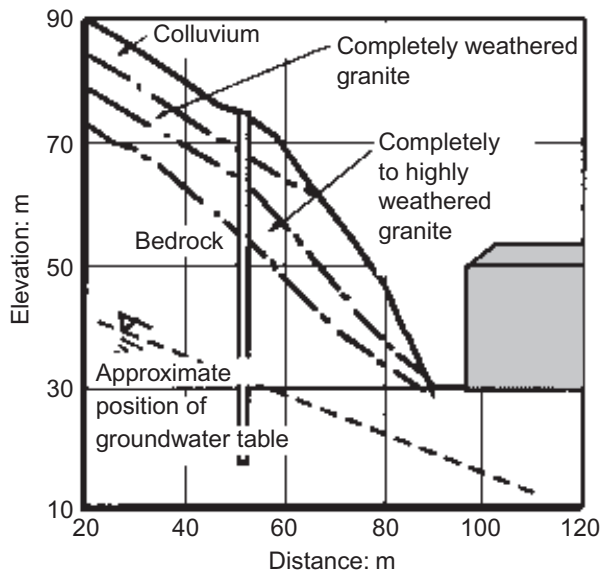

(a)

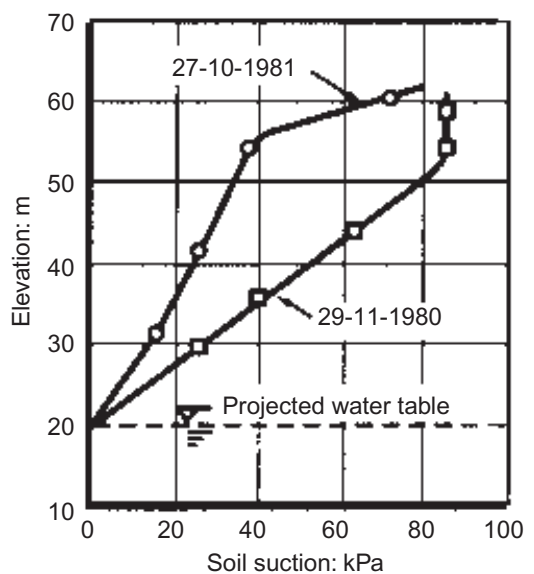

(b)

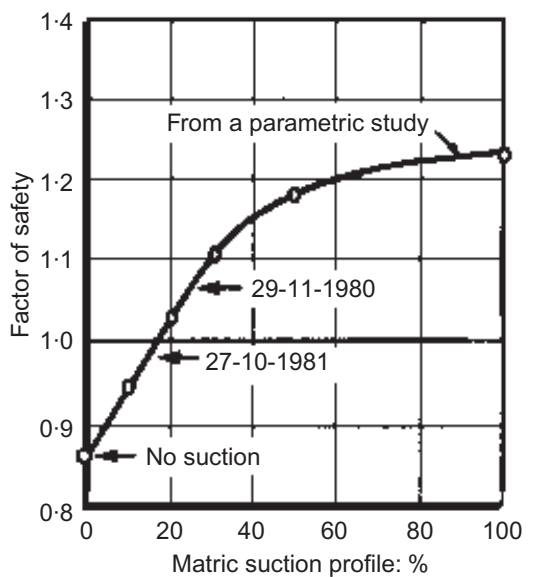

(c)

Fig. 67. Slope in unsaturated weathered granite in Hong Kong: (a) section; (b) measured suction; (c) calculated factors a safety (after Fredlund \& Rahardjo, 1993)

of soil-cement and lime plaster, and has been subjected to small failures at the crest. Fig. 67(b) shows matric suction profiles defined at two different dates, and Fig. 67(c) shows the variation of the factor of safety calculated on the basis of equation (2) with a $\phi^{\mathrm{b}}$ angle of $15^{\circ}$. The factors of safety calculated on the basis of the measured matric suctions are very close to $1 \cdot 0$, and that corresponding to zero suction is equal to 0.86 (Fig. 67(c)). These values are in agreement with the observations of precarious stability, and confirm the need to maintain protection against infiltrations.

\section{Collapse and failure of slopes in loess}

A particular case of unsaturated soil is loess, which is often collapsible under saturation. Movements in these materials can be examined with the concepts of limit state, which have been shown to apply on these types of material (Vaunat et al., 1994; Maâtouk et al., 1995; Leroueil et al., 1996). Unsaturated loess can be characterised by the limit state curve drawn with a full line in Fig. 68, which reflects bonding between particles (Feda et al., 1993; Dijkstra et al., 1994), and the matric suction existing in natural conditions; in saturated conditions, the limit state curve could be as represented by the dashed line. If stress conditions representative of a slope are at a point such as $I_{1}$, above the strength envelope of the saturated soil, a decrease in suction by wetting will result in a shrinking of the limit state curve and in failure similar to those observed in other soils when the lowering limit state curve will reach $I_{1}$. This is illustrated by case (a) in Fig. 69. If stress conditions representative of a slope are at a point such as $I_{2}$, below the strength envelope of the saturated soil, a decrease in suction may result

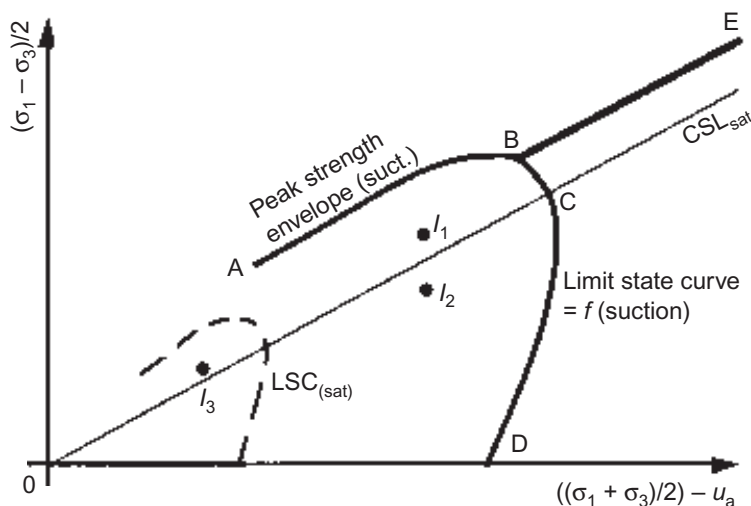

Fig. 68. Schematic stress conditions and effects of suction in slopes in loess (after Leroueil et al., 1996)

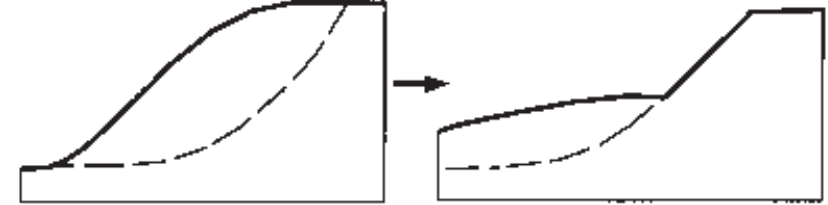

(a)

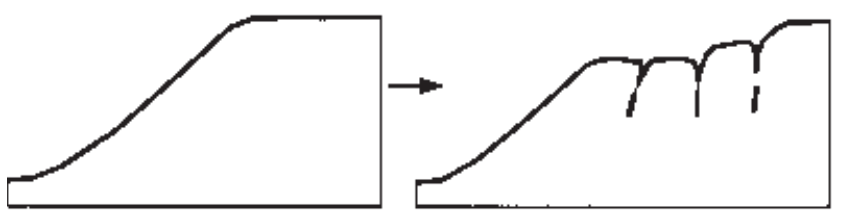

(b)

Fig. 69. Types of collapse in loess, depending on average stress conditions

in important deformations and settlements when the shrinking limit state curve will reach $\mathrm{I}_{2}$, but not in a generalised failure. This is illustrated by case (b) in Fig. 69. Finally, if stresses representative of a slope are inside the limit state curve of the saturated material, as point $\mathrm{I}_{3}$, a decrease in suction will not produce any significant movement. Lin (1994) presents a similar approach when he compares the vertical yield stress (preconsolidation pressure) obtained on the saturated loess with the vertical stress applied on the soil at the considered depth.

Table 1 indicates the Dong Xiang landslide (also called the Sale Shan landslide), which occurred in 1983 in China and killed more than 200 people. About 50 million $\mathrm{m}^{3}$ of loess were involved, and the disintegrated material covered a distance of $1.6 \mathrm{~km}$ in approximately $55 \mathrm{~s}$ (Cao et al., 1997; Dijkstra, 2000).

More recently, in 1993, close to the Sale Shan landslide, another landslide, the Bafeng Shan landslide, occurred. It was triggered by heavy rainfalls and a basal saturation of the loess. There were at first essentially vertical displacements and then slow sliding of the loess mass which travelled a distance of about $50 \mathrm{~m}$ over a three-day period (Dijkstra, 1999, personal communication). It is probable that the stress conditions in this case were between $I_{1}$ and $I_{2}$ in Fig. 68, and very close to the critical state line of the saturated material.

\section{Particular case of excavations in clay}

In relation to excavations in clay, the geotechnical engineer may have to answer the following questions: What is the shortterm factor of safety? What is the long-term factor of safety? How does the factor of safety vary with time and, in particular, how long can one rely on the short-term factor of safety? 
Short-term factor of safety. As the behaviour of the clay mass around an excavation is controlled by effective stresses, the stability of such an excavation is directly related to the pore pressures, and should be evaluated in effective stress. However, owing to the difficulty of predicting the changes in pore pressures associated with excavation, the short-term factor of safety is generally evaluated in $\phi=0$ stability analyses. Leroueil et al. (1990) compiled data on cut failures that had occurred during excavation or shortly after the end of excavation, and plotted the factor of safety calculated on the basis of the undrained shear strength measured with the field vane test, uncorrected, or in undrained triaxial tests, $\left(F_{\mathrm{ST}}(\phi=0)\right)$, as a function of the plasticity index (Fig. 70). Bjerrum (1973) did the same for soft clays on the basis of the data available at that time and found the same relationship of $F_{\mathrm{ST}}(\phi=0)$ with $I_{\mathrm{p}}$ as for embankments (dashed line in Fig. 70). This similarity of the relationships established for embankments and excavations was not anticipated by Bjerrum, who wrote that he 'had expected, that due to anisotropy of the soft clay, the correlation between safety factors and plasticity index would deviate considerably from that established from failures of embankments.' This relationship established by Bjemum (1973) for excavations was strongly influenced by the Seven Sisters Falls case at a plasticity index of 70, and for which, according to Peterson et al. (1960), a factor of safety of 1.58 is a minimum value. In fact, the liquidity index on that site is of $0 \cdot 17$, and the clay could not be reported as soft.

The data reported in Fig. 70 are divided in two groups: clays for which the liquidity index is larger than $0 \cdot 4$, and those for which the liquidity index is smaller than $0 \cdot 2$. As often reported in the past, and in particular by Skempton \& La Rochelle (1965) and Chandler (1984), in stiff clays (clays having liquidity indices smaller than 0.2 and often fissured) the undrained shear strength of the clay, as measured in undrained triaxial tests, strongly overestimates the shear strength back-analysed from short-term failures. As indicated by the figure, the overestimation is by a factor of about 2 .

Considering the clays with liquidity indices greater than $0 \cdot 4$, and with the exception of the cases of La Bosse-Galin and of Bang Bo, which will be discussed later on, the factors of safety are reasonably close to $1 \cdot 0$.

The La Bosse-Galin, France, test excavation is reported by Blondeau \& Queyroi (1976). It is a $4 \mathrm{~m}$ deep excavation that was carried out over a three-week period in a soft plastic and

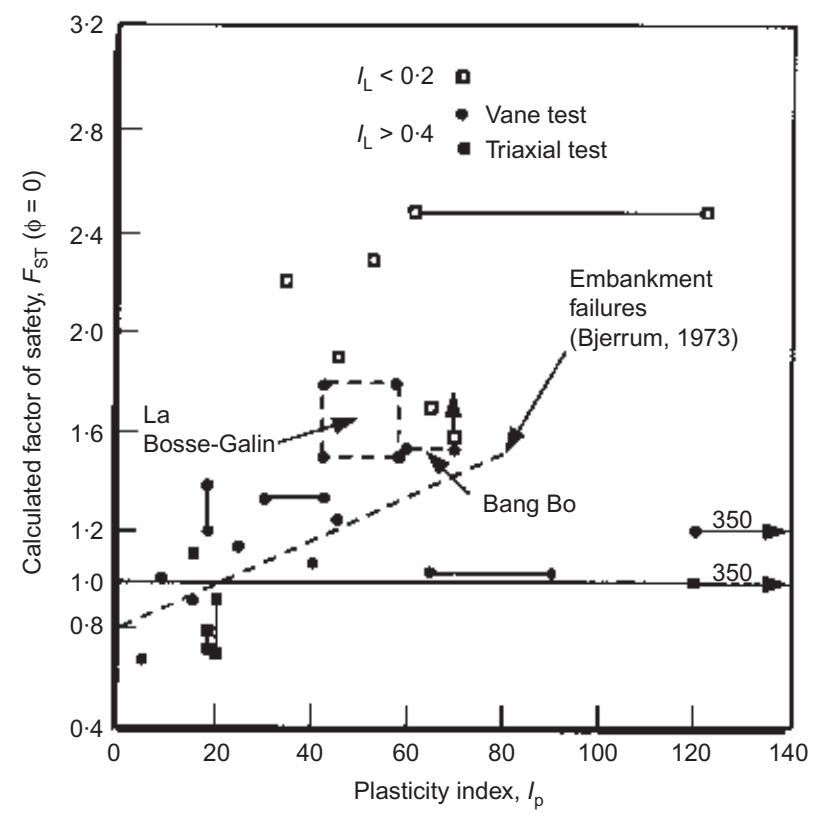

Fig. 70. Factors of safety obtained by total stress analysis of shortterm failures plotted against plasticity index (after Leroueil et al., 1990) organic clay layer, about $10 \mathrm{~m}$ thick. The factor of safety at failure calculated on the basis of the uncorrected vane shear strength varies between 1.45 and 1.85 , which is much higher than those calculated for other non-fissured clays. However, piezometric data indicated that pore pressure equilibration was reached as the excavation was progressing. The failure is thus a long-term failure in an overconsolidated non-fissured clay, and it is not surprising that under these conditions failure occurred with a calculated short-term factor of safety equal to about $1 \cdot 65$.

The Bang Bo test excavation in Bangkok clay is reported by Phien-Wej \& Chavalitjiraphan (1991), and complementary information was obtained from Phien-Wej (1992, personal communication). This excavation was performed in Bangkok clay $(\mathrm{OCR}=1.35-1.4)$, about $80 \mathrm{~km}$ south-east of Bangkok, Thailand. It was a $4 \mathrm{~m}$ deep excavation with four sides among which one was non-treated and in undisturbed clay. The slope was initially $4: 1$, but failure was reached only when it was trimmed to a 3:1 slope. The work was realised over a two-month period. The authors reported factors of safety based on corrected vane strengths of 0.91 but, according to Phien-Wej (1992, personal communication), the factor of safety based on the uncorrected vane strength was $1.54(0.91: 0.59)$, and thus much larger than $1 \cdot 0$. The question to be resolved is whether this high $F$ value is due to the high plasticity of the clay $(60-70)$ or to partial drainage during the two months of excavation, as in the La Bosse-Galin test excavation, or to a combination of both.

Results from another excavation, also carried out in Bangkok clay, can possibly be used to get some indication (Phien-Wej 1993, personal communication). This latter excavation had a final depth of $4 \mathrm{~m}$ reached in 31 days; 54 days later, during heavy rain, a local failure occurred and cracks were observed, indicating that the stability (then long term) was precarious. The factor of safety calculated on the basis of uncorrected vane shear strength was also on the order of $1 \cdot 6$. Pore pressures in the clay mass were measured during excavation and after. They show an equalibration within the 10 days following the end of construction, indicating that the equilibration process was very probably significant during excavation. It can thus be thought that the Bang Bo cut was not in undrained conditions when failure occurred two months after the beginning of excavation. As for the Bosse-Galin case, the calculated factor of safety at failure must then very probably be associated with a long-term failure and not a short-term one.

If the two cases of La Bosse Galin and Bang Bo, which do not correspond to short-term conditions, are ignored, it seems that the short-term factor of safety for clays with liquidity index larger than 0.4 can be estimated on the basis of the vane shear strength without applying any correction factor. This is shown in Fig. 71, which gives $F_{\mathrm{ST}}(\phi=0)$ as a function of the liquidity index. The figure also shows that clays characterised by a low liquidity index and often fissured give much higher calculated short-term factors of safety at failure.

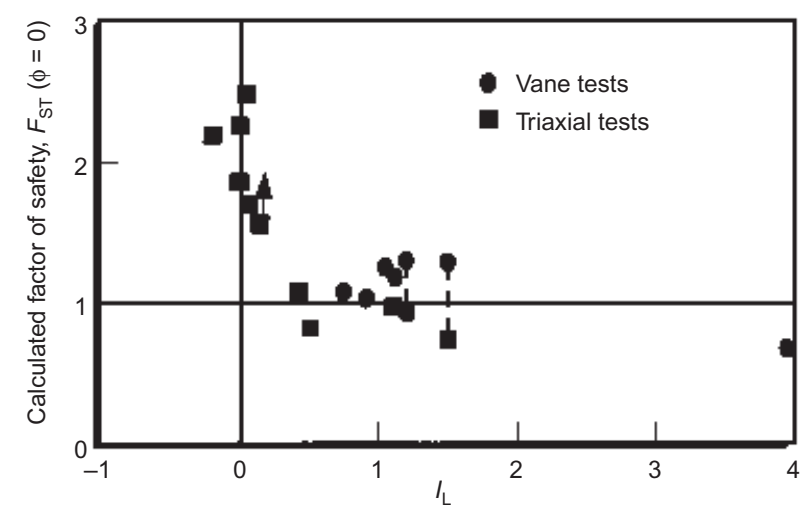

Fig. 71. Factors of safety obtained by total stress analysis of shortterm failures plotted against liquidity index 
Long-term factor of safety. The long-term stability of excavations is usually estimated by effective stress analysis, as for any first-time failure of a natural slope.

Variation of the factor of safety with time. As previously indicated, the time for pore pressure equibration varies considerably from case to case. There is, however, little information on the evolution of the factor of safety with time. Kenney \& Uddin (1974) have presented such an evolution for the Kimola canal excavation. Fig. 72 shows the variation of $F$ with time for the $27^{\circ}$ slope of the Saint-Hilaire excavation (Fig. 36) on the basis of calculated pore pressures, which, as shown in Fig. 37, are in good agreement with measured ones, and strength parameters backcalculated from failures of the $34^{\circ}$ and $45^{\circ}$ slopes by Lafleur et al. (1988b). Fig. 73 shows the variation of $F$ for excavation in the Brown London Clay deduced from Fig. 34. It can be seen that in both the latter cases about $50 \%$ of the difference between the short- and long-term factors of safety is lost in about $20 \%$ of the

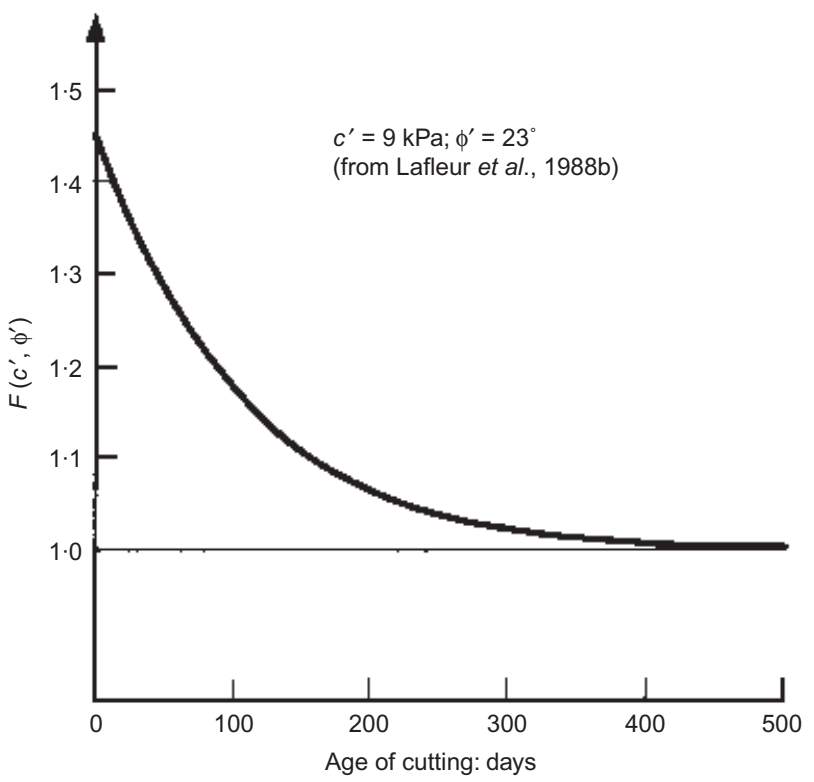

Fig. 72. Variation of the factor of safety with time for the $27^{\circ}$ slope at Saint-Hilaire (after Laflamme et al., 2001)

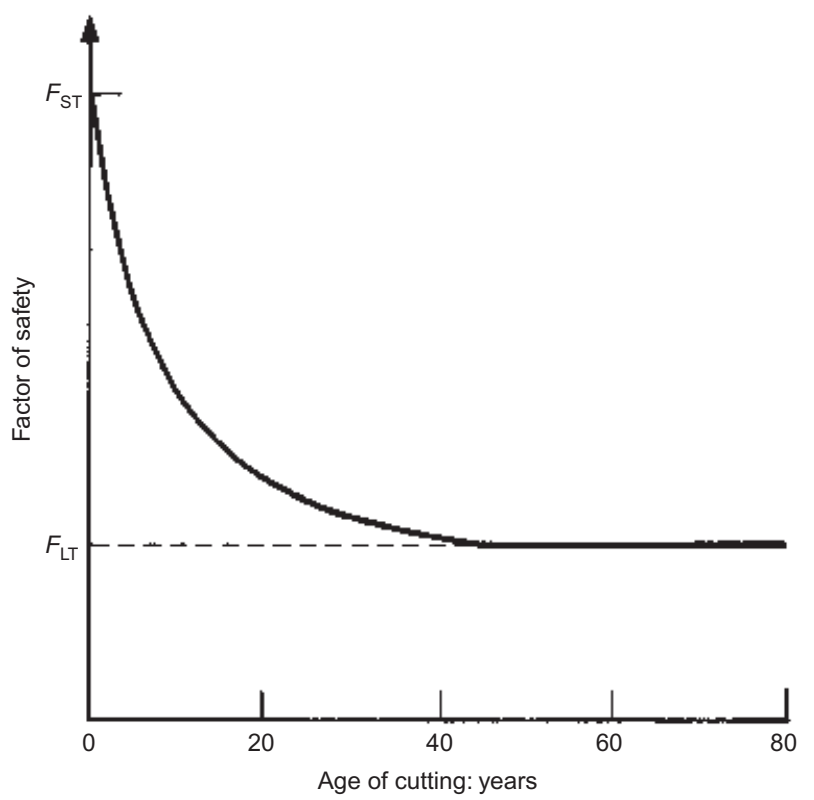

Fig. 73. Variation of the factor of safety with time for slopes excavated in Brown London Clay (deduced from Fig. 34) time required to reach complete pore pressure equilibrium. So the time for which one can rely on the short-term factor of safety can be very short, especially in soft clays.

In addition to the time for which one can rely on the shortterm factor of safety, it is important to have an idea of the difference between the short-term and long-term factors of safety. An observation made by Leroueil et al. (1983) can help in getting an approximate value of such a difference. These authors, and then Tavenas (1984), analysed first-time failures of eastern Canada natural slopes in total stress analysis based on the vane shear strength. They found that for such failures, for which the long-term factor of safety was obviously $1 \cdot 0$, the factor of safety calculated on the basis of the field vane shear strength correlates well with the average overconsolidation ratio (OCR) of the clay:

$$
F(\phi=0)=0.9 \text { OCR }
$$

It is worth noting that, with a different data set, Peck \& Lowe (1960) found for long-term failures in cuts and natural slopes an increase of the factor of safety caculated in total stress analysis as the liquidity index of the clay decreases. As in general the overconsolidation ratio increases as the liquidity index decreases, both series of results indicate the same tendency.

As previously discussed, Fig. 71 indicates that total stress analyses seem appropriate for evaluating the short-term factor of safety of excavations in soft clays. On this basis, the factor of safety given in equation (10) would be the short-term factor of safety of excavations having the same characteristics as the natural slopes that failed and for which the long-term factor of safety was $1 \cdot 0$. The difference between the short- and long-term factors of safety $\left(F_{\mathrm{ST}}-F_{\mathrm{LT}}\right)$ in eastern Canada clays thus seems to be approximately equal to $(0.9 \mathrm{OCR}-1)$. This is shown in Fig. 74, and is explained as follows. In excavations, there is a decrease in pore pressure associated with the reduction in mean stress (equation (5)). In strongly overconsolidated clays, $\alpha$ is negative and shear stresses generate additional negative pore pressures in such a way that the difference in pore pressure between the end of excavation and steady-state conditions is important, and so is the variation in the factor of safety. On the other hand, in nearly normally consolidated clays, $\alpha$ is positive and shear stresses generate positive pore pressures, compensating to some extent for the negative pore pressures due to the reduction in mean stress. The change in pore pressure and, consequently, the change in factor of safety after the end of excavation are then small.

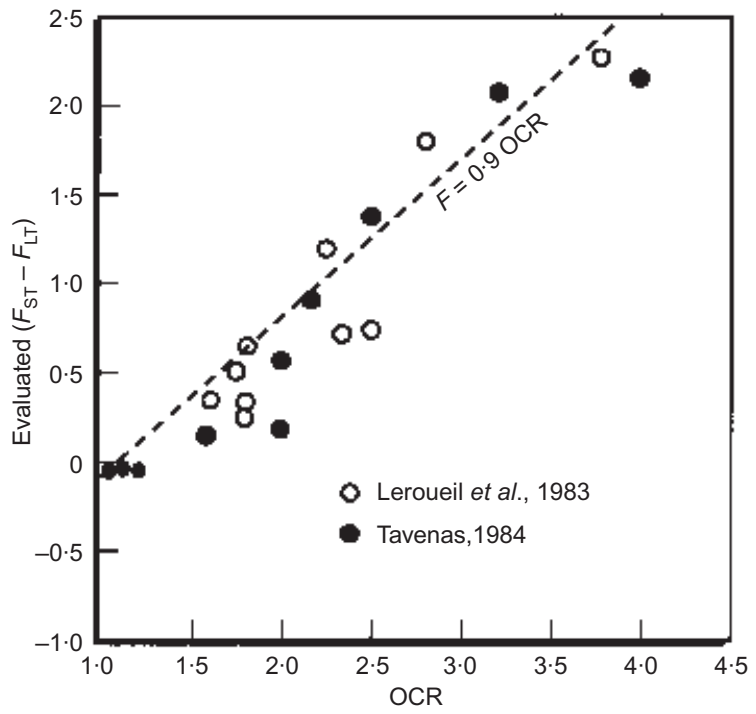

Fig. 74. Evaluated difference between the short-term and long-term factors of safety for slopes in eastern Canada clays plotted against the overconsolidation ratio of the clay 


\section{POST-FAILURE}

Post-failure refers to the stage from the onset of failure until the mass of soil involved essentially stops moving.

Post-failure as an energy redistribution process

At the time of failure, some potential energy $\left(E_{\mathrm{P}}\right)$ becomes available, and what happens then depends on how this energy is redistributed. Part of the potential energy will dissipate into friction $\left(E_{\mathrm{F}}\right)$; the rest will be dissipated in breaking up, disaggregating and remoulding the soil $\left(E_{\mathrm{D}}\right)$, and for generating movement (kinetic energy, $E_{\mathrm{K}}$ ). Over a time interval during the post-failure stage:

$$
\Delta E_{\mathrm{P}}+\Delta E_{\mathrm{F}}+\Delta E_{\mathrm{D}}+\Delta E_{\mathrm{K}}=0
$$

Such a description of post-failure movements from an energy perspective was made by Vaunat et al. (1994) and D'Elia et al. (1998), but similar considerations were also made by Bishop (1967) and Eigenbrod (1972). Several relevant aspects will be examined in the following sections.

\section{Disaggregating or remoulding energy}

The disaggregating or remoulding energy $\left(E_{\mathrm{D}}\right)$ may play an important role at the post-failure stage in microstructured materials, but is poorly documented in the literature. There are, however, geomaterials for which there are some indications (Leroueil et al., 1996).

Sensitive Canadian clays. Tavenas et al. (1983) conducted a laboratory study of the energy necessary to remould eastern Canada sensitive clays. Their data show that this energy generally increases with the plasticity index, $I_{\mathrm{p}}$, and the undrained shear strength, $c_{\mathrm{u}}$, of the intact soil. As indicated in Fig. 75, an energy per unit volume equal to approximately $12 \cdot 5 c_{\mathrm{u}} I_{\mathrm{p}}$ is necessary to obtain a remoulding index, $I_{\mathrm{r}}$, of $75 \%$.

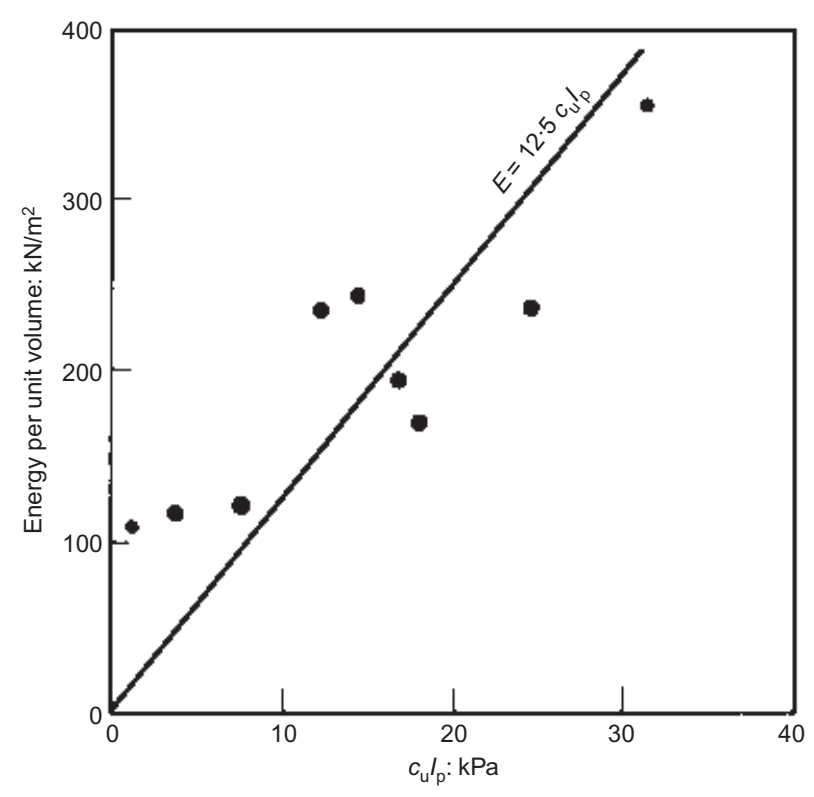

Fig. 75. Energy per unit volume necessary for reaching a remoulding index equal to $75 \%$ in eastern Canada clays (after Tavenas et al., 1983; from Leroueil et al., 1996)

"The remoulding index, $I_{\mathrm{r}}=100\left(c_{\mathrm{u} \text { intact }}-c_{\mathrm{u}}\right) /\left(c_{\mathrm{u} \text { intact }}-c_{\mathrm{ur}}\right)$, in which $c_{\mathrm{u}}$ is the undrained shear strength of the clay, and $c_{\mathrm{u}}$ intact and $c_{\mathrm{ur}}$ are the undrained shear strengths of the clay when intact and remoulded respectively.
This energy is thus proportional to the undrained shear strength of the intact clay, which seems logical, and to the plasticity index, which is consistent with the fact that the energy necessary to remould a cohesionless soil is extremely small.

Chalk. Observations reported by Hutchinson (1988, 1999) give an idea of the energy necessary to disintegrate chalk from the coastal cliffs of Kent, UK. As indicated in Fig. 76, for heights of cliffs smaller than about $60 \mathrm{~m}$, collapses produce 'normal talus' with a width, $L$, equal to about $70 \%$ of the height, $H$, of the cliff. For higher cliffs, there is what Hutchinson calls an 'impactcollapse flow slide', with the disintegrated debris running over large distances, up to six times the height of the cliff. For this chalk with a porosity of $42-47 \%$, the potential energy corresponding to a height of about $60 \mathrm{~m}$ (that is, an energy per unit volume of $600 \mathrm{kNm} / \mathrm{m}^{3}$ or slightly less) appears to be necessary for its disintegration. Only larger heights and energies can generate important displacements of the material.

Data from other parts of the UK, Denmark, France and Germany presented by Hutchinson (1999) suggest that hardness and porosity are major factors controlling the disaggregating energy of chalks, this latter generally increasing as porosity decreases. There are, however, factors other than porosity, such as degree of saturation, nature of cementation, jointing and fissuring, cliff profile, and volume of the failing mass (Hutchinson, 1999), that can influence the development of a chalk flow. In particular, at Saint-Aubin-sur-Mer, France, flow slides were observed for heights of $34-40 \mathrm{~m}$ in chalk with a porosity in the range 40-47\% (Evrard \& Sinelle, 1981; Hutchinson, 1999).

To understand post-failure movements better, it will be necessary to get more information on disaggregating or remoulding energy, and to incorporate this component in the numerical modelling of post-failure slope movements.

\section{Frictional energy}

The proportion of the energy dissipated in friction depends on the brittleness of the material, but again defined for the stress path followed in in situ conditions, up to failure and after. The importance of this aspect has been evidenced by work by Anderson \& Riemer (1995), Anderson \& Sitar (1995) and Santos et al. (1996) in relation to slides induced by pore pressure increase. Indeed, most laboratory tests are performed in compression or in extension, whereas in situ behaviour corresponds to a decrease in effective mean stress under an approximately constant shear stress. This was mentioned by Brand (1981), but soil behaviour under this latter stress path has been seldom examined (Brenner et al., 1985; Bressani \& Vaughan, 1989). Anderson \& Riemer (1995) performed constant-sheardrained (CSD) triaxial tests at constant deviatoric stress and decreasing mean effective stress. Two very loose soils were studied: a fine, uniformly graded, Monterey \#0 sand, and a clayey colluvial soil from Briones Park, near San Francisco. Fig. 77 shows the CSD test results in $e-\log p^{\prime}$ diagrams. For Monterey \#0 sand (Fig. 77(a)), specimens S1, S2 and S4 consolidated at void ratios above the steady- (or critical) state line showed collapse, with an important decrease in void ratio; tests S3 and S5, closer to the steady-state line, showed little if any contractive behaviour. Dilatant behaviour was exhibited by all the colluvium specimens (Fig. 77(b)), even if they were all (except one) consolidated at void ratios above the steady-state line. This latter behaviour could be considered surprising, since the same soil showed a contractant behaviour in anisotropically consolidated undrained compression (CAU) tests, with an ultimate deviatoric stress generally smaller than the initial deviatoric stress (Anderson \& Sitar, 1995). A similar behaviour was observed by Santos et al. (1996) on a residual soil from Soberbo Road, Rio de Janeiro, questioning the relevance of CAU tests for evaluating contractancy-dilatancy behaviour after failure.

The behaviour shown in Fig. 77 can be explained as follows (see schematic in Fig. 78). If initial stress conditions are at 

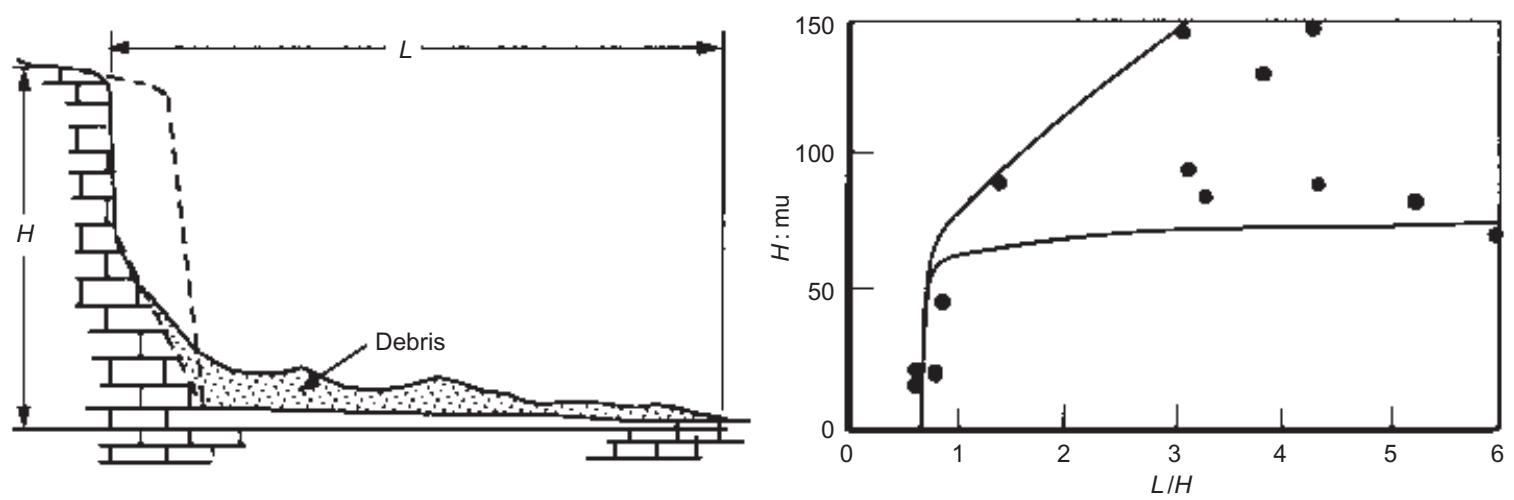

Fig. 76. Morphology of debris after a slide in chalk (after Hutchinson, 1988, 1999)

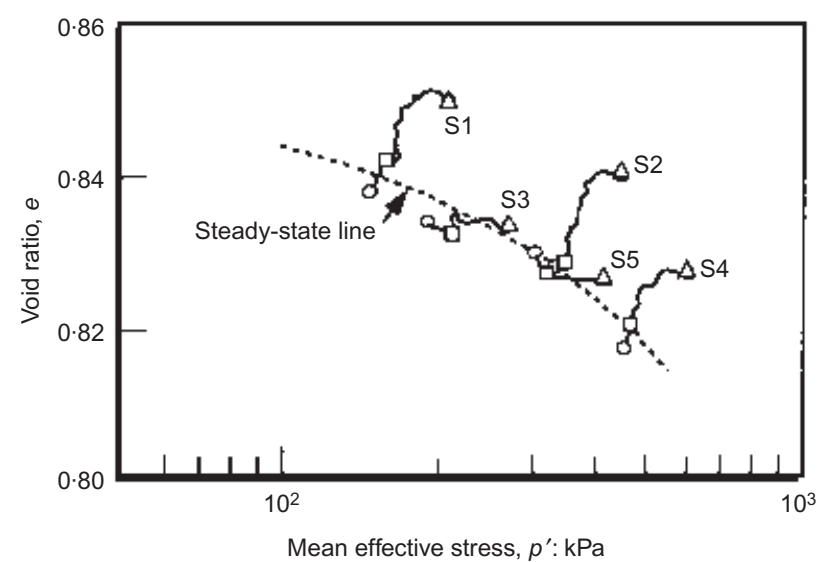

(a)

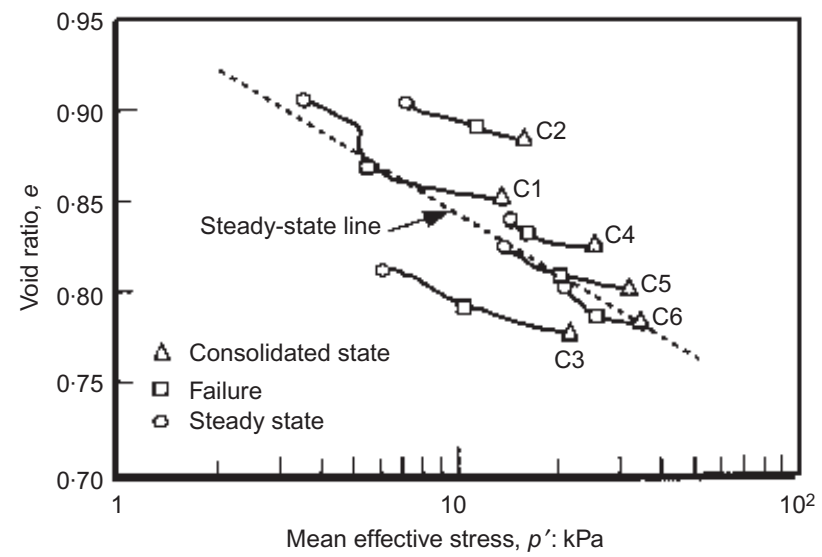

(b)

Fig. 77. State paths in CSD tests: (a) Monterey \#0 sand; (b) colluvial soil from Briones Park (from Anderson \& Riemer, 1995)

point I, in Figs 78(a) and (b), and if the mean effective stress is decreased, there is first some volume change of the soil, generally swelling, and yielding or failure is reached at a point such as Y. This latter point can be on the steady-state or critical-state line (CSL), as shown in Fig. 78(a), or above in structured soils, or below, on the collapse surface, as observed in loose sands (Sladen et al., 1985; Konrad, 1993; Lade, 1993; Sasitharan et al., 1993). If initial conditions are at point $\mathrm{I}_{1}$, well above the CSL, the soil at yielding, $\mathrm{Y}_{1}$, is above the CSL (Fig. 78(b)); for undrained post-failure conditions, the ultimate

Note that the effect of an increase in pore pressure can be different in collapsible unsaturated soils, as indicated in the section on 'Failure in collapsible unsaturated soils'.

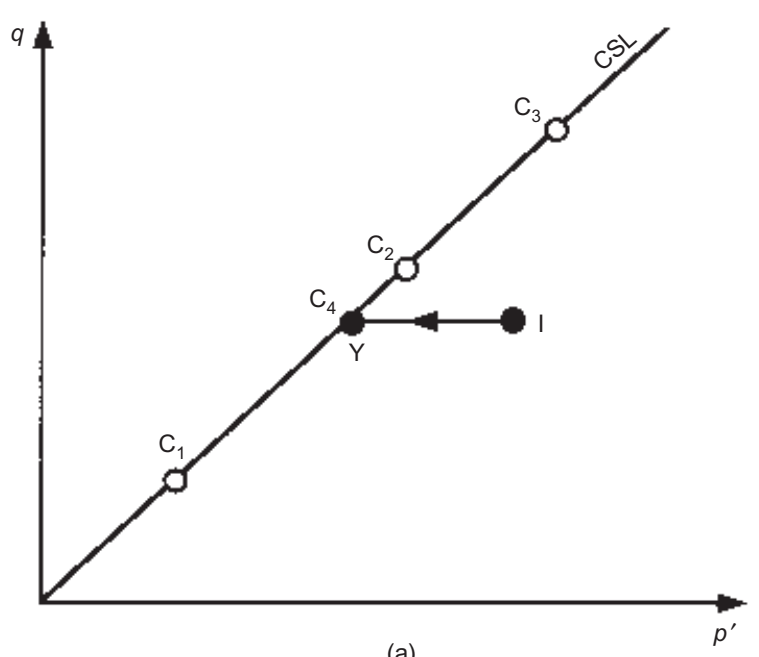

(a)

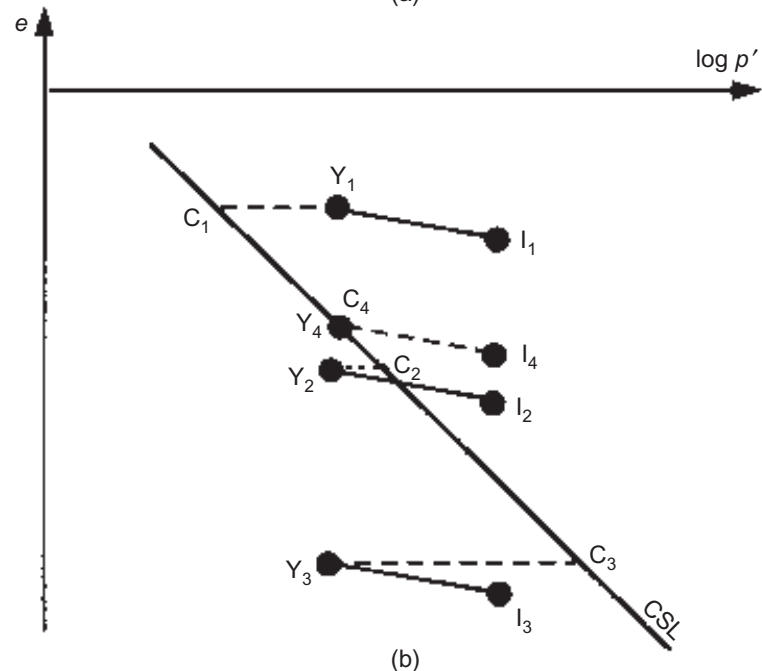

(b)

Fig. 78. State paths followed in CSD tests (schematic). In (a), Y could be above, on or below the critical-state line, depending on the soil considered

strength, at $\mathrm{C}_{1}$, is smaller than the initially applied shear stress, and failure is followed by an undrained collapse and flow of the soil mass. Such a situation corresponds to Monterey \#0 sand conditions (Fig. 77(a)). If initial conditions are at point $I_{3}$, below the CSL, yielding will appear at $\mathrm{Y}_{3}$ (Fig. 78(b)). The ultimate state in undrained conditions, $\mathrm{C}_{3}$, then corresponds to a strength larger than the shear stress at failure and is thus stabilising. For the intermediate case with initial stress conditions, $\mathrm{I}_{2}$, above the CSL and yielding, $\mathrm{Y}_{2}$, below (Fig. 78(b)), the soil would be dilatant at failure with a tendency to swell to $\mathrm{C}_{4}$. This seems to correspond to observations made by 
Anderson \& Riemer (1995) on colluvial soil (Fig. 77(b)) and by Santos et al. (1996) on Soberbo Road residual soil. Finally, we can imagine initial stress conditions such as $\mathrm{I}_{4}$ leading to yielding at point $\mathrm{Y}_{4}$, identical to $\mathrm{C}_{4}$, on the $\mathrm{CSL}$; in this case, the soil would not have a tendency to change its void ratio after reaching failure.

In terms of generalised brittleness index, $I_{\mathrm{GB}}$ (Fig. 79(a)), undrained behaviour following yielding at point $\mathrm{Y}$ could be dilatant, contractant or perfectly ductile, depending on the state path, which can be $\mathrm{Y}_{3} \mathrm{C}_{3}, \mathrm{Y}_{1} \mathrm{C}_{1}$ or $\mathrm{Y}_{4} \mathrm{C}_{4}$ respectively (Fig. 78(b)).

\section{Kinetic energy and post-failure rate of movement}

As indicated in equation (11), the kinetic energy and the post-failure rates of movement result from the part of the potential energy that is not dissipated into friction and disaggregation of the geomaterial. In ductile materials $\left(I_{\mathrm{GB}}\right.$ close to 0$)$, most of the available potential energy is dissipated into friction and kinetic energy, and rates of movement are small. If the material shows a loss of shear strength (increasing $I_{\mathrm{GB}}$ with strain or displacement), the driving forces become unbalanced and there is acceleration of the soil mass. Therefore high rates as well as long runout distances can be reached. A parameter of particular importance in the case where flow slide may develop is thus the value of the ultimate strength obtained at large strains or displacements. This ultimate strength can be the residual strength in stiff plastic clays, the remoulded strength for clays in undrained conditions, or the steady-state strength in cohesionless soils.

An example of the implications of the stress-strain behaviour of soils for post-failure movements is well illustrated by the two landslides that occurred in the Santa-Barbara mine, Italy, namely the Allori and Bomba landslides. Detailed information on these slides, and in particular on the movements observed before and after failure, has been reported by D'Elia, Esu and co-workers in the literature, and is summarised by D'Elia et al. (1998). The Allori landslide occurred in the ductile 'Argille

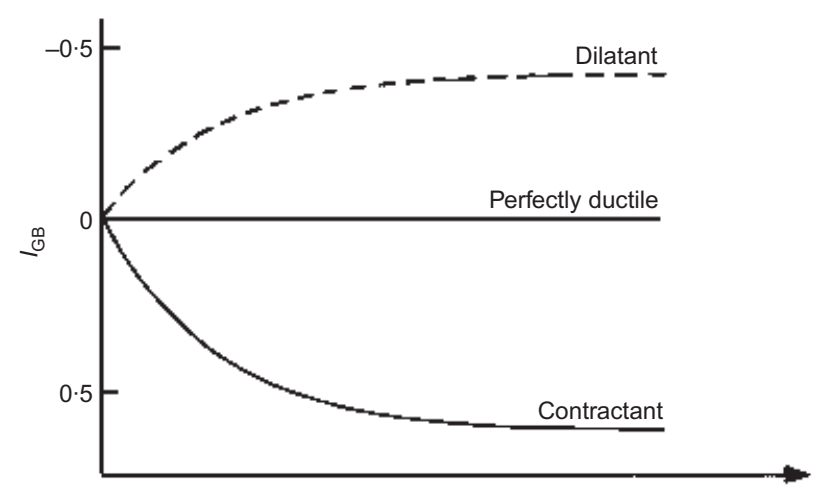

(a)

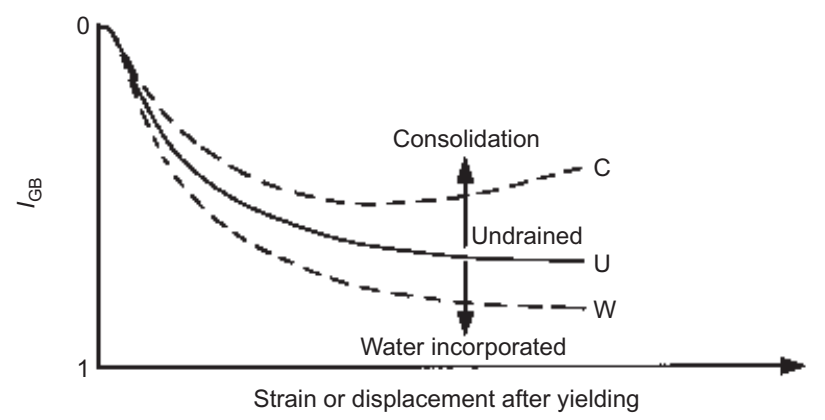

(b)

Fig. 79. Variation of $I_{\mathrm{GB}}$ with strain or displacement for different conditions: (a) in undrained conditions; (b) with possible consolidation or incorporation of water in the moving material
Scagliose' and showed post-failure movements that were moderate and not much faster than the ones observed before the slide (dashed line in Fig. 80). By contrast, the Bomba landslide, which occurred in a very brittle, stiff-jointed clay, showed very rapid post-failure movements, with rates almost three orders of magnitude larger than those observed before failure (full line in Fig. 80).

Another implication is the possible development of flow-like movements, an aspect that is examined in the following section.

\section{Movements of flow-like form}

Failure is initiated by a drained process (I to $\mathrm{Y}$ in Fig. 78(a)), but a debris flow develops only if the ultimate strength corresponding to point $\mathrm{C}$ in Figs 78(a) and (b) is less than or equal to the driving shear stress. This was explained and discussed by Lee et al. (1988), who suggested evaluating the potential for debris flow by considering the position of initial void ratio-effective stress conditions (I in Fig. 78(b)) relative to the CSL of the soil. From field observations and laboratory tests performed in relation to sites prone to debris flow development, they found an association between initial states lying above the critical-state line and debris flow occurrence, whereas initial states near or below the critical-state line corresponded to the occurrence of slow-moving, non-disintegrative failures. Considering what has been said previously, it seems more appropriate to consider state conditions at yielding rather than initial stress conditions for evaluating the possibility of debris flows.

If the soil is contractant in undrained conditions (with variation of $I_{\mathrm{GB}}$ such as YU in Fig. 79(b)), collapse may be very sudden, as observed by Eckersley (1990), who triggered flowslides in instrumented coking coal stockpiles $1.0 \mathrm{~m}$ high by slowly increasing pore pressures. Eckersley (1990) also observed increases in pore pressure during flowsliding.

When soils are dilatant after reaching yielding (points $\mathrm{Y}_{2}$ or $\mathrm{Y}_{3}$ in Fig. 78(b)), the strength has a tendency to increase with strains, and the movement should stop at that point. However, if water is easily available, the water content of the soil may increase and the large strain strength may decrease along the critical state line, up to $\mathrm{C}_{4}$ in Figs $78(\mathrm{a})$ and (b). The possibility of dilatant behaviour of soil masses prior to some post-failure movements is supported by some observations:

(a) Casagrande (1975) indicates that prior to liquefaction and flow of large masses of rather dense granular talus in the Alps, brooks emerging from the toe of the talus deposits stop flowing.

(b) Fleming et al. (1989) report observations of time lags

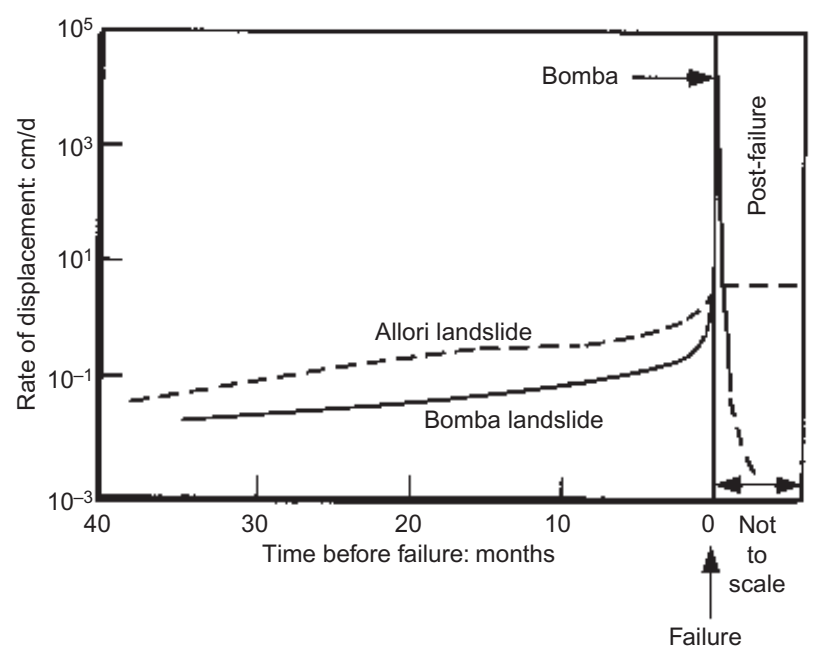

Fig. 80. Rates of movements of Bomba and Allori landslides (after D'Elia et al., 1998) 
between the beginning of landslide movements and the initiation of debris flows.

(c) In three slides that Harp et al. (1990) triggered by artificial subsurface irrigation, they observed abrupt decreases in the pore pressure 5-50 minutes before failure.

It appears from these observations that decrease in pore pressure could be a precursory sign of debris flow in some slopes prone to this kind of movement.

Consideration of the critical-state approach for predicting the transformation of shallow slides into debris flows is theoretically interesting but difficult to apply in practice, in particular because of soil variability in in situ conditions and uncertainty in the location of the steady-state line from laboratory tests. It can be easier to perform CSD tests on intact specimens and see whether they show contractant or dilatant behaviour after yielding of the soil (see Anderson \& Sitar, 1995).

At the post-failure stage, if the nature of the material and the rate of movement allow some consolidation of the moving mass, brittleness of the soil decreases and the $I_{\mathrm{GB}}$ curve can be as YC in Fig. 79(b), above the undrained curve YU; in these conditions, less energy will be transferred into kinetic energy. Hutchinson (1986) considered this aspect in the analysis of the Aberfan flow slide, South Wales, and proposed a theoretical sliding-consolidation model. By constrast, incorporation of water in the moving soil mass can modify the $I_{\mathrm{GB}}$ curve from YU to YW, thus increasing the brittleness and the mobility of the soil.

\section{REACTIVATION}

For landslides in which there is a movement along one or several pre-existing slip surfaces, the mobilised shear strength corresponds to residual conditions. As the residual shear strength represents a lower limit, the soil does not present any strain softening, and the rates of displacement are generally small. Limit equilibrium analyses are then well suited to evaluating the stability. A variety of mechanisms, in addition to past landsliding, can give rise to pre-shearing. The most important processes are tectonic activity, glaciotectonic activity, periglacial processes and valley rebound (Hutchinson, 1988; Morgenstern, 1990).

Among 'reactivations', we find what is often called 'active landslides' and 'reactivated landslides':

(a) In active landslides, the rate of displacement varies with the seasonal changes in pore pressures. This is particularly true for translational landslides in which the driving forces do not change significantly with time. The rates of displacement are generally small, varying between some centimetres and some metres per year (Urciuoli, 1990).

(b) In contrast to active landslides, reactivated landslides may be associated with sudden and fairly rapid displacements (Hutchinson, 1987; D'Elia et al., 1998). These authors listed mechanisms that can produce such movements, among which the most common seem to be:

(i) rapid pore pressure increase due to filling of cracks or breaking of pipes

(ii) stress change due to excavation

(iii) rapid change in load distribution along the shear surface (Lacerda, 1997 mentions the case of a huge rock mass that fell on a talus and triggered a landslide)

(iv) increase in strength along the shear surface due to cementation or chemical change that could give some brittleness to the soil at the time of failure

(v) seismic forces.

In this latter case, as reported by D'Elia et al. (1985), the main movements may be delayed, probably because of pore pressure redistribution.

As previously shown on the basis of laboratory test results, the residual shear strength can be influenced by applied stresses, the presence of coarser and stiffer particles (lithorelicts in particular), the chemistry of pore water (see Figs 20 and 21), and the rate of displacement (see Fig. 19). The three first elements should be encouragements for testing the soil in conditions as close as possible to in situ ones. It is worth mentioning at this point that Skempton (1985) and Bromhead (1992) report that tests on specimens including natural slip surfaces give residual strengths very similar to those deduced from back-analyses. As for the influence of the rate of displacement, it has been shown that it is generally very small, typically $1-3 \%$ per logarithm cycle of rate. Considering extreme field rates of displacement and typical rates used in the laboratory, Skempton (1985) concludes that field strength should not deviate from the laboratory value by more than $5 \%$.

The evaluation of residual shear strength may, however, depend on the type of test performed in the laboratory. The ring shear apparatus, which allows a continuous displacement of large magnitude on a well-defined shear surface where maximum particle orientation is achieved, provides the lowest value of residual shear strength. From experience gathered in the UK (Chandler, 1984; Skempton, 1985) this latter strength (generally obtained on remoulded samples) tends to be somewhat lower than the field value, by the equivalent of $1-3^{\circ}$ of the residual friction angle (Fig. 81). However, Stark \& Eid (1992) found good agreement between both values for a slide in Southern California.

If viscosity has no significant influence on residual strength, it has an important influence on the rate of movement and its variations in in situ conditions. Owing to the viscous nature of soils (Bracegirdle et al., 1992; Leroueil \& Marques, 1996), the rate of movement, $v$, does not abruptly vary from 0 when the factor of safety is larger than 1.0 to infinity when it becomes equal to $1 \cdot 0$, but increases progressively with the applied shear stress level. Because the particle arrangement does not change significantly after large displacements, the rate of displacement is not influenced by the amount of displacement, time or history of the movement. Vulliet (1986), who reviewed the literature on the topic, suggested that $v$ should be expressed as follows (see

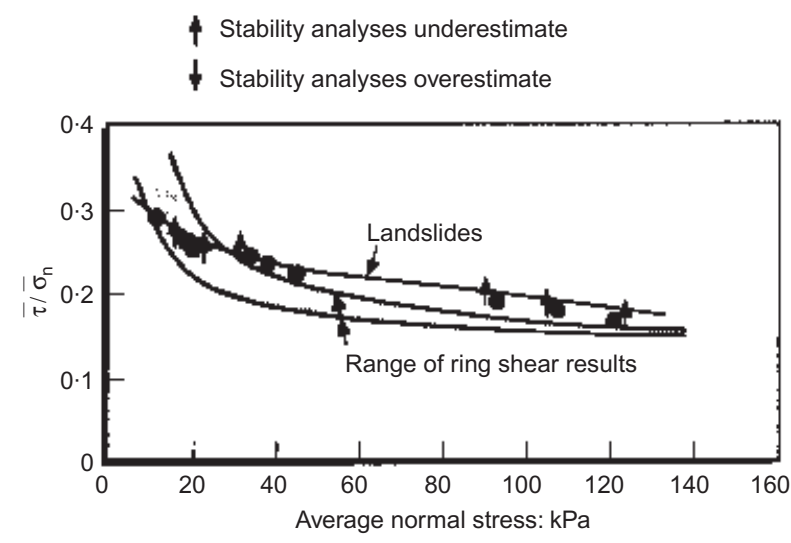

(a)

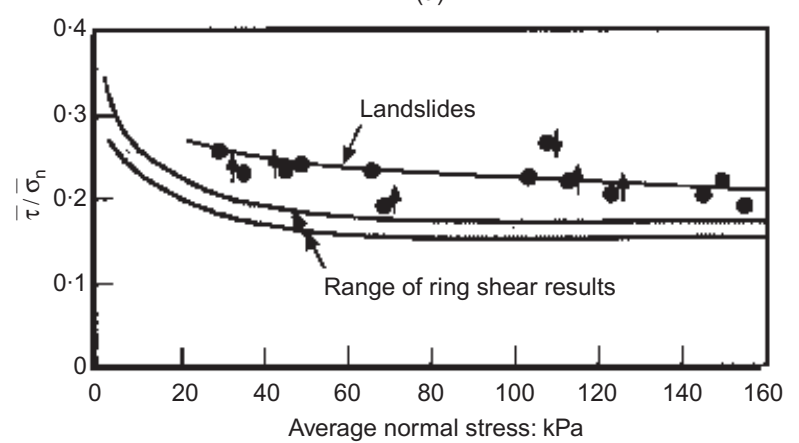

(b)

Fig. 81. Comparison of field and laboratory measurements of residual strength: (a) Upper Lias; (b) London Clay (after Chandler, 1984) 
also Vulliet \& Hutter, 1988):

$$
v=F\left(\sigma^{\prime}{ }_{\mathrm{n}}, \tau\right) \tau
$$

in which $\mathrm{F}$ is a function of the normal effective stress, $\sigma^{\prime}{ }_{n}$, and the applied shear stress, $\tau$. It can take several forms, one of them being the power law:

$$
F=A \tau^{n-1} /\left(\sigma^{\prime}{ }_{\mathrm{n}} \tan \phi^{\prime}{ }_{\mathrm{r}}\right)^{n}
$$

The non-linearity of $v$ with $\tau$ is confirmed by field observations (Bertini et al., 1986; Cartier \& Pouget, 1988; Azimi et al., 1992).

\section{Embankment on an unstable slope at Sallèdes}

The example of the instrumented slope at Sallèdes, in the central part of France (Cartier \& Pouget, 1988; Pouget \& Livet, 1994), can be used to illustrate movements of a reactivated or active slide, and the relations between hydrologic conditions, pore pressures, factor of safety and rate of displacement, as indicated in Fig. 28.

On this site, two test embankments were built on an already unstable slope. Test embankment A was built up to failure (Blondeau et al., 1983) and confirmed that the mobilised strength along the pre-existing shear surface corresponds to residual strength parameters. Test embankment $\mathrm{B}$ was built in 1980 to a height such that the downslope displacements of the embankment vary with rainfall conditions, but without leading to complete collapse. The slope was well instrumented and regularly monitored until 1991. The observations were presented in several reports and papers, mostly in Pouget et al. (1985), Cartier \& Pouget (1988) and Pouget \& Livet (1994).

The site is characterised by about $7 \mathrm{~m}$ of plastic clayey colluvium overlying a marl and marly limestone substratum. Fig. 82 shows a section of the slope and the test embankment B. The shear surface, also shown in the figure, was found at a depth of about $6 \mathrm{~m}$ under the embankment.

For reasons of clarity, and because they have been analysed in detail by Cartier \& Pouget (1988) and Pouget \& Livet (1994), only the average pore pressure measured in the 3 piezometers at a depth of $6 \mathrm{~m}$ under the embankment and the lateral displacement measured in the inclinometer G1Q5 situated at the toe of the embankment (Fig. 82) are considered here. The average pore pressure is shown in Fig. 83(a) for the period 1980-1989; it varies, mostly with the seasons, from $5.7 \mathrm{kPa}$ to $51.5 \mathrm{kPa}$. The lateral displacements are shown in Fig. 83(b). These data allowed Pouget and co-workers to establish the chain

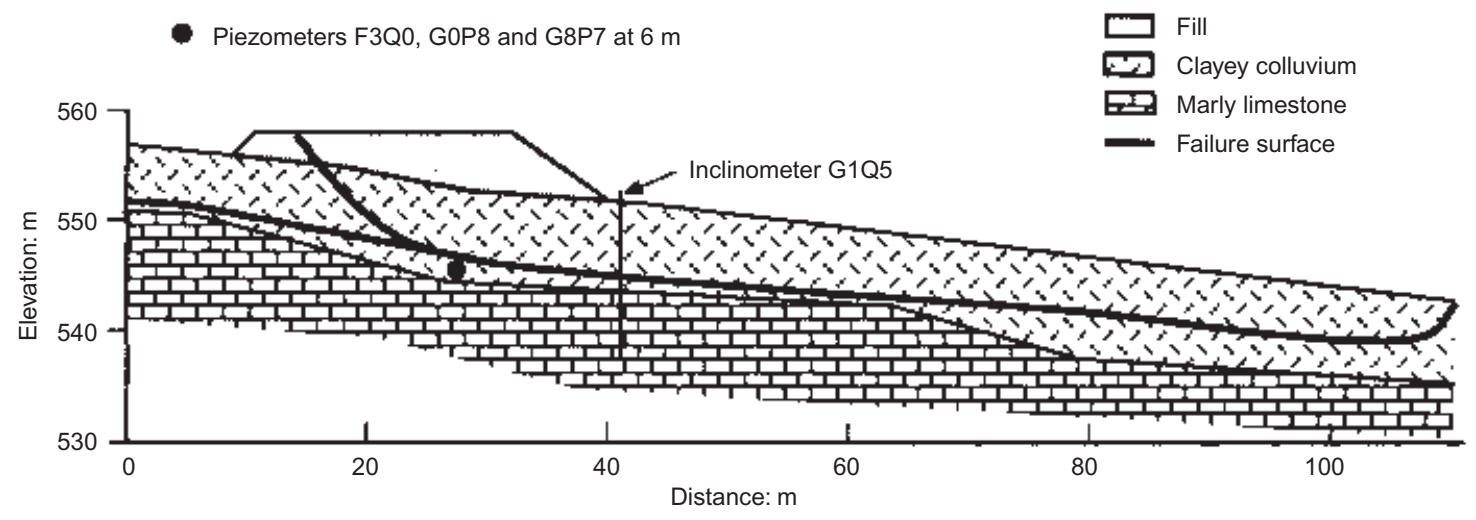

Fig. 82. Section through the embankment on slope at Sallèdes (from Pouget \& Livet, 1988, and Pouget \& Livet, 1994)

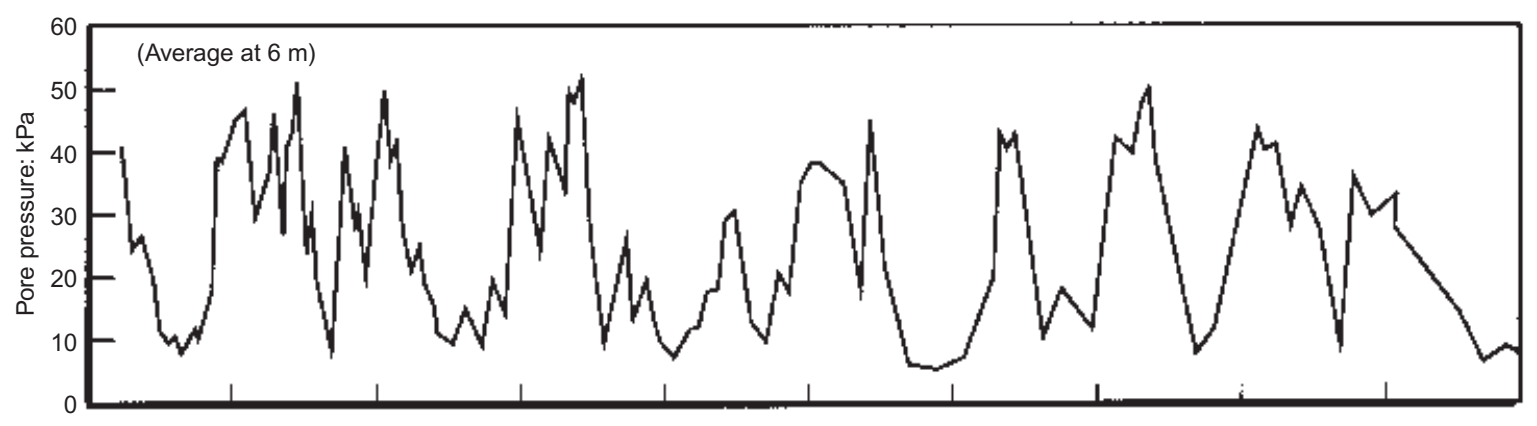

(a)

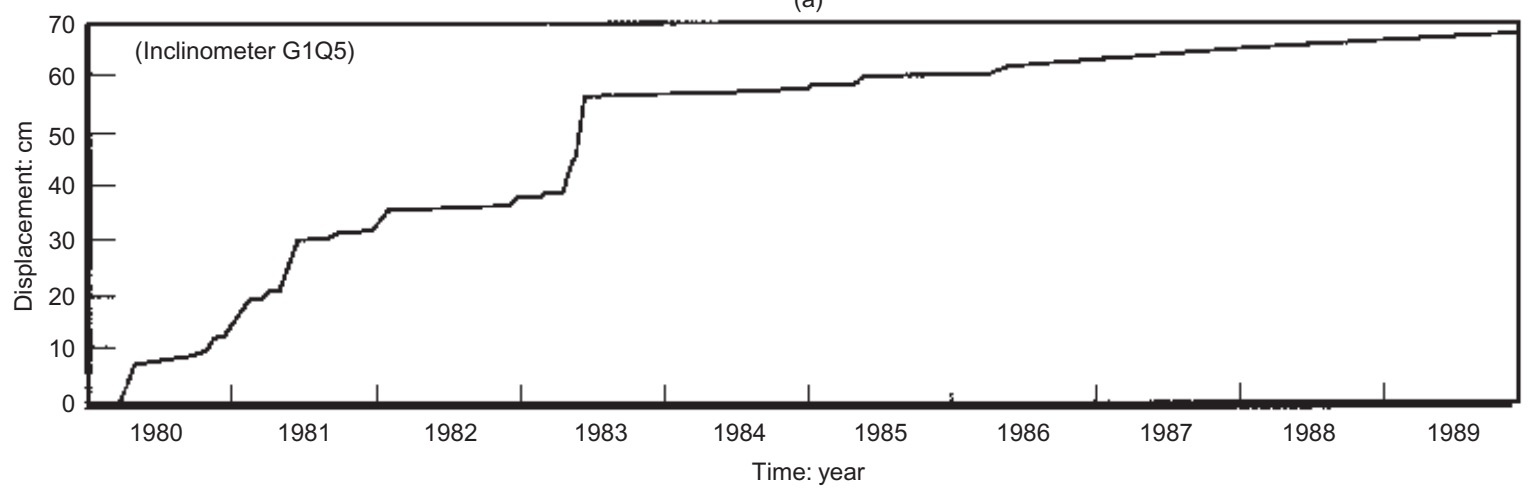

(b)

Fig. 83. Evolution of pore pressure and displacement at Sallèdes (from Pouget \& Livet, 1994) 
of relations indicated in Fig. 28.

Pouget \& Livet (1994) considered several models to relate hydrologic conditions and pore pressures (relation $\mathrm{R}-\mathrm{U}$ in Fig. 28). Taking antecedent rainfall and evapo-transpiration into account, they found that the pore pressure at $6 \mathrm{~m}\left(u_{6 \mathrm{~m}}\right.$ in $\left.\mathrm{kPa}\right)$ is best defined by an equation that can be slightly simplified as follows:

$$
u_{6 \mathrm{~m}}=30 \cdot 3+0 \cdot 20 R F_{1-30 \mathrm{~d}}+0 \cdot 10 R F_{30-50 \mathrm{~d}}-0.088 E V P_{1-100 \mathrm{~d}}
$$

where $R F_{x-y \mathrm{~d}}$ is the rainfall between days $x$ and $y$ prior to the considered day, and $\mathrm{EVP}_{1-100 d}$ is the evapo-transpiration in the previous 100 days. $R F$ and EVP are expressed in $\mathrm{mm}$ of water.

From equation (14), several remarks can be made:

(a) Pore pressure at a depth of $6 \mathrm{~m}$ depends on the antecedent rainfall, mostly over a period of one month but up to 50 days, and on the evapo-transpiration over 100 days. This can be explained by the fact that infiltration, which benefits from cracks, root-holes etc. in the soil, is more rapid than drying by evapo-transpiration.

(b) Equation (14) has been fitted over the period 1980-1982 (3 years). It can be seen that the prediction for the following 7 years is relatively good (Fig. 84).

Cartier \& Pouget (1988) established that the stability of the slope corresponded to a residual friction angle of $9^{\circ}$ on the preexisting shear surface. With this value, they obtained a global factor of safety equal to 1.01 on 22 May 1983, when the maximum rate of displacement $(15 \mathrm{~mm} / \mathrm{d})$ was observed. From data presented by Cartier \& Pouget (1988), it was possible to establish the relationship U-F in Fig. 28 between local pore pressures measured at a depth of $6 \mathrm{~m}$ under the embankment and the global factor of safety calculated on the basis of pore pressures measured at different places in the slope (Fig. 85). The relationship does not appear linear, which can be explained by the influence of pore pressures at places along the failure surface other than below the embankment.

Cartier and Pouget (1988) examined the relation between factor of safety, $F$, and rate of displacement, $v$. Fig. 86 presents the relation for the inclinometer G1Q5 (relation F-V in Fig. 28). It can be seen that the rate of displacement increases progressively as the calculated factor of safety decreases. From

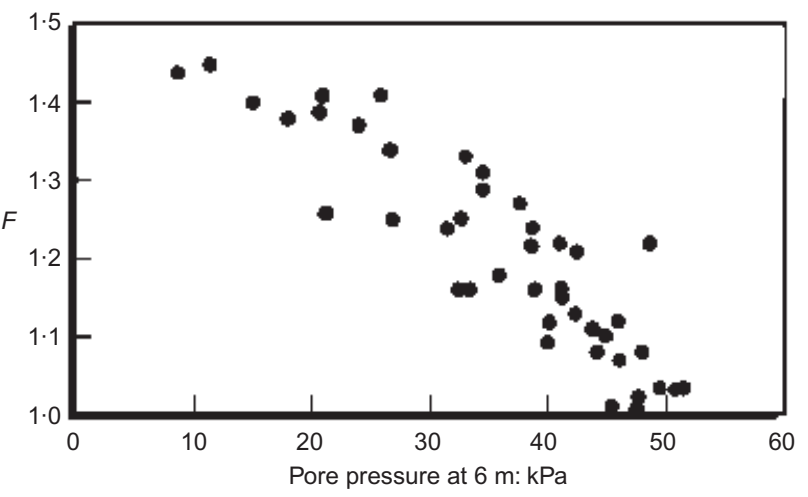

Fig. 85. Relation between factor of safety and pore pressure measured under the embankment at Sallèdes (after Cartier \& Pouget, 1988)

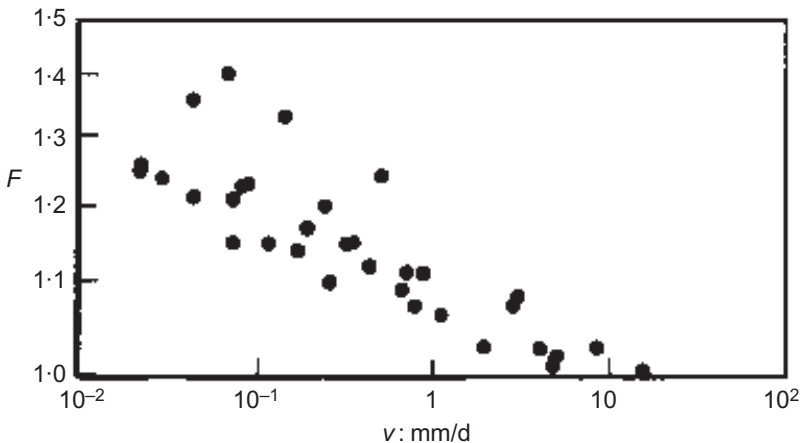

Fig. 86. Relation between rate of displacement at the toe of the embankment and factor of safety at Sallèdes (after Cartier \& Pouget, 1988)

the data presented in Fig. 86, the logarithm of the rate of displacement varies essentially linearly with the logarithm of the factor of safety, which is in agreement with the power law suggested by equations (12) and (13) from Vulliet (1986).

Figure 86 indicates a change in factor of safety, and thus in



Fig. 84. Evolution of measured and calculated pore pressure at Sallèdes (from Pouget \& Livet, 1994) 
strength, of about $8 \%$ per logarithm cycle of rate of displacement. This is an important change, which can be explained by the fact that displacements are not uniform on this site and reach their maximum at the toe of the embankment, where the data presented in Figs 83 and 86 were obtained. Laboratory data (Fig. 19 and from Salt, 1988), but also field observations reported by Bertini et al. (1986), Hutchinson (1988) and Azimi et al. (1992), show much smaller rates, indicating that, typically, the rate of displacement decreases by two orders of magnitude when the factor of safety is increased by about $5 \%$. So, if the viscosity of clayey soils in residual conditions has no significant influence on the calculated factor of safety, it is of paramount importance for rates of displacement. It is also worth noting that Nakamura (1984) and Bertini et al. (1986) observed, for the same factor of safety, larger rates of movement when pore pressures were increasing than when they were decreasing.

\section{GEOTECHNICAL CHARACTERISATION AND THE ASSESSMENT}

OF HAZARD AND RISK ASSOCIATED WITH SLOPE MOVEMENT

With French colleagues and colleagues from Université Laval, we started working on the development of an expert system on slope stability about 15 years ago (Faure et al., 1988). However, we rapidly realised that the problem involves a large variety of geomaterials and many types of slope movement under a variety of climatic conditions, that the problem is complex and controlled by laws and parameters that vary with the stage of movement, and the type of geomaterial, that the relevant information was extremely scattered in the literature, and that solutions to problems related to slopes have often been developed on a local or regional basis. We then tried to find a way to organise the information, and suggested the geotechnical characterisation of slope movements (Vaunat et al., 1994; Leroueil et al., 1996), which is briefly described below.

\section{Geotechnical characterisation of slope movements}

The geotechnical characterisation of slope movements schematically takes the form of a 3-D matrix, the three axes being types of movement, types of material and the four stages of

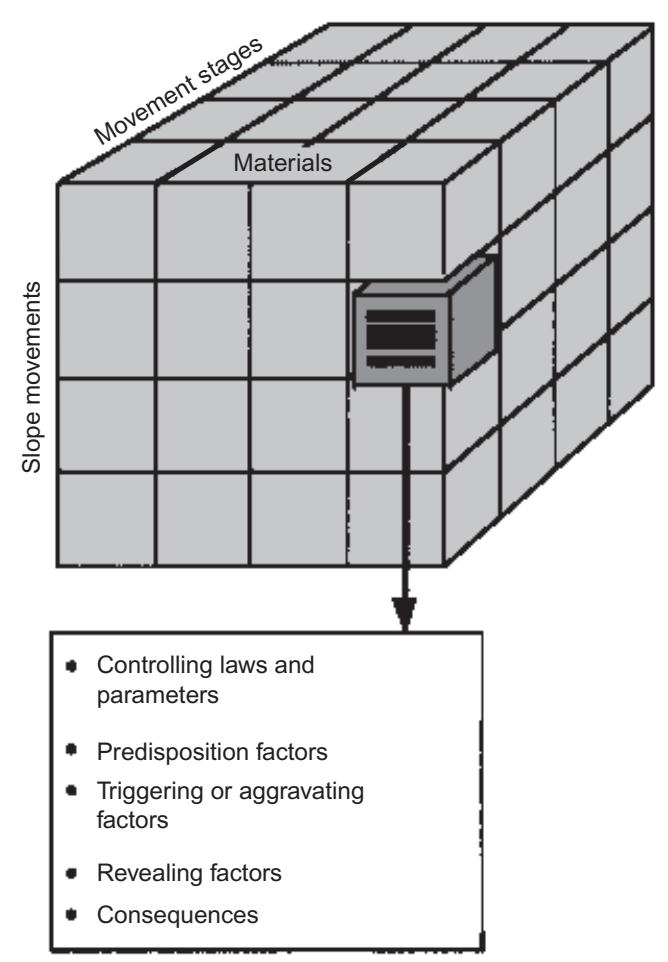

Fig. 87. Schematic slope movement characterisation (from Leroueil et al., 1996) movement previously described: pre-failure, failure, post-failure and reactivation. This matrix is schematised in Fig. 87. Obviously, all the elements of the matrix are not representative of real situations.

The types of movement are those proposed in the geomorphological classifications of landslides suggested by Varnes (1978), Sassa (1985), Vargas (1985, for residual soils, and modified by Wolle, 1998), Hutchinson (1988) and Cruden \& Varnes (1996). They link geology and landslide activity. The types of material must reflect specific mechanical behaviour as it intervenes in in situ conditions. This is not the case in the geomorphological classifications proposed up to now, and thus it appeared necessary for Morgenstern (1992) and Vaunat et al. (1994) to propose more detailed classifications. Fig. 88 shows the one suggested by Vaunat et al. (1994) and slightly modified by Locat (1999, personal communication).

For each relevant element of the characterisation matrix, and according to the methodology proposed by Vaunat et al. (1992), we should find a characterisation sheet with (Fig. 87):

(a) the laws and parameters controlling the phenomenon (for example the Mohr-Coulomb criterion, and $c^{\prime}$ and $\phi^{\prime}$ at the failure stage). As previously shown, they vary considerably from one stage of the movement to another. They also vary with the type of movement and material.

(b) the predisposition factors that give information about the present situation and determine the slope response following the occurrence of a triggering factor (for example the presence of a weak layer)

(c) the triggering factors that lead to failure, or aggravating factors that produce a significant modification of stability conditions or of the rate of movement. They can be temporary (e.g. heavy rainfall) or progressive (e.g. erosion). The most common triggering or aggravating factors are listed in Table 3. They are divided into three classes: those that contribute to increase the shear stress, those that contribute to decrease the shear strength, and those that can influence both shear stress and strength.

(d) the revealing factors that provide evidence of slope movement but generally do not participate to the process (presence of cracks for example)

(e) the possible consequences of the movement.

Figure 89 shows an example of a characterisation sheet. It is for retrogressive slides in soft clays, which is an important concern in sensitive clays found, in particular, in Canada and Scandinavia. If there is a landslide in such materials, the remoulded material may flow out of the slide crater, and if the back-scarp is unstable there may be a second landslide, which can be followed by another one until stable conditions are reached. The main factors determining predisposition for such a retrogressive failure have been described by Tavenas et al. (1983) and Tavenas (1984). They are (Fig. 89):

(a) the ability of the clay to be remoulded. This depends on the height of the slope, $H$, which controls the available potential energy, and on the mechanical and physical characteristics of the clay. It is characterised by the stability number $N_{\mathrm{c}}=\gamma H / c_{\mathrm{u}}$, in which $c_{\mathrm{u}}$ is the undrained shear strength of the intact soil.

(b) the ability of the clay to flow out of the slide crater when remoulded. This is related to the consistency of the remoulded material and thus to the liquidity index or the remoulded shear strength.

(c) a topography that permits the evacuation of the liquefied debris.

The geotechnical characterisation constitutes a general framework for analysing slope movements, and may have several uses:

(a) as previously indicated, to synthesise knowledge on slope movements in different geological and climatic contexts. This has been done for structurally complex clay soils and stiff-jointed clays on the basis of the experience gained in 


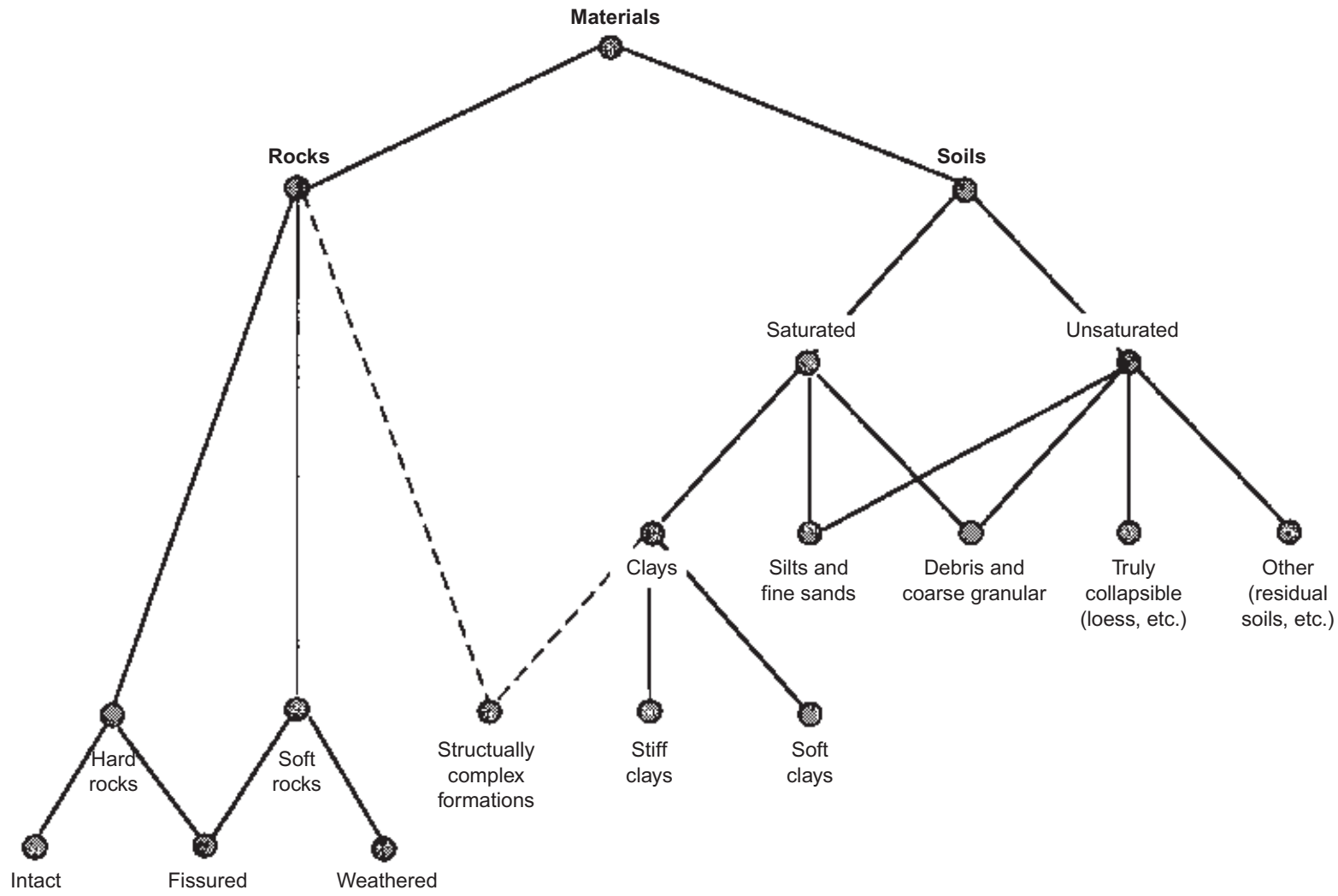

Fig. 88. Material types considered in the characterisation (from Vaunat et al., 1994, modified by Locat, personal communication, 1999)

\section{Table 3. Common triggering or aggravating factors}

Increase in shear stress

Erosion and excavation at the toe

Surcharging at the crest

Rapid drawdown

Fall of rock (Bovis \& Dagg, 1992; Lacerda, 1997)

Earthquake (Sassa, 1996)

Decrease in strength

Infiltration due to rainfall, snow melt, irrigation water leakage from utilities

Pile driving

Weathering

Fatigue due to cyclic loading

Physico-chemical changes

Possible increase in shear stress and decrease in strength

Vibrations and earthquake shaking that can generate excess pore pressure

Swinging of trees due to wind gusts

Thunderstorm lightning (Lacerda, 1997)

Storm waves

southern and central Italy (D'Elia et al., 1998) and for soft clays (Vaunat, 2001), and some work is currently being done with Brazilian colleagues to integrate experience on slopes in residual soils into the geotechnical characterization framework.

(b) to describe a slope. The geotechnical characterisation forces the engineer to define the different factors that influence or may influence the movements of a given slope, and the consequences of these movements, helping him in improving his understanding of the situation and in selecting appropriate solutions. The approach is now used on a regular basis by the governmental organisation of the Province of Québec, that examines slope-related problems.
Movement: retrogressive slide

Stage: post-failure

Material: soft clay

Controlling laws and parameters

- Undrained shear strength

- Remolding energy: $f\left(I_{\mathrm{p}} c_{\mathrm{u}}\right)$

- Liquidity index

Predisposition factors

- Existing slope of precarious stability

- $c_{\mathrm{ur}}<1 \mathrm{kPa}$ or $I_{\mathrm{L}}>1 \cdot 2$; the distance of retrogression has a tendency to increase with $I$

- $\gamma_{\mathrm{H}} / c_{\mathrm{u}}>4$ if $I_{\mathrm{p}} \sim 10 ; \gamma \mathrm{H} / c_{\mathrm{u}}>8$ if $I_{\mathrm{p}} \sim 40$

- Favourable topography allowing the evacuation of the liquefied clay

Triggering or aggravating factors

- Initial slope failure with unstable backscarp

- Presence of under-pressures

Revealing factors

- Evidence of retrogressive slides in the area

Movement consequences

- Very fast movements on a distance of regression difficult to predict

- Generally, no remedial works can be considered

Fig. 89. Slope movement characterisation sheet for retrogressive slides in soft clays (from Leroueil et al., 1996) 
(c) for hazard and risk assessment (Locat \& Leroueil, 1997; Leroueil \& Locat, 1998). Details are given below.

\section{Hazard and risk assessment}

Varnes et al. (1984) defined the total risk, $R_{\mathrm{T}}$, as the set of damages resulting from the occurrence of a phenomenon. It can be described by the following equation:

$$
R_{\mathrm{T}}=\Sigma H R_{i} V_{i}
$$

in which $H$ is the hazard or the phenomenon occurrence probability within a given area and a given time period; $R_{i}$ (for $i=1$ to $n)$ are the elements at risk (persons, buildings etc.), potentially damaged by the phenomenon; and $V_{i}$ is the vulnerability of each element $R_{i}$, represented by a damage degree between 0 (no loss) and 1 (total loss).

In the context of slopes, risk has often been associated with failures. This indeed constitutes an important proportion of encountered problems, particularly when risk is examined in terms of loss of lives. However, it does not satisfy all the geotechnical engineering needs. In particular, for cases of linear structures or infrastructures, such as bridges, roads, railway tracks and pipelines, that are in zones of precarious stability, the risk is often more related to movements and rates of movement than to failure as such. The geotechnical characterisation seems to be appropriate for this general consideration of risk, as indicated by Leroueil \& Locat (1998).

Considerations on acceptable risk, perception of risk by people, and socio-economic implications are beyond the scope of this paper (see e.g. Fell, 1994; Cruden \& Fell, 1997; Finlay \& Fell, 1997).

Elements at risk and their vulnerability. The elements at risk may be individuals, properties and goods, activities, or social functions. These elements can suffer consequences directly from the phenomenon or from induced phenomena. For example, the fact that pylons of an electric power line are destroyed by a landslide is a direct consequence; the fact that this deprives a factory of electricity and stops its production is an indirect consequence. All these elements must be considered in a risk analysis.

In the context of the geotechnical characterisation, the elements at risk as well as their vulnerability should be, directly or indirectly, found in 'Movement consequences' in Fig. 90. In particular, the rate of movement is of major importance when the element 'loss of life' is considered (Morgenstern, 1995). Indeed, when the rate of movement is relatively low, say smaller than about $10 \mathrm{~m} / \mathrm{h}$, people normally have time to escape from the area concerned. (A landslide velocity scale has been proposed by the Working Party on the World Landslide Inventory; see Cruden \& Varnes, 1996.)

Hazard. This is the probability that a phenomenon such as a first-time failure or an active landslide reaching a given rate will occur. When failure stage is concerned, the hazard, $H_{\mathrm{f}}$, is directly the probability of the triggering factor to reach a critical value leading to failure; at the pre-failure and reactivation stages, the hazard associated to a rate of movement is the probability that the aggravating factor will reach a given value leading to this rate (Fig. 90). For the post-failure stage, the hazard, $H_{\text {post-f }}$, associated with a movement with given characteristics is more difficult to define (see discussion by Leroueil \& Locat, 1998).

When considering a landslide, two stages are involved in the geotechnical characterisation: the failure stage, and then the post-failure stage. As a consequence, the hazard has to be subdivided into two parts: the hazard associated with the possibility of having a failure $\left(H_{\mathrm{f}}\right)$, and the hazard associated with the possibility that the post-failure stage presents specific characteristics $\left(\mathrm{H}_{\text {post-f }}\right)$ :

$H=H_{\mathrm{f}} \times H_{\text {post-f }}$

The main difficulty in risk assessment comes from the

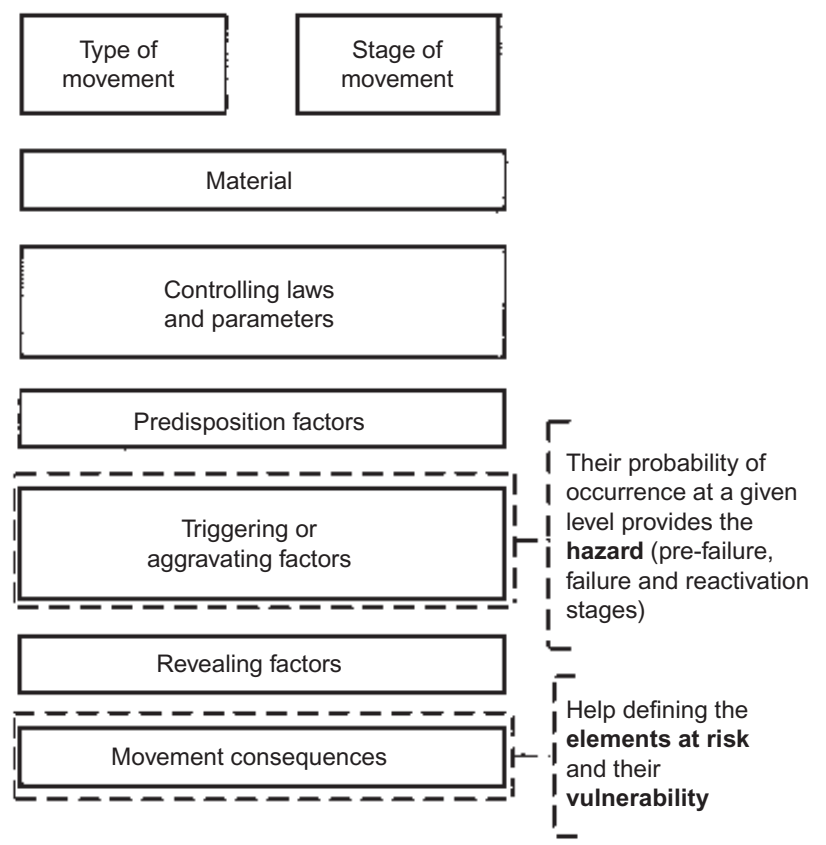

Fig. 90. Geotechnical characterisation and risk assessment (after Leroueil \& Locat, 1998)

evaluation of hazard. The problem is often complex and involves several phenomena; there are also uncertainties that Morgenstern (1995) associates with three main sources: parameter uncertainty, model uncertainty, and human uncertainty.

The uncertainty about parameters can be subdivided in two parts, well identified in the geotechnical characterisation:

(a) the uncertainty that depends on the spatial variation of the parameters characterising the material and the predisposition factors (see Fig. 90). This uncertainty also depends on the extent and the quality of the investigation. It is interesting in this connection to mention the Swedish national rules for slope stability analysis (Sällfors et al., 1996). These associate degree of sophistication of site investigation, elements at risk (from new development to undeveloped land) and required minimum factor of safety, which can be seen as an indirect evaluation of hazard.

(b) the uncertainty due to temporal variation of the triggering or aggravating factors. It is essentially because of these variations that there can be failure or a change in the rate of movement.

So, with the possible exception of well-documented active landslides, it is often difficult to establish the hazard quantitatively. In such conditions, the hazard has to be defined semiquantitatively or qualitatively. For that purpose, Hungr (1997) suggests a useful scale (Table 4) in which the class limits have been selected so as to possess a certain physical meaning. An annual probability of more than $1 / 20$ means that the event is imminent; an annual probability of $1 / 100$ indicates a situation in which the event is expected within the lifetime of a person

Table 4. Suggested semi-quantitative probability scale for landslide hazard magnitude or intensity

\begin{tabular}{l|c}
\multicolumn{1}{c|}{ Term } & Range of frequency: $1 /$ year \\
\hline Very high probability & $>1 / 20$ \\
High & $1 / 100-1 / 20$ \\
Medium & $1 / 500-1 / 100$ \\
Low & $1 / 2500-1 / 500$ \\
Very low & $<1 / 2500$ \\
\hline
\end{tabular}

From Hungr (1997) 
or of a typical structure; and so on

Also, because of the difficulty of establishing the hazard, and according to the principle that 'past and present are keys for the future' (Hutchinson, 1995), engineers often use several sources of information to help in defining hazard semi-quantitatively or qualitatively. They can be defined as:

(a) historical information: for example, Locat et al. (1984) specified landslide activity along the Chacoura river, Québec, by examining aerial photographs taken at different times over a 30 -year period;

(b) geomorphological information: for example, Lebuis et al. (1983) compiled geometrical characteristics of slopes of the Saint-Ambroise area, Québec, in a diagram of slope height against slope angle, and defined a line separating obviously stable slopes from slopes presenting signs of instability

(c) climatic-landslide activity relationships; such relationships have been established for several geological and climatic contexts. Fig. 30 shows an example for the Rio de Janeiro area.

In conclusion, the evaluation of risk associated with slope movements is a difficult task. It is thought that the geotechnical characterisation of slope movements can help. As indicated by Leroueil \& Locat (1998), it can also be useful for the selection of appropriate mitigation approaches or warning systems.

\section{CONCLUSION}

Movements and failure of cuts and natural slopes constitute a problem that involves a variety of geomaterials in a variety of geological and climatic contexts. Their understanding requires a joint effort from geologists, geomorphologists, geotechnical engineers, hydrologists and hydrogeologists. However, movements and failures are mechanical responses to changes in geometry, boundary conditions, pore pressures, or strength parameters with time, and it is the role of the geotechnical engineer to develop the knowledge necessary to the understanding of the involved processes. It is on these geotechnical aspects that this paper has focused.

As it is a complex problem, and the related information is huge and scattered, it appears necessary to integrate the relevant knowledge into frameworks. Two are used in this paper. To understand the behaviour of a geomaterial element, the concepts of limit and critical states, extended to incorporate the effects of anisotropy, viscosity, microstructure and partial saturation, are extremely useful, even if they do not integrate some aspects such as residual strength. At the scale of the slope, the geotechnical characterisation of slope movements constitutes another framework that includes the types of movement, the types of material and the stages of movement, as well as the factors controlling the movements and the possible consequences of these movements. This geotechnical characterisation appears to be useful for synthesising knowledge on slopes, for describing a given slope, or for assessing the risk associated to slope movements.

The review of the knowledge on slopes shows that several aspects are poorly understood, though they are important: for example, creep, fatigue, weathering and other destructuration processes, influence of partial saturation, infiltration in in situ conditions, progressive failure, and development of post-failure movements. In fact, slopes seem to be the most complex problem that geotechnical engineers face. Surprisingly, however, the research effort in these areas is quite limited and probably decreasing compared with what was done three or four decades ago. Considering the social and economical costs associated with landslides, it is thought that this effort should be considerably increased, and that more young researchers should be involved. More field observations have to be made, in particular at the pre-failure stage in order to identify precursory signs of landslides; and modelling, which is the only way to integrate basic knowledge into complex slope problems, has to be improved.

\section{ACKNOWLEDGEMENTS}

I should first like to thank the British Geotechnical Society for inviting me to deliver the 39th Rankine Lecture. I also thank all the persons and organisations who helped me in reaching this honour:

(a) my wife Françoise, my son Vianney and his wife, and close friends for their continuous support

(b) François Tavenas, from whom I learned the meaning of the word 'research' and became interested in geotechnical engineering, and in slopes in particular

(c) those who, very generously, helped me in preparing this lecture: Angelo Amarosi, Giovanni Calabresi, MarieChristine Delisle, Denis Demers, Catia Di Maio, Tom A. Dijkstra, David W. Hight, John N. Hutchinson, Nebojsa Kovacevic, Willy Lacerda, Jean-François Laflamme, Pierre La Rochelle, Andrew W. Malone, Luciano Picarelli, Pierre Pouget, Sebastiano Rampello, Nicholas Sitar, and Peter R. Vaughan

(d) those with whom I have discussed several aspects of slope behaviour: Jacques Locat, Jean Vaunat, René Faure, Gilles Sève, and Beniamino D'Elia. I should mention again Luciano Picarelli for ten years of fruitful collaboration

(e) colleagues and technicians at Université Laval, as well as my present and former students

( $f$ ) the organisations who support my research: Université Laval, the Natural Sciences and Engineering Research Council of Canada, the Fonds pour la Formation de Chercheurs et l'Aide à la Recherche du Québec, le Ministère des Transports du Québec, and Hydro-Québec

( $g$ ) the following for permission to present their data: E. N. Bromhead, M. R. Cooper and D. J. Petley for in situ observations at Selborne; the Geotechnical Engineering Office for data on the influence of antecedent rainfall on the occurrence of landslides in Hong Kong.

\section{NOTATION}

$A$ creep parameter; Skempton pore water pressure parameter

$c^{\prime}$ effective cohesion

$c^{\prime}{ }_{\mathrm{p}} \quad$ cohesion relative to the peak strength envelope

$c^{\prime}{ }_{\mathrm{r}}$ cohesion relative to the residual strength envelope

$c_{u}$ undrained shear strength

$c_{\mathrm{ur}}$ undrained shear strength of the remoulded soil

$c_{\mathrm{vs}}$ coefficient of swelling or swelling/consolidation

CAU anisotropically-consolidated-undrained triaxial test

CAD anisotropically-consolidated-drained triaxial test

CA-creep triaxial creep test after anisotropic consolidation

CIU isotropically-consolidated-undrained triaxial test

CPT, CPTU cone penetration test

CRS constant rate of strain oedometer test

CSD constant-shear-drained triaxial test

CSL critical state line

DMT dilatometer test

e void ratio

$E_{\mathrm{D}}$ energy dissipated in disaggregating and remoulding the soil

$E_{\mathrm{F}}$ energy dissipated in friction

$E_{\mathrm{K}}$ kinetic energy

$E_{\mathrm{p}}$ potential energy

EVP evapo-transpiration

$F$ failure; factor of safety

$F_{\mathrm{ST}}$ short term factor of safety

$F_{\text {LT }}$ long term factor of safety

GWL ground water level

$G_{\max }$ small strain shear modulus

$H$ height; hazard

$H_{\mathrm{f}}$ hazard associated to failure

$H_{\text {post-f }}$ hazard associated to post-failure

$I_{\mathrm{B}}$ brittleness index

$I_{\mathrm{GB}}$ generalised brittleness index

$I_{\mathrm{L}}$ liquidity index

$I_{\mathrm{p}} \quad$ plasticity index

$I_{\mathrm{r}}$ remoulding index

$k_{\mathrm{x}}, k_{\mathrm{z}}$ hydraulic conductivity in direction $x$ or $z$

$K_{\mathrm{D}}$ horizontal stress index deduced from DMT 


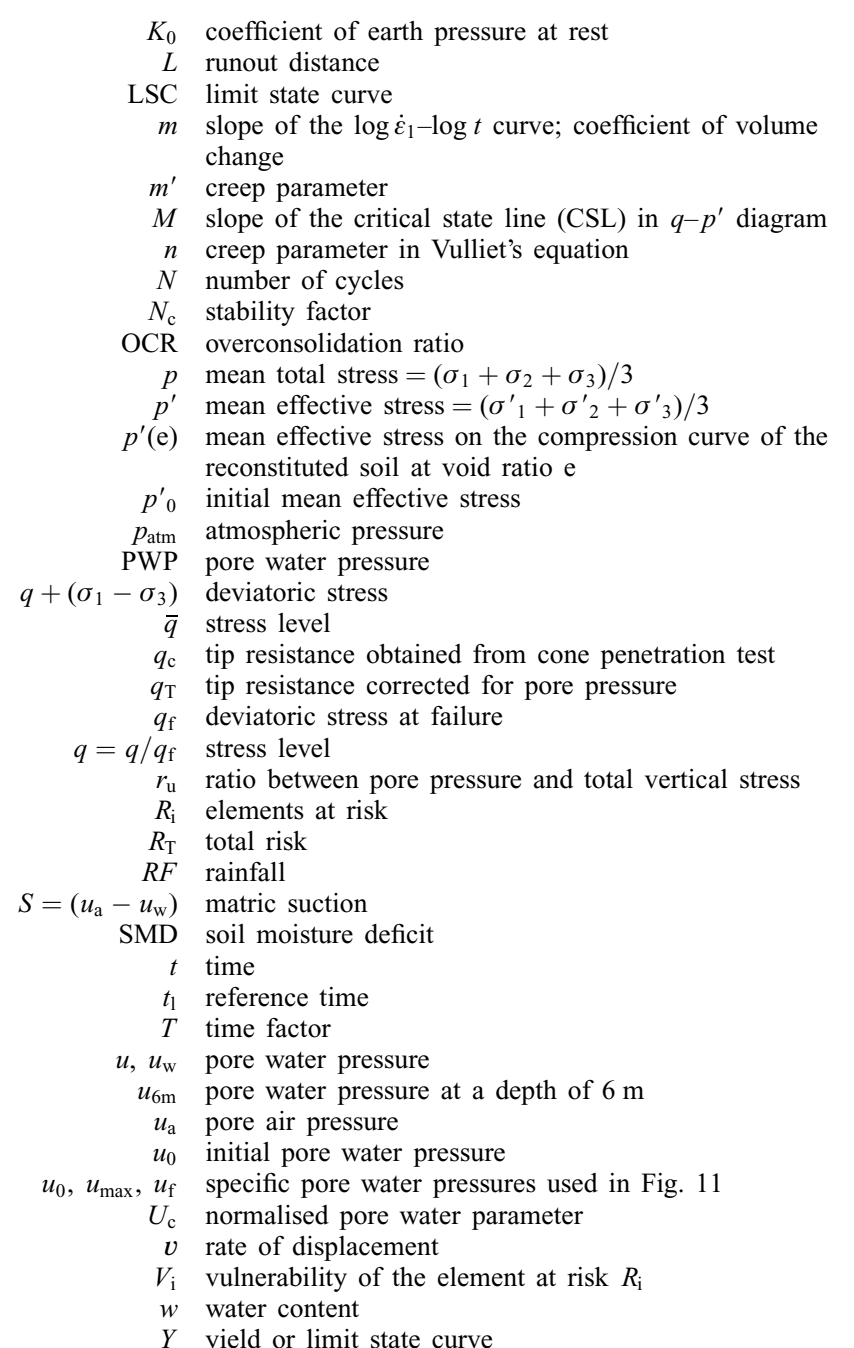
parameter

$\beta$ henkel pore water pressure parameter

$\Delta e$ change in void ratio

$\Delta E$ energy increment

$\Delta u_{\mathrm{z}}$ change in pore water pressure at depth $z$

$\Delta u_{\mathrm{z}=0} \quad$ change in pore water pressure at depth $z=0$

$\Delta_{\text {uw }}$ change in pore water pressure

$\Delta \sigma_{\mathrm{i}} \quad$ change in total stress $\sigma_{\mathrm{i}}$

$\varepsilon_{1} \quad$ axial strain

$\varepsilon_{\mathrm{j}}^{\mathrm{p}}$ plastic strain in the direction $i$

$\varepsilon_{\mathrm{D}}^{\mathrm{p}}$ deviatoric plastic strain invariant

$\dot{\varepsilon}_{1}$ axial strain rate

$\varepsilon_{\mathrm{f}} \quad$ strain at failure

$\dot{\varepsilon}_{\text {max }}$ maximum strain rate

$\varepsilon_{\mathrm{V}} \quad$ volumetric strain

$\gamma$ unit weight

$\gamma_{\mathrm{w}}$ unit weight of water

$\phi=0$ refer to total stress stability analysis

$\phi^{\prime}$ friction angle

$\phi^{\prime}{ }_{\text {cr }}$ critical state friction angle

$\phi^{\mathrm{b}}$ friction angle with respect to changes in matric suction

$\phi^{\prime}{ }_{n c}$ friction angle in the normally consolidated range

$\phi_{\mathrm{p}}^{\prime} \quad$ friction angle at the peak

$\phi^{\prime}{ }_{\mathrm{r}}$ residual friction angle

$\sigma_{\mathrm{i}}$ total principal stress in the direction $i$

$\sigma_{1}$ total major principal stress or axial stress

$\sigma_{3}$ total minor principal stress or radial stress

$\sigma_{\mathrm{n}}$ total normal stress

$\sigma_{\text {vo }}$ total vertical stress

$\sigma^{\prime}{ }_{n}$ effective normal stress

$\sigma^{\prime}$ effective stress

$\sigma^{\prime}$ c effective confining pressure

$\sigma^{\prime}{ }_{i}$ effective principal stress in the direction $i$

$\sigma^{\prime}{ }_{n}$ effective normal stress

$\sigma^{\prime}{ }_{\mathrm{v}}$ effective vertical stress

$\sigma^{\prime}{ }_{\text {vo }}$ initial effective vertical stress

\author{
$\sigma^{\prime}$ p preconsolidation pressure \\ $\sigma^{\prime}{ }^{\prime}$ i isotropic yield stress \\ $\sigma^{\prime}{ }_{1}$ effective major principal stress or effective axial stress \\ $\sigma^{\prime}{ }_{3}$ effective minor principal stress or effectve radial stress \\ $\sigma^{\prime}{ }_{\text {a }}$ effective axial stress \\ $\tau$ shear stress \\ $\tau_{\mathrm{m}}, \tau_{\mathrm{mob}}$ mobilised shear stress \\ $\tau_{\mathrm{p}}$ peak shear strength \\ $\tau_{\mathrm{f}}$ shear strength \\ $\tau_{\mathrm{r}}$ shear strength in residual conditions
}

\section{REFERENCES}

Adachi, T., Oka, F. \& Zhang, F. (1998). An alasto-viscoplastic constitutive model with strain softening. Soils Found. 38, No. 2, 27-35.

Alberro, J. (1979). Stabilité à long terme des excavations dans la ville de Mexico. Proceedings of the international symposium on soil mechanics, Oaxaca, Vol. 1, pp. 125-143.

Alonso, E. E., Gens, A. \& Josa, A. (1990). A constitutive model for partially saturated soils. Géotechnique 40, No. 3, 405-430.

Alonso, E. E., Gens, A., Lloret, A. \& Delahaye, C. (1995). Effect of rain infiltration on the stability of slopes. Proc. 1st Int. Conf. Unsaturated Soils, Paris 1, 241-248.

Amarosi, A. \& Rampello, S. (1998). The influence of natural soil structure on the mechanical behaviour of a stiff clay. Proc. 2nd Int. Symp. Geotechnics of Hard Soils-Soft Rocks, Naples 1, 395-402, Balkema, Rotterdam.

Anderson, S. A. \& Riemer, M. F. (1995). Collapse of saturated soil due to reduction in confinement. J. Geotech. Engng Div., ASCE 121, No. 2, 216-220.

Anderson, S. A. \& Sitar, N. (1995). Analysis of rainfall-induced debris flows. J. Geotech. Engng Div., ASCE 121, No. 7, 544-552.

Archambault, G., Daigneault, R., Rouleau, A. \& Tavchandjian, O. (1990). Mechanics of shear zones and faults belts development by anastomosing patterns of fractures at all scales. In Mechanics of jointed and faulted rocks. Rotterdam: Balkema.

Attewell, P. B. \& Farmer, I. W. (1973). Fatigue behaviour of rock. Int. J. Rock Mech. Mining Sciences 10, 1-9.

Aversa, S., Evangelista, A., Leroueil, S. \& Picarelli, L. (1993). Some aspects of the mechanical behaviour of 'structured' soils and soft rocks. Proc. Int. Symp. Hard Soils-Soft Rocks, Athens 1, 359-366, Balkema, Rotterdam.

Azimi, C., Biarez, J., Desvarreux, P., Giuliani, Y. \& Ricard, C. (1992) Mécanisme des glissements de terrains argileux-Bilan de surveillance sur plusieurs années. Proc. 6th Int. Symp. Landslides, Christchurch 3, 1903-1908, Balkema, Rotterdam.

Barbour, S. L. \& Fredlund, D. G. (1989). Mechanisms of osmotic flow and volume change in clay soils. Can. Geotech. J. 26, No. 4, 551-562.

Benko, B. \& Stead, D. (1998). The Frank slide: a reexamination of the failure mechanism. Can. Geotech. J. 35, No. 2, 299-311.

Berntson, J. A. \& Sällfors, G. B. (1984). Pore pressure variations in marine clay deposits. Proc. 4th Int. Symp. Landslides, Toronto $\mathbf{1}$, 363-366.

Bertini, T., Cugusi, F., D’Elia, B. \& Rossi-Doria, M. (1986). Lenti movimenti di versante nell' Abruzzo Adriatico: caratteri e criteri di stabilizzazione. Proc. 16th Convegno Nationale di Geotecnica, Bologna 1, 91-100

Bishop, A. W. (1967). Progressive failure-with special reference to the mechanism causing it. Proc. Geotech. Conf., Oslo 2, 142-150.

Bishop, A. W. \& Bjerrum, L. (1960). The relevance of the triaxial test to the solution of stability problems. Proceedings of the ASCE research conference on shear strength of cohesive soils, Boulder. pp. 437-501.

Bishop, A. W. \& Lovenbury, H. T. (1969). Creep characteristics of two undisturbed clays. Proc. 7th Int. Conf. Soil Mech. Found. Engng, Mexico City 1, 29-37.

Bishop, A. W., Webb, D. L. \& Lewin, P. I. (1965). Undisturbed samples of London clay from the Ashford Common shaft; strength-effective stress relationships. Géotechnique 15, No. 1, 1-13.

Bjerrum, L. (1967). Progressive failure in slopes in overconsolidated plastic clay and clay shales. J. Soil Mech. Found. Div., ASCE 93, No. 5, 3-49.

Bjerrum, L. (1973). Problems of soil mechanics and construction on soft clays and structurally unstable soils (collapsible, expansive and others). Proc. 8th Int. Conf. Soil Mech. Found. Engng, Moscow 3, $111-159$.

Blight, G. E. (1997). 37th Rankine Lecture: Interactions between the atmosphere and the Earth. Géotechnique 47, No. 4, 715-766.

Blondeau, F. \& Queyroi, D. (1976). Rupture de la tranchée expérimentale de la Bosse-Galin (argile molle). Bulletin de Liaison des 
Laboratoires des Ponts et Chaussées. Numéro spécial III-Stabilité des talus-2: Déblais et remblais, 59-69.

Blondeau, F., Morin, P. \& Pouget, P. (1983). Comportement d'un remblai construit jusqu'a la rupture sur un versant naturel, Site experimental de Sallèdes (Puy-de-Dome), Laboratoire Central des Ponts et Chaussées, Research Report No. 126.

Bovis, M. J. \& Dagg, B. R. (1992). Debris flow triggering by impulsive loading: mechanical modelling and case studies. Can. Geotech. J. 29, No. 3, 345-352.

Brabb, E. E. \& Harrod, B. L. (eds) (1989). Proceedings of the symposium on landslides: extent and economic significance. Rotterdam: Balkema.

Bracegirdle, A., Vaughan, P. R. \& Hight, D. W. (1992). Displacement prediction using rate effects on residual shear strength. Proc. 6th Int. Symp. Landslides, Christchurch 1, 343-347, Balkema, Rotterdam.

Brand, E. W. (1981). Some thoughts on rain-induced slope failures. Proc. 10th Int. Conf. Soil Mech. Found. Engng, Stockholm 3, 373-376.

Brand, E. W. (1982). Analysis and design in residual soils. Proceedings of the ASCE special conference on engineering and construction in tropical and residual soils, Hawaii, pp. 463-482.

Brand, E. W. (1995). Keynote paper: Slope instability in tropical areas. Proc. 6th Int. Symp. Landslides, Christchurch 3, 2031-2051, Balkema, Rotterdam.

Brand, E. W., Premchitt, J. \& Phillipson, H. B. (1984). Relationship between rainfall and landslides in Hong Kong. Proc. 4th Int. Symp. Landslides, Toronto 1, 377-384.

Brenner, R. P., Tam, H. K. \& Brand, E. W. (1985). Field stress path simulation of rain-induced slope failure. Proc. 11th Int. Conf. Soil Mech. Found. Engng, San Francisco 2, 991-996.

Bressani, L. A. (1997). Field suction measurement in a residual soil slope. Proc. 2nd Int. Pan-American Symp. Landslides, Rio de Janeiro 1, 363-369.

Bressani, L. A. \& Vaughan, P. R. (1989). Damage to soil structure during triaxial testing. Proc. 12th Int. Conf. Soil Mech. Found. Engng, Rio de Janeiro 1, 17-20.

Bromhead, E. N. (1992). The stability of slopes. Glasgow: Blackie Academic \& Professional.

Bromhead, E. N. \& Dixon, N. (1984). Pore-water pressure observations in the coastal clay cliffs at the Isle of Sheppey, England. Proc. 4th Int. Symp. Landslides, Toronto 1, 385-390.

Bromhead, E. N., Cooper, M. R. \& Petley, D. J. (1998). The Selborne cutting slope stability experiment (CD-ROM The Selborne data collection $C D)$.

Burland, J. B. (1990). 30th Rankine Lecture: On the compressibility and shear strength of natural clays. Géotechnique 40, No. 3, 329-378.

Burland, J. B., Longworth, T. I. \& Moore, J. F. A. (1977). A study of ground movement and progressive failure caused by a deep excavation in Oxford clay. Géotechnique 27, No. 4, 557-591.

Burland, J. B., Rampello, S., Georgiannou, V. N. \& Calabresi, G. (1996). A laboratory study of the strength of four stiff clays. Géotechnique 46, No. 3, 491-514.

Calabresi, G. (1980). The effect of sample size on strength parameters for intact and fissured stiff clays. Proc. Euromechanical Colloquium No. 134. Copenhagen: Technical University of Denmark.

Calabresi, G. \& Rampello, S. (1987). Swelling of overconsolidated clays in excavations. Proc. 9th European Conf. Soil Mech. Found. Engng, Dublin 1, 11-15.

Calabresi, G. \& Scarpelli, G. (1985). Effects of swelling caused by unloading in overconsolidated clays. Proc. 11th Int. Conf. Soil Mech. Found. Engng, San Francisco 2, 411-414.

Cao, B., Yang, Z. \& Zheng, X. (1997). Movement mechanism and disaster prediction of typical high speed landslide in Northwest. China. Proceedings of the international symposium on landslide hazard assessment, Kyoto University, Kyoto, pp. 247-260.

Carlslaw, H. S. \& Jaeger, J. C. (1959). Conduction of heat in solids. Oxford: Oxford University Press.

Cartier, G. \& Pouget, P. (1988). Etude du comportement d'un remblai construit sur un versant instable, le remblai de Sallèdes (Puy-deDome), Laboratoire Central des Ponts et Chaussées, Research Report No. 153.

Casagrande, A. (1975). Liquefaction and cyclic deformation of sands, a critical review. Proc. 5th Panamerican Conf. Soil Mech. Found. Engng, Buenos Aires 5, 79-133.

Chandler, R. J. (1984). Recent European experience of landslides in over-consolidated clays and soft rocks. Proc. 4th Int. Symp. Landslides, Toronto 1, 61-81.

Chandler, R. J. \& Apted, J. P. (1988). The effect of weathering on the strength of London clay. Q. J. Engng Geol. 21, 59-68.

Collins, B. \& Znidarcic, D. (1997). Triggering mechanisms of rainfall induced debris flows. Proc. 2nd Int. Pan-American Symp. Landslides, Rio de Janeiro 1, 277-286.
Collins, B. \& Znidarcic, D. (1998). Slope stability issues of rainfall induced landslides. Proc. 11th Danube-European Conf. Soil Mech. Geotech. Engng, Porec, Croatia, 791-798.

Cooper, M. R. (1996). The progressive development of a failure surface in overconsolidated clay at Selborne, UK. Proc. 7th Int. Symp. Landslides, Trondheim 2, 683-688, Balkema, Rotterdam.

Cooper, M. R., Bromhead, E. N., Petley, D. J. \& Grant, D. I. (1998). The Selborne cutting stability experiment. Géotechnique 48, No. 1, 83-101.

Cotecchia, F. \& Chandler, R. J. (1997). The influence of structure on the pre-failure behaviour of a natural clay. Géotechnique 47, No. 3, 623-544.

Cruden, D. M. (1997). Panel discussion: Landslides and the international decade for natural disaster reduction. Proc. 14th Int. Conf. Soil Mech. Found. Engng, Hamburg 4, 2301-2304.

Cruden, D. M. \& Fell, R. (eds) (1997). Proceedings of the international workshop on landslide risk assessment, Honolulu.

Cruden, D. M. \& Krahn, J. (1978). Frank rockslide, Alberta, Canada. In Rockslides and avalanches. (ed. B. Voight), pp. 97-112. Amsterdam: Elsevier.

Cruden, D. M. \& Varnes, D. J. (1996). Landslide types and processes. In Landslides-investigation and mitigation, Special Report 247, pp. 36-75. Washington: Transportation Research Board.

Cruden D. M., Thomson, S. \& Tsui, P. C. (1989). The geotechnical characteristics of an ice-thrust mudstone, Wabamun Lake area, Alberta. Can. Geotech. J. 26, No. 2, 227-234.

Cui, Y. J. \& Delage, P. (1996). Yielding and plastic behaviour of an unsaturated compacted silt. Géotechnique 46, No. 2, 291-311.

De Beer, E. E. (1969). Experimental data concerning clay slopes. Proc. 7th Int. Conf. Soil Mech. Found. Engng, Mexico City 2, 517-525.

De Campos, L. E. P. \& Menezes, M. S. S. (1992). A proposed procedure for slope stability analysis in tropical soils. Proc. 6th Int. Symp. on Landslides, Christchurch 2, 1351-1355, Balkema, Rotterdam.

De Campos, T. M. P., De N. Andrade, M. H., Gerscovitch, D. M. S. \& Vargas E. A. Jr, (1997). Analysis of the failure of an unsaturated gneissic residual soil slope in Rio de Janeiro, Brazil. In Short course on the geotechnical characterization of slope movements in the Brazilian context. COPPE, Federal University of Rio de Janeiro.

D'Elia, B. (1984). Comparison between processes of internal deformation in two cut slopes. Proc. 4th Int. Symp. Landslides, Toronto 3, $111-112$.

D'Elia, B. (1991). Deformation problems in the Italian structurally complex clay soils. Proc. 10th European Conf. Soil Mech. Found. Engng, Florence 4, 1159-1170.

D'Elia, B. (1994). Ricerca sperimentale sul comportamento reologico delle argille sovraconsolidate del Valdarno Superiore (Ropporto Finale). Internal Report, Universita di Roma La Sapienza.

D’Elia, B., Esu, F., Pellegrino, A. \& Pescatore, T. S. (1985). Some effects on natural slope stability induced by the 1980 Italian earthquake. Proc. 11th Int. Conf. Soil Mech. Found. Engng, San Francisco 4, 1943-1949.

D’Elia, B., Picarelli, L., Leroueil, S. \& Vaunat, J. (1998). Geotechnical characterization of slope movements in structurally complex clay soils and stiff jointed clays. Italian Geotech. J. No. 32, No. 3, 532.

Delisle, M.-C. \& Leroueil, S. (2000). Détection, à l'aide du piézocône, de zones ramollies dans des pentes argileuses et évaluation de leur comportement mécanique, Report GCT-98-23 prepared for the Ministère des Transports du Québec, Québec: Université Laval.

Demers, D., Leroueil, S. \& D'Astous, J. (1999). In situ testing in a landslide area at Maskinongé, Québec. Can. Geotech. J. 36, No. 6, 1001-1014.

Desai, C. S. \& Siriwardane, H. J. (1984). Constitutive laws for engineering materials: with emphasis on geological materials. Englewood Cliffs, NJ: Prentice Hall.

Deschamps, R. J. \& Leonards, G. A. (1992). A study of slope stability analysis. ASCE Specialty Conf. Stability and Performance of Slopes and Embankments II, San Francisco 1, 267-291.

Diaz-Rodriguez, J. A. , Leroueil, S. \& Aleman, J. D. (1992). Yielding of Mexico City clay and other natural clays. J. Geotech. Engng. Div., ASCE 118, No. 7, 981-995.

Dijkstra (1999). Personal communication.

Dijkstra, T. A. (2000). Landslides in the Lanzhou Region, China, Netherlands Geographical Studies, 269. KNAG/University Utrecht

Dijkstra, T. A., Rogers, C. D. F., Smalley, I. J., Derbyshire, E., Li Yong Jin \& Meng Xing Min. (1994). The loess of north-central China: geotechnical properties and their relation to slope stability. Engng Geol. 36, 153-171.

Di Maio, C. (1996a). The influence of pore fluid composition on the residual shear strength of some natural clayey soils. Proc. 7th Int. Symp. Landslides, Trondheim 2, 1189-1194, Balkema, Rotterdam. 
Di Maio, C. (1996b). Exposure of bentonite to salt solution: osmotic and mechanical effects. Géotechnique 46, No. 4, 695-707.

Di Nocera, S., Iaccarino, G., Pescatore, T. S., Picarelli, L. \& Urciuoli, G. (1995). An example of the geotechnical implications of geological history. Proc. 11th European Conf. Soil Mech. Found. Engng, Copenhagen 8, 39-48.

d'Orsi, R., d'Avila, C., Ortigao, J. A. R., Dias, A., Moraes, L. \& Santos, M. D. (1997). Rio-Watch: the Rio de Janeiro landslide watch system. Proc. 2nd Pan-American Symp. Landslides, Rio de Janeiro 1, 21-30.

Duncan, J. M. (1992). State-of-the-art: static stability and deformation analysis. ASCE Specialty Conf. Stability and Performance of Slopes and Embankments II, San Francisco 1, 222-266.

Dunlop, P. \& Duncan, J. M. (1970). Development of failure around excavated slopes. J. Soil Mech. Found. Div., ASCE 96, No. 2, 471493.

Eckersley, D. (1990). Instrumented laboratory flowslides. Géotechnique 40, No. 3, 489-502.

Eden, W. J. (1977). Evidence of creep in steep natural slopes in Champlain sea clays. Can. Geotech. J. 14, No. 4, 620-627.

Eigenbrod, K. D. (1972). Progressive failure in overconsolidated clays and mudstones. $\mathrm{PhD}$ thesis, University of Alberta, Edmonton.

Eigenbrod, K. D. (1975). Analysis of the pore pressure changes following the excavation of a slope. Can. Geotech. J. 12, No. 3, 429-440.

Evrard, H. \& Sinelle, C. (1981). Stabilité des falaises du Pays de Caux. Le Grand-Quevilly, France: Centre d'études techniques de l'équipement.

Eringen, A. C. (1975). Continuum Physics, Vol. 2, Academic Press, New York.

Faure, R., Leroueil, S., Rajot, J. P., La Rochelle, P., Sève, G. \& Tavenas, F. (1988). Xpent, système expert en stabilité des pentes. Proc. 5th Int. Symp. Landslides, Lausanne 1, 625-629.

Feda, J., Bohac, J. \& Herle, I. (1993). Compression of collapsed loess: studies on bonded and unbonded soils. Eng. Geol. 34, 95-103.

Fell, R. (1994). Landslide risk assessment and acceptable risk. Can. Geotech. J. 31, No. 2, 261-272.

Fenelli, G. B. \& Picarelli, L. (1990). The pore pressure field built up in a rapidly eroded soil mass. Can. Geotech. J. 27, No. 3, 387-392.

Finlay, P. J. \& Fell, R. (1997). Landslides: risk perception and acceptance. Can. Geotech. J. 34, No. 2, 169-188.

Fleming, R. W., Ellen, S. D. \& Algus, M. A. (1989). Transformation of dilative and contractive landslide debris into debris flows-An example from Marin County, California. Engng Geol. 27, 201-223.

Fredlund, D. G. (1989). Negative pore-water pressures in slope stability. Proc. 1st South-American Symp. Landslides, Bogota, 226-256.

Fredlund, D. G. \& Rahardjo, H. (1993). Soil mechanics for unsaturated soils. John Wiley \& Sons.

Fredlund, D. G., Morgenstern, N. R. \& Widger, R. A. (1978). The shear strength of unsaturated soils. Can. Geotech. J. 15, No. 3, 313-321.

Gens, A. \& Alonso, E. E. (1992). A framework for the behaviour of unsaturated expansive clays. Can. Geotech. J. 29, No. 6, 10131032.

Gens, A., Hutchinson, J. N. \& Cavounidis, S. (1988). Three dimensional analysis of slides in cohesive soils. Géotechnique 38, No. 1, 1-23.

Guerriero, G. (1995). Modellazione sperimentale del comportamento meccanico di terreni in colata. PhD thesis, Universita di Napoli Federico II, Naples.

Gullà, G. \& Sorbino, G. (1996). Soil suction measurements in a landslide involving weathered gneiss. Proc. 7th Int. Symp. Landslides, Trondheim 2, 749-754, Balkema, Rotterdam.

Hampton, M. A., Lee, H. J. \& Locat, J. (1996). Submarine landslides. Rev. Geophys. 34, No. 1, 33-59.

Harp, E. W., Weels, W. G. II \& Sarmiento, J. G. (1990). Pore pressure response during failure in soils. Geol. Soc. Am. Bull. 102, No. 4, $428-438$.

Hayashi, Y., Higaki, D. \& Ishizuka, T. (1992). Structure of slip surface formed by rock block slide. Proc. 6th Int. Symp. Landslides, Chistchurch 1, 127-132, Balkema, Rotterdam.

Henkel, D. J. (1960). The shear strength of saturated remoulded clays. Proceedings of the ASCE research conference on shear strength of cohesive soils, Boulder, pp. 533-554.

Hight, D. W. (1998). Soil characterization: the importance of structure and anisotropy. 38th Rankine Lecture. London, 18 March 1998.

Hight, D. W., Georgiannou, V. N., Martin, P. L. \& Mundegar, A. K. (1998). Flow slides in micaceous sands. Proceedings of the international symposium on Problematic Soils, IS-Tohoku'98, Sendai, Vol. 2, pp. 945-958, Balkema, Rotterdam.

Hungr, O. (1987). An extension of Bishop's simplified method of slope stability analysis to three dimensions. Géotechnique 37, No. 1, 113117.

Hungr, O. (1997). Some methods of landslide hazard intensity mapping.
Proceedings of the international workshop on landslide risk assessment, Honolulu, pp. 215-226.

Hutchinson, J. N. (1986). A sliding-consolidation model for flow slides Can. Geotech. J. 23, No. 2, 115-126.

Hutchinson, J. N. (1987). Mechanisms producing large displacements in landslides on pre-existing shears. Mem. Geol. Soc. of China 9, $175-200$

Hutchinson, J. N. (1988). Morphology and geotechnical parameters of landslides in relation to geology and hydrogeology. Proc. 5th Int Symp. Landslides, Lausanne 1, 3-35, Balkema, Rotterdam.

Hutchinson, J. N. (1995). Keynote paper: Landslide hazard assessment. Proc. 6th Int. Symp. Landslides, Chistchurch 3, 1805-1841, Balkema, Rotterdam.

Hutchinson, J. N. (1999). Chalk flows from the coastal cliffs of northwest Europe. Geol. Soc. Am., Rev. Engng Geol. (in press).

Hvorslev, M. J. (1937). Uber die Festigkeitseigenschaften Gestorter Bindinger Boden. Danmarks Naturvidenskabelige Samfund. Ingeniorvidensk. Skr. A, No. 45.

Ishizuka, Y., Abe, T., Koyama, H. \& Komura, S. (1993). Effects of strain rate and frequency on fatigue strength of rocks. Proc. Jap. Soc. Civ. Engng, No. 469, 15-24 (in Japanese).

James, P. M. (1970). Time effects and progressive failure in clay slopes $\mathrm{PhD}$ thesis, University of London.

Janbu, N. (1977). Slopes and excavations in normally or lightly overconsolidated clays. Proc. 9th Int. Conf. Soil Mech. Found. Engng, Tokyo 2, 549-566.

Jardine, R. J. (1992). Some observations on the kinematic nature of soil stiffness. Soils Found. 32, No. 2, 111-124.

Jardine, R. J., St-John, H. D., Hight, D. W. \& Potts, D. M. (1991). Some practical applications of a non-linear ground model. Proc. 10th Eur. Conf. Soil Mech. Found. Engng, Florence 1, 223-228.

Johnson, K. A. \& Sitar, N. (1990). Hydrologic conditions leading to debris-flow initiation. Can. Geotech. J. 27, No. 6, 789-801.

Kankare, E. (1969). Failures at Kimola floating canal in Southern Finland. Proc. 7th Int. Conf. Soil Mech. Found. Engng, Mexico City 3, 609-616.

Kavvadas, M. J. (1998). General report: Modelling the soil behaviourSelection of soil parameters. Proc. 2nd Int. Symp. Geotech. Hard Soils-Soft Rocks, Naples 3, 1441-1481, Balkema, Rotterdam.

Kenney, T. C. (1967). The influence of mineral composition on the residual strength of natural soils. Proceedings of the geotechnical conference on the shear strength properties of natural soils and rocks, Oslo, Vol. 1, pp. 123-129.

Kenney, T. C. \& Lau, K. C. (1984). Temporal changes of groundwater pressure in a natural slope of nonfissured clay. Can. Geotech. J. 21, No. 1, 138-146.

Kenney, T. C. \& Uddin, S. (1974). Critical period for stability of an excavated slope in clay soil. Can. Geotech. J. 11, No. 4, 620-623.

Kirk, P. A., Campbell, S. D. G., Fletcher, C. J. N. \& Merriman, R. J. (1997). The significance of primary volcanic fabrics and clay distribution in landslides in Hong Kong. J. Geol. Soc. London, 154, 1009-1019.

Kirkebo, S. (1994). A numerical study of excavations in low permeable soils. $\mathrm{PhD}$ thesis, Norwegian Institute of Technology, University of Trondheim

Kirkebo, S., Nordal, S. \& Svano, G. (1996). Time-dependent stability of an excavated slope. Proc. 7th Int. Symp. Landslides, Trondheim 2, 1269-1275, Balkema, Rotterdam

Konrad, J. M. (1993). Undrained response of loose compacted sands during monotonic and cyclic compression tests. Géotechnique $\mathbf{4 3}$, No. 1, 69-89.

Konrad, J.-M. \& Ayad, R. (1997). Desiccation of a sensitive clay: field experimental observations. Can. Geotech. J. 34, No. 6, 929-942.

Koppula, S. D. \& Morgenstern, N. R. (1984). Deficient pore pressures in an eroding soil mass. Can. Geotech. J. 21, No. 2, 277-288.

Kovacevic, N. (1994). Numerical analyses of rockfill dams, cut slopes and road embankments. $\mathrm{PhD}$ thesis, University of London.

Kulhawy, F. H. \& Mayne, P. W. (1990). Manual of estimating soil properties for foundation design. Ithaca: Geotechnical Engineering Group, Cornell University.

Lacerda, W. A. (1989). Fatigue of residual soils due to cyclic pore pressure variation. Proc. 12th Int. Conf. Soil Mech. Found. Engng, Rio de Janeiro 5, 3085-3087.

Lacerda, W. A. (1997). Stability of natural slopes along the tropical coast of Brazil. Proceedings of the international symposium on recent developments in soil and pavement mechanics, Rio de Janeiro, pp. 17-39.

Lacerda, W. A., Santos, O. F. Jr \& Ehrlich, M. (1997). The influence of piezometric level variations on the stability of residual soil slopes. Proc. 2nd Pan-American Symp. Landslides-2nd Brazilian Conf. Slope Stability, Rio de Janeiro 1, 381-388 (in Portuguese).

Lacerda (1998). Personal communication. 
Lade, P. V. (1993). Initiation of static instability in the submarine Nerlerk berm. Can. Geotech. J. 30, No. 6, 895-904.

Laflamme, J. F. \& Leroueil, S. (1999). Analyse des pressions interstitielles mesurees aux sites d'excavation de Saint-Hilaire et de Rivière-Vachon, Québec, Report GCT-99-10 prepared for the Ministère des Transports du Québec. Québec: Université Laval.

Laflamme, J. F. et al. (2001). Simulation of pore pressures of the SaintHilaire test excavation (in preparation).

Lafleur, J., Soulié, M. \& Silvestri, V. (1988a). Pressions interstitielles autour d'une fouille expérimentale dans l'argile molle. Proc. 5th Int. Symp. Landslides, Lausanne 1, 707-712, Balkema, Rotterdam.

Lafleur, J., Silvestri, V., Asselin, R. \& Soulié, M. (1988b). Behaviour of a test excavation in soft Champlain Sea clay. Can. Geotech. J. 25, No. 4, 705-715

Larsson, R. (1977). Basic behaviour of Scandinavian soft clays, Report No. 4. Linköping: Swedish Geotechnical Institute.

Lebuis, J., Robert, J.-M., \& Rissman, P. (1983). Regional mapping of landslides hazard in Québec. Proceedings of the symposium on slopes in soft clays, Linköping, SGI Report No 17, pp. 205-262. Linköping: Swedish Geotechnical Institute.

Lee, H. J. (1989). Undersea landslides: extent and significance in the Pacific Ocean. Proc. 28th Int. Geol. Cong.: Symp. Landslides, Washington, 367-380

Lee, H. J., Ellen, S. D. \& Kayen, R. E. (1988). Predicting transformation of shallow landslides into high-speed debris flows. Proc. 5th Int. Symp. Landslides, Lausanne 1, 713-718, Balkema, Rotterdam.

Lefebvre, G. (1970). Contribution à l'étude de la stabilité des pentes dans les argiles cimentées. $\mathrm{PhD}$ thesis, Université Laval, Québec.

Lefebvre, G. (1981). Fourth Canadian Geotechnical Colloquium: strength and slope stability in Canadian soft clay deposits. Can. Geotech. J. 18, No. 3, 420-442.

Lefebvre, G. \& La Rochelle, P. (1974). The analysis of two slope failures in cemented Champlain clays. Can. Geotech. J. 11, No. 1, 89-108.

Lefebvre, G. \& Leboeuf, D. (1987). Rate effects and cyclic loading of sensitive clays. J. Geotech. Engng Div., ASCE 113, No. 5, 476-489.

Léone, F. (1996). Concept de vulnérabilité appliqué à l'évaluation des risques générés par les phénomènes de mouvements de terrain, Document du BRGM No. 250. Orléans, France: Editions BRGM.

Leroueil, S. (1997). Critical state soil mechanics and the behaviour of real soils. Proceedings of the international symposium on recent developments in soil and pavement mechanics, Rio de Janeiro, pp. 41-80.

Leroueil, S. (1998a). Elements of time-dependent mechanical behaviour of overconsolidated clays. Proc. 51st Can. Geotech. Conf., Edmonton 2, 671-677.

Leroueil, S. (1998b). Contribution to the Round Table: Peculiar aspects of structured soils. Proc. 2nd Symp. Hard Soils-Soft Rocks, Naples 3, 1669-1678, Balkema, Rotterdam.

Leroueil, S. \& Locat, J. (1998). Slope movements: geotechnical characterization, risk assessment and mitigation. Proc. 11th DanubeEuropean Conf. Soil Mech. Geotech. Engng, Porec, Croatia, 95106. Also published in Proc. 8th Congress Int. Assoc. Engng Geology, Vancouver, 933-944, Balkema, Rotterdam.

Leroueil, S. \& Marques, M. E. S. (1996). State of the art on the importance of strain rate and temperature effects in geotechnical engineering. Proc. ASCE Conv., Washington, Geotechnical Special Publication No. 61, 1-60.

Leroueil, S. \& Vaughan, P. R. (1990). The general and congruent effects of structure in natural soils and weak rocks. Géotechnique 40, No. 3, 467-488

Leroueil, S., Tavenas, F., Brucy, F., La Rochelle, P. \& Roy, M. (1979). Behaviour of destructured natural clays. J. Geotech. Engng Div., ASCE 105, No. 6, 759-778.

Leroueil, S., Collins, G. \& Tavenas, F. (1983). Total and effective stress analysis of slopes in Champlain clay. Proceedings of the symposium on slopes in soft clays, Linköping. SGI Report No. 17, pp. 293-321. Linköping: Swedish Geotechnical Institute.

Leroueil, S., La Rochelle, P., Tavenas, F. \& Roy, M. (1990). Remarks on the stability of temporary cuts. Can. Geotech. J. 27, No. 5, 687692

Leroueil, S., Vaunat, J., Picarelli, L., Locat, J., Faure, R. \& Lee, H. (1996). A geotechnical characterization of slope movements. Proc. 7th Int. Symp. Landslides, Trondheim 1, 53-74, Balkema, Rotterdam.

Leroueil, S., Guerriero, G., Picarelli, L. \& Saihi, F. (1997). Large deformation shear strength of two types of structured soils. Proceedings of the international symposium on deformation and progressive failure in geomechanics, Nagoya, pp. 217-222, Pergamon.

Li, T. (1989). Landslides: extent and economic significance in China. Proc. 28th Int. Geol. Cong.: Symp. Landslides, Washington, 271287.
Lim, T. T., Rahardjo, H., Chang, M. F. \& Fredlund, D. G. (1996). Effect of rainfall on matric suctions in a residual soil slope. Can. Geotech. J. 33, No. 4, 618-628.

Lin, Z. D. (1994). Variation in collapsibility and strength of loess with age. Proceedings of the NATO advanced research workshop on genesis and properties of collapsible soils, Loughborough, pp. 247265.

Lo, K. Y. \& Lee, C. F. (1973). Analysis of progressive failure in clay slopes. Proc. 8th Int. Conf. Soil Mech. Found. Engng, Moscow 1, $251-258$

Locat (1999). Personal communication.

Locat (1999). Personal communication.

Locat, J. \& Lee, H. J. (2000). Submarine landslides: achievements and challenges. Proc. 8th Int. Symp. Landslides, Cardiff, 4 (in press).

Locat, J. \& Leroueil, S. (1997). Landslides risk assessment in sensitive clays: pre-failure, failure and post-failure issues. Proceedings of the workshop on landslide risk assessment, Honolulu, pp. 261-270.

Locat, J., Demers, D., Lebuis, J. \& Rissmann, P. (1984). Prédiction des glissements de terrain: application aux argiles sensibles, rivière Chacoura, Québec. Proc. 4th Int. Symp. Landslides, Toronto 2, 549-555.

Lupini, J. F. (1980). The residual strength of soils. $\mathrm{PhD}$ thesis, University of London.

Lupini, J. F., Skinner, A. E. \& Vaughan, P. R. (1981). The drained residual strength of cohesive soils. Géotechnique 31, No. 2, 181213

Maâouk, A., Leroueil, S. \& La Rochelle, P. (1995). Yielding and critica state of a collapsible unsaturated silty soil. Géotechnique 35, No 3, $465-477$.

Malone, A. W. (1998). Slope movement and failure: evidence from field observations of landslides associated with hillside cuttings in saprolites in Hong Kong. Proc. 13th Southeast Asian Geotech. Conf., Taipei 2 (in press).

Marchand, G. (1982). Quelques considérations sur le comportement avant rupture des pentes argileuses naturelles. MSc thesis, Université Laval, Québec.

Marsland, A. (1974). Comparison of the results from static penetration tests and large in-situ plate tests in London clay. Proceedings of the European symposium on penetration testing, Stockholm.

Marsland, A. \& Butler, M. F. (1967). Strength measurement of stiff fissured Barton clay from Fawley, Hampshire. Proceedings of the geotechnical conference, Oslo, Vol. 1, pp. 139-145.

Mesri, G., Ullrich, C. R. \& Choi, Y. K. (1978). The rate of swelling of overconsolidated clays subjected to unloading. Géotechnique 28, No. $3,281-307$

Mitchell, R. J. \& Eden, W. J. (1972). Measured movements of clay slopes in the Ottawa area. Can. J. Earth Sci. 9, 1001-1013.

Mitchell, J. K., Greenberg, J. A. \& Witherspoon, P. A. (1973). Chemicoosmotic effects in fine-grained soils. J. Soil Mech. Found Div. ASCE, 99, No. 4, 307-322

Moller, B., Rankka, K., Sällfors, G. \& Ahnberg, H. (1989). Horizontal stresses and deformations in slopes-Case histories, Commission on Slope Stability Report 2-89. Linköping, Sweden: Royal Swedish Academy of Engineering Sciences.

Montgomery, D. R., Dietrich, W. E., Torres, R., Anderson, S. P., Heffner, J. T. \& Loagues, K. (1997). Hydrologic response of a steep unchanneled valley to natural and applied rainfall. Water Resour. Res. 33, No. 1, 91-109.

Morgenstern, N. R. (1990). Instability mechanisms in stiff soils and weak rocks. Proc. 10th Southeast Asian Geotech. Conf., Taipei 2, $27-36$.

Morgenstern, N. R. (1992). The evaluation of slope stability-a 25 year perspective. Proceedings of the specialty conference on stability and performance of slopes and embankments-II, Berkeley 1, 1-26.

Morgenstern, N. R. (1995). Managing risk in geotechnical engineering. Proc. 10th Pan-American Conf. Soil Mech. Found. Engng, Guadalajara, 4, 102-106.

Morgenstern, N. R. \& Tchalenko, J. S. (1967a). Microscopic structures in kaolin subjected to direct shear. Géotechnique 17, 309-328.

Morgenstern, N. R. \& Tchalenko, J. S. (1967b). Microscopic observations on shear zones from slips in natural clays. Proceedings of the geotechnical conference, Oslo, Vol. 1, pp. 147-152

Muir Wood, D., Jendele, L., Chan, A. H. C. \& Cooper, M. R. (1995). Slope failure by pore pressure recharge: numerical analysis. Proc. 11th Eur. Conf. Soil Mech. Found. Engng, Copenhagen 6, 1-8.

Nakamura, H. (1984). Landslides in silts and sands, mainly in Japan. Proc. 4th Int. Symp. Landslides, Toronto 1, 155-178.

Nemčok, A., Pašek, J. \& Rybár, J. (1972). Classification of landslides and other mass movements. Rock Mechanics 4, 71-78.

Neuzil, C. E. (1993). Low fluid pressure within the Pierre Shale: a transient response to erosion. Water Resour. Res. 29, No. 7, 20072020 
Nishi, K., Okamoto, T. \& Esashi, Y. (1983). Strength-deformation characteristics of mudstone under some kinds of loading conditions and its unificative interpretation. Proc. Jap. Soc. Civ. Engng 338 149-158 (in Japanese).

Öberg, A. L., (1995). Negative pore pressures-Seasonal variation and importance in slope stability analysis. Proc. 1st Int. Conf. Unsaturated Soils, Paris 2, 907-913.

Ottosson, E. \& Johansson, L. (1995). Behaviour of a natural slope close to failure. Proc. 11th Eur. Conf. Soil Mech. Found. Engng, Copenhagen 4, 95-100.

Peck, R. B. \& Lowe, J. III (1960). Moderators' Report. Session 4 Shear strength of undisturbed cohesive soils. Proceedings of the ASCE research conference on shear strength of cohesive soils, Boulder, pp. 1137-1140.

Peterson, R., Jaspar, J. L., Rivard, P. J. \& Iverson, N. L. (1960) Limitations of the laboratory shear strength in evaluating stability of highly plastic clays. Proceedings of the ASCE research conference on shear strength of cohesive soils, Boulder, pp. 765-791.

Petley, D. J. (1966). The shear strength of soils at large strains. PhD thesis, University of London, U.K.

Phien-Wej, N. \& Chavalitjiraphan, S. (1991). Properties of coastal Bangkok soft clay and application to cut slope analysis. Proceedings of Geo-Coast'91, Yokohama, Vol. 1, pp. 69-74, Coastal Development Institute of Technology.

Phien-Wej (1992). Personal communication.

Phien-Wej (1993). Personal communication.

Picarelli, L. (1991). Resistenza e meccanismi di rottura nei terreni naturali. Convegno dei ricercatori sul tema: Deformazioni in prossimita della rottura e resistenza dei terreni naturali e delle rocce, Ravello 2, II.7-II.61.

Picarelli, L. (1993). Structure and properties of clay shales involved in earthflows. Proc. int. symp. on geotech. engng Hard Soils-Soft Rocks, Athens, 3, pp. 2009-2019, Balkema, Rotterdam.

Picarelli (1999). Personal communication.

Picarelli, L., Leroueil, S., Urciuoli, G., Guerriero, G. \& Delisle, M.-C. (1997). Experience on the occurrence of shear zones in clayey slopes. Proc. 4th Int. Workshop Localization and Bifurcation Theory, Gifu, 259-268.

Picarelli, L., Di Maio, C., Olivares, L. \& Urciuoli, G. (1998). Properties and behaviour of tectonized clay shales in Italy. Proc. 2nd Int. Symp. Geotech. Hard Soils-Soft Rocks, Naples, 3, 1211-1241, Balkema, Rotterdam.

Pilot, G. (1984). Instrumentation and warning systems for research and complex slope stability problems. Proc. 4th Int. Symp. Landslide, Toronto 1, 275-305.

Pitts, J. \& Cy, S. (1987). In situ soil suction measurements in relation to slope stability investigation in Singapore. Proc. 9th Eur. Conf. Soil Mech. Found. Engng, Dublin 1, 79-82.

Popescu, M. E. (1993). General co-report, Session 4: Slope stability and protection. Proc. Int. Symp. Geotech. Engng Hard Soils-Soft Rocks, Athens 3, 1965-2006, Balkema, Rotterdam.

Potts, D. M., Dounias, G. T. \& Vaughan, P. R. (1990). Finite element analysis of progressive failure of Carsington embankment. Géotechnique 40, No. 1, 79-101.

Potts, D. M., Kovacevic, N. \& Vaughan, P. R. (1997). Delayed collapse of cut slopes in stiff clay. Géotechnique 47, No. 5, 953-982.

Pouget, P. \& Livet, M. (1994). Relations entre la pluviométrie, la piézométrie et les déplacements d'un versant instable (Site de Sallèdes, Puy-de-Dome). Études et recherches des Laboratoires des Ponts et Chaussées, Série Géotechnique GT57.

Pouget, P., Cartier, G. \& Pilot, G. (1985). Comportement de remblais construits sur versants instables. Proc. 11th Int. Conf. Soil Mech. Found. Engng, San Francisco 4, 2345-2348.

Prior, D. B. (1984). Subaqueous landslides. Proc. 4th Int. Symp. Landslides, Toronto 1, 179-196.

Pun, W. K., Wong, A. C. W. \& Pang, P. L. R. (1999). Review of landslip warning criteria 1998. Special Project Report, Geotechnical Engineering Office, Hong Kong.

Rampello, S. (1989). Effetti del rigonfamiento sul comportamento maccanico di argille fortemente sovraconsolidate. Doctoral thesis, University of Rome.

Rampello, S. (1991). Some remarks on the mechanical behaviour of stiff clays: the example of Todi clay. Proceedings of the workshop on experimental characterization and modelling of soils and soft Rocks, Naples, pp. 131-186.

Rankka, K. (1994). In situ stress conditions across clay slopes: a study comprising seven test sites. $\mathrm{PhD}$ thesis, Chalmers University of Technology, Gothenburg, Sweden.

Riedel, W. (1929). Zur mechanik geologischer brucherscheinungen. Ein Beitrag zum Problem der 'Fiederspalten'. Centralblatt für Mineralogie, Geologie, und Paleontologie, Part B, 354-368.
Roscoe, K. H. \& Burland, J. B. (1968). On the generalized stress-strain behaviour of 'wet' clay. Proceedings of the symposium on plasticity, Cambridge, pp. 535-610.

Roscoe, K. H., Schofield, A. N. \& Wroth, C. P. (1958). On the yielding of soils. Géotechnique 8, No. 1, 22-53.

Saihi, F. (1997). Résistance à grande déformation des argiles de l'est du Canada. $\mathrm{PhD}$ thesis, Université Laval, Québec, Canada.

Sällfors, G., Larsson, R. \& Ottosson, E. (1996). New Swedish national rules for slope stability analysis. Proc. 7th Int. Symp. Landslides, Trondheim 1, 377-380, Balkema, Rotterdam.

Salt, G. (1988). Landslide mobility and remedial measures. Proc. 5th Int. Symp. Landslides, Lausanne 1, 757-762, Balkema, Rotterdam.

Santos, O. F., Lacerda, W. A. \& Ehrlich, M. (1996). Discussion of 'Collapse of saturated soil due to reduction in confinement' by Anderson \& Riemer (1995). J. Geotech. Engng. Div., ASCE 122, No. 6, 505-506

Santos, O. F., Lacerda, W. A. \& Ehrlich, M. (1997). Triaxial tests with cyclic pore pressure variation for simulation of the seasonal variation of water level in slopes. Proceedings of the international symposium on recent developments in soil and pavement mechanics, Rio de Janeiro, pp. 279-282.

Sasitharan, S., Robertson, P. K., Sego, D. C. \& Morgenstern, N. R. (1993). Collapse behavior of sand. Can. Geotech. J. 30, No. 4, 569577.

Sassa, K. (1985). The geotechnical classification of landslides. Proc. 4th Int. Conf. Field Workshop on Landslides, Tokyo 1, 31-40.

Sassa, K. (1996). Prediction of earthquake induced landslides. Proc. 7th Int. Symp. Landslides, Trondheim 1, 115-132, Balkema, Rotterdam.

Schofield, A. N. \& Wroth, C. P. (1968). Critical state soil mechanics. London: McGraw-Hill.

Schuster, R. L. (1996). Socioeconomic significance of landslides. In Landslides: Investigation and Mitigation, Special Report 247, pp. 12-35. Washington: Transportation Research Board.

Singh, A. W. \& Mitchell, J. K. (1968). General stress-strain-time function for soils. J. Soil Mech. Found. Div., ASCE 94, No. 1, 21-46.

Sitar (1998). Personal communication.

Skempton, A. W. (1964). 4th Rankine Lecture: Long term stability of clay slopes. Géotechnique 14, No. 2, 77-101.

Skempton, A. W. (1967). Some observations on tectonic shear zones Proc. 2nd Int. Conf. Rock Mechanics, Belgrade 1, 329-335.

Skempton, A. W. (1977). Slope stability of cuttings in brown London Clay. Proc. 9th Int. Conf. Soil Mech. Found. Engng, Tokyo 3, 261270.

Skempton, A. W. (1985). Residual strength of clays in landslides, folded strata and the laboratory. Géotechnique 35, No. 1, 3-18.

Skempton, A. W. \& La Rochelle, P. (1965). The Bradwell slip: a shortterm failure in London Clay. Géotechnique 15, No. 3, 221-242.

Skempton, A. W. \& Petley, D. J. (1967). The strength along structural discontinuities of stiff clays. Proceedings of the geotechnical conference, Oslo, Vol. 2, pp. 29-46.

Sladen, J. A., D'Hollander, R. D. \& Krahn, J. (1985). The liquefaction of sands, a collapse surface approach. Can. Geotech. J. 22, No. 4, $564-578$.

Stark, T. D. \& Eid, H. T. (1992). Comparison of field and laboratory residual strength. Proceedings of the ASCE specialty conference on stability and performance of slopes and embankments-II, Berkeley, Vol. 1, pp. 876-889.

Stark, T. D. \& Eid, H. T. (1994). Drained residual strength of cohesive soils. J. Geotech. Engng Div., ASCE 120, No. 5, 856-871.

Sun, H. W., Wong, H. N. \& Ho, K. K. S. (1988). Analysis of infiltration in unsaturated ground. Proc. Ann. Sem. Slope Engng. in Hong Kong, Hong Kong, 101-109

Sweeney, D. J. (1982). Some in situ soil suction measurements in Hong Kong's residual soil slopes. Proc. 7th Southeast Asian Geotech. Conf., Hong Kong 1, 91-106.

Tani, K. \& Ueta, K. (1998). Surface rupturing of unconsolidated layer along the Najima fault after the 1995 Hyogo-ken Nanbu earthquake, Japan. Proc. 8th Int. IAEG Cong., Vancouver 2, 637-642.

Tavenas, F. (1984). Landslides in Canadian sensitive clays: a state-ofthe-art. Proc. 4th Int. Symp. Landslides, Toronto 1, 141-153.

Tavenas, F. \& Leroueil, S. (1981). Creep and failure in slopes in clays. Can. Geotech. J. 18, No. 1, 106-120.

Tavenas, F., Chagnon, J.-Y. \& La Rochelle, P. (1971). The Saint-JeanVianney landslide: observations and eyewitnesses accounts. Can. Geotech. J. 8, No. 3, 463-478.

Tavenas, F., Trak, B. \& Leroueil, S. (1980). Remarks on the validity of stability analyses. Can. Geotech. J. 17, No. 1, 61-73.

Tavenas, F., Leroueil, S., La Rochelle, P. \& Roy, M. (1978). Creep behaviour of an undisturbed lightly overconsolidated clay. Can. Geotech. J. 15, No. 3, 402-423.

Tavenas, F., Flon, P., Leroueil, S. \& Lebuis, J. (1983). Remolding energy 
and risk of slide retrogression in sensitive clays. Proceedings of the symposium on slopes on soft clays, Linköping, SGI Report No 17, pp. 423-454. Linköping: Swedish Geotechnical Institute.

Taylor, D. W. (1948). Fundamentals of soil mechanics. New York: Wiley.

Taylor, R. K. \& Cripps, J. C. (1987). Weathering effects: slopes in mudrocks and overconsolidated clays. In Slope stability, pp. 405445. New York: Wiley.

Tchalenko, J. S. (1970). Similarities between shear zones of different magnitudes. Geol. Soc. Am. Bull. 81, 1625-1640.

Terzaghi, K. (1950). Mechanism of landslides. In Application of geology to engineering practice (Berkeley volume) (ed. S. Paige), pp. 83123. New York: Geological Society of America.

Terzaghi, K. \& Peck, R. B. (1948). Soil mechanics in engineering practice. New York: John Wiley.

Tien, Y. M., Lee, D. H. \& Juang, C. H. (1990). Strain, pore pressure and fatigue characteristics of sandstone under various load conditions. Int. J. Rock Mech. Mining Sci. 27, No. 4, 283-289.

Tika, T. E., Vaughan, P. R., \& Lemos, L. J. L. J. (1996). Fast shearing of pre-existing shear zones in soil. Géotechnique 46, No. 2, 197-233.

Totani, G., Marchetti, S., Calabrese, M. \& Monaco, P. (1997). Stability evaluation of a slope in a building area by in situ dilatometer (DMT). Proc. 2nd Pan-American Symp. Landslides, Rio de Janeiro 1, 573-582.

Tsui, P. C., Cruden, D. M., \& Thomson, S. (1988). Mesofabric, microfabric and submicrofabric of ice-thrust bedrock, Highvale mine, Wabamun Lake area, Alberta. Can. J. Earth Sci. 25, 1420-1431.

Urciuoli, G. (1990). Contributo alla caratterizzazione geotecnica delle frane dell'Appennino, Reports of the Istituto di Tecnica delle Fondazioni e Costruzioni in Terra. Naples: Universita di Napoli Federico II.

Urciuoli, G. (1992). Rigonfiamento di un'argilla di alta plasticita' $e$ modellazione dei fenomeni erosivi del colle di Bisaccia. $\mathrm{PhD}$ thesis, Università di Napoli Federico II.

Urciuoli, G. (1998). Pore pressures in unstable slopes constituted by fissured clay shales. Proc. 2nd Int. Symp. Hard Soils-Soft Rocks, Naples 2, 1177-1185, Balkema, Rotterdam.

Vargas, M. (1985). Discussion on Theme 3.2: Slope stability. Proc. 1st Int. Conf. Geomechanics in Tropical Lateritic and Saprolitic Soils, Brasilia 3, 379-381, 391-392.

Varnes, D. J. (1978). Slope movement: types and processes. In Landslides. Analysis and control, Transportation Research Board Report 176 pp. $11-33$.

Varnes, D. J. and the IAGE Commission on Landslides and other Mass Movements on Slopes. (1984). Landslide hazard zonation: a review of the principles and practice. Paris: UNESCO.

Vaughan, P. R. (1985). Pore pressures due to infiltration into partly saturated slopes. Proc. 1st Int. Conf. Geomechanics in Tropical Lateritic and Saprolitic Soils, Brasilia 2, 61-71.

Vaughan, P. R. (1994). 34th Rankine Lecture: Assumption, prediction and reality in geotechnical engineering. Géotechnique 44, No. 4, $571-609$.

Vaughan, P. R. \& Hamza, M. M. (1977). Clay embankments and foundations: Monitoring stability by measuring deformations. Specialty Session 8: Deformation of earth-rockfill dams, Proc. 9th Int. Conf. Soil Mech. Found. Engng, Tokyo, 37-48.

Vaunat, J. (2000). PhD thesis in preparation.

Vaunat, J., Leroueil, S. \& Tavenas, F. (1992). Hazard and risk analysis of slope instability. Proc. 1st Can. Symp. Geotechnique and Natural Hazards, Vancouver, 397-404.

Vaunat, J., Leroueil, S. \& Faure, R. (1994). Slope movements: a geotechnical perspective. Proc. 7th Cong. Int. Assoc. Engng Geol., Lisbon, 1637-1646.

Vulliet, L. (1986). Modélisation des pentes naturelles en mouvement. Thesis No. 635, École Polytechnique Fédérale de Lausanne, Switzerland.

Vulliet, L. \& Hutter, K. (1988). Viscous-type sliding laws for landslides. Can. Geotech. J. 25, No. 3, 467-477.

Wang, G. \& Xu, B. (1984). Brief introduction of landslides in loess in China. Proc. 4th Int. Symp. Landslides, Toronto 1, 197-207.

Wilcox, R. E., Harding, T. P. \& Seely, D. R. (1973). Basic wrench tectonics. Am. Assoc. Petroleum Geol. Bull. 57, 74-96.

Wilson, G. W. (1999). The role of climate and soil properties in the evaluation of flux boundary conditions for application to unsaturated soil mechanics. Proc. 11th Panamerican Conf. Soil Mech. Found. Engng, Foz do Iguassu 4, in press.
Wolle, C. M. (1998). Landslides in Serra do Mar, Southeastern Brazil. Short course on 'The geotechnical characterization of slope movements in the Brazilian context', COPPE, Federal University of Rio de Janeiro.

Yamaguchi, U. \& Shimotani, T. (1986). A case study of slope failure in a limestone quarry. Int. J. Rock Mech. Mining Sci. 23, 95-104.

Yoshinaka, R. \& Osada, M. (1995). The comparison between dynamic and static strength of soft sedimentary rocks. In Rock foundation (ed. R. Yoshinaka and K. Kikuchi), pp. 109-114. Rotterdam: Balkema.

Zakaria, I., Wheeler, S. J. \& Anderson, W. F. (1995). Yielding of unsaturated compacted kaolin. Proc. 1st Conf. Unsaturated Soils, Paris 1, 223-228.

\section{VOTE OF THANKS}

PROFESSOR R. J. CHANDLER, Professor of Geotechnical Engineering, Imperial College of Science, Technology and Medicine

We have been privileged to hear a fascinating lecture by one of the world's leading geotechnical practitioners. Serge Leroueil has made the subject of the behaviour of natural soft clays his own, concentrating, inevitably, on the behaviour of Canadian soft clays. As Dr Hight has just reminded us, these clays can be quite strongly bonded, or 'structured', and Serge has studied their engineering behaviour both in the laboratory, and at full scale in the field. The geotechnical world owes Serge a considerable debt for his work in characterising the behaviour of these most interesting soils, the results of which have implications well beyond Canada.

His work does not just encompass the behaviour of soft clays; he has also made significant contributions regarding our knowledge of two well known UK soils, London Clay and Bothkennar clay. This breadth of interest has had a very obvious impact on the 39th Rankine Lecture, which we have just heard. The discussion of the stages of landslide development, from pre-failure, to failure, post-failure, and reactivation, have all been considered in the rigorous context of the study of soil behaviour, which has been the main line of Serge's research throughout his career. This is a most valuable review of landslide mechanics to which we will refer for many years.

I first met Serge in Canada-where else? - at, most appropriately, given the subject of tonight's lecture, the International Landslide Symposium at Toronto in 1984. I presented a paper, and in the break that followed, Serge introduced himself and invited me to have a coffee with himself and his Laval colleague with whom he has done so much work, Francois Tavenas. There was an element of a royal command about this invitation, but the ensuing discussion ranged around the then current ideas concerning the mechanism of slope failure, ranging from 'fully softened strength' to progressive failure.

A few years later Serge spent a one year sabbatical with us here at Imperial College. We all much enjoyed his visit, not least, I suspect, Serge himself. Several publications resulted from his visit. As with many of his papers, these were written jointly, demonstrating Serge's ability to work as a member of a team, but as a team member who provided many of the ideas, much of the energy, and who acted as far more than a mere catalyst.

This lecture adds further to Serge Leroueil's reputation. We have all listened with great interest, and have enjoyed the manner in which the arguments were marshalled, developed and brought to their conclusion.

It is with great pleasure that I propose the vote of thanks to Serge Leroueil for an enjoyable, stimulating and memorable 39th Rankine Lecture. 